LBNL-57962

\title{
A Model of U.S. Commercial Distributed Generation Adoption
}

\author{
Prepared for the \\ Distributed Energy Program \\ Assistant Secretary for Energy Efficiency and Renewable Energy \\ U.S. Department of Energy \\ Principal Authors \\ Kristina Hamachi LaCommare, Ryan Firestone, Karl Maribu, Nan Zhou, \\ and Chris Marnay \\ Ernest Orlando Lawrence Berkeley National Laboratory \\ 1 Cyclotron Road, MS 90R4000 \\ Berkeley CA 94720-8136
}

January 2006

This work described in this paper was funded by the Assistant Secretary of Energy Efficiency and Renewable Energy, Distributed Energy Program of the U.S. Department of Energy under Contract No. DE-AC02-05CH11231. 



\section{Table of Contents}

Acronyms and Abbreviations ....................................................................................... vii

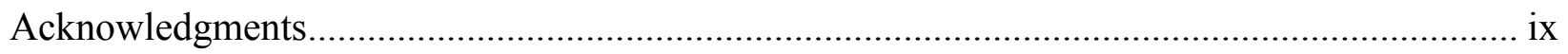

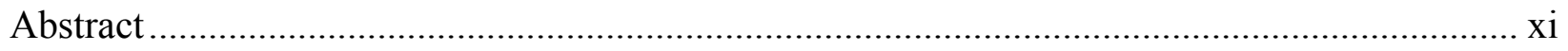

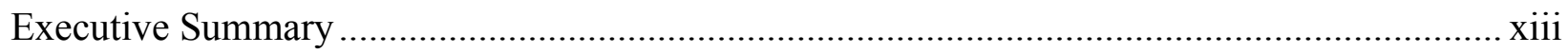

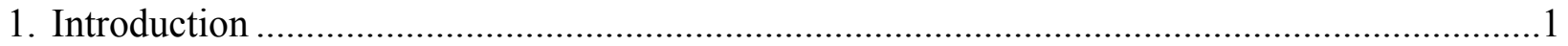

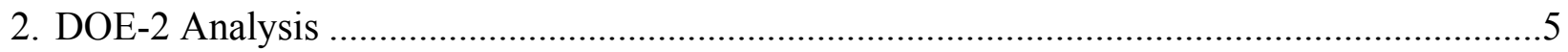

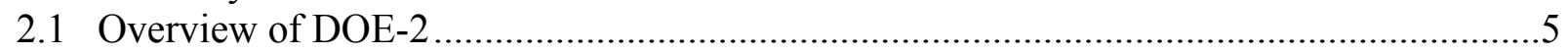

2.2 Selection of Building Types...................................................................................... 6

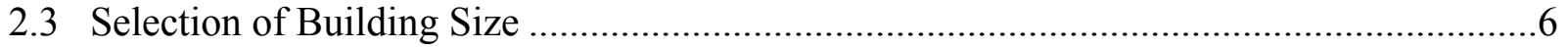

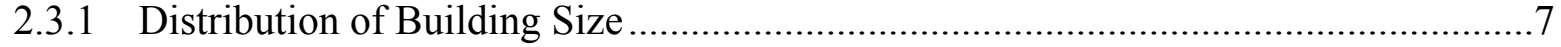

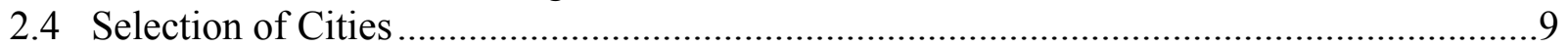

2.5 Summary of DOE-2 Load Profile Results ................................................................. 10

2.5.1 Summary of the Peak Loads of Prototype Buildings............................................. 11

2.5.2 Analysis of Selected Hourly Load Profiles....................................................... 12

3. Distributed Energy Resources Customer Adoption Model (DER-CAM) Analysis.................19

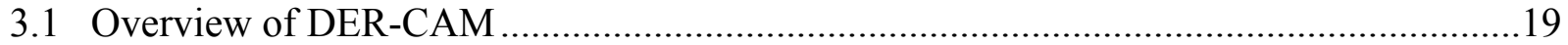

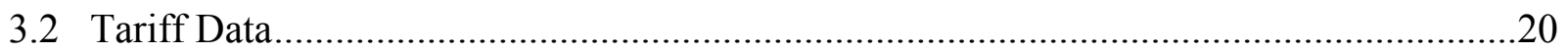

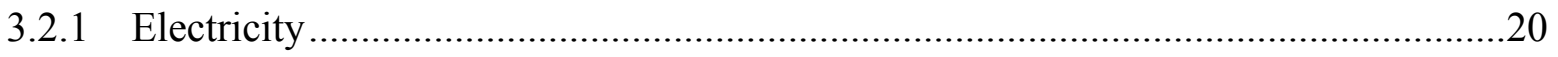

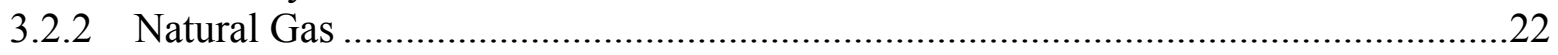

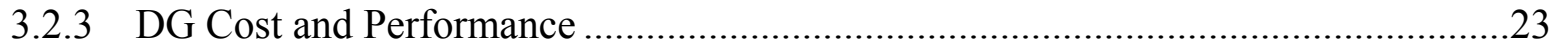

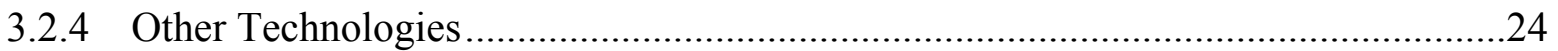

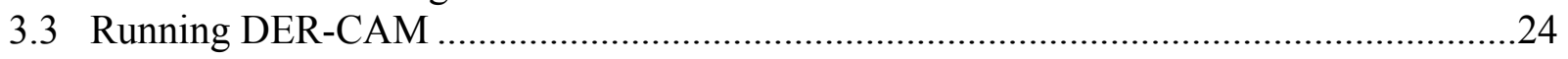

4. Distributed Energy Resource Market Diffusion Model (DER-MaDiM) Analysis ..................31

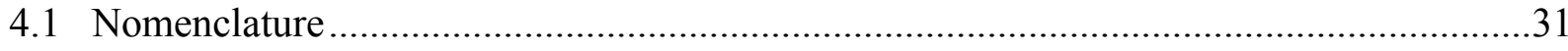

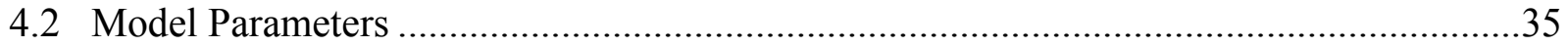

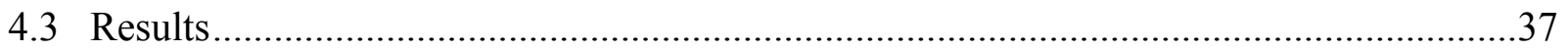

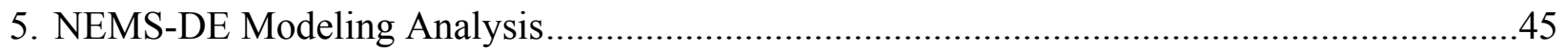

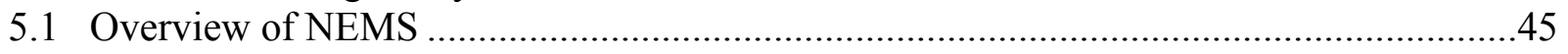

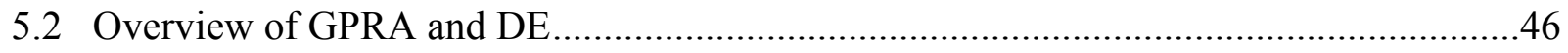

5.3 Commercial Building Representation in NEMS......................................................4

5.4 Overview of DG Treatment in the Commercial Demand Module .................................47

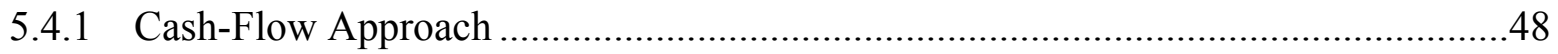

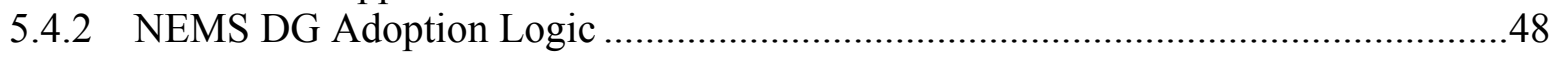

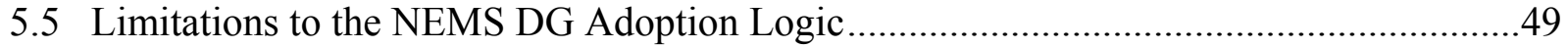

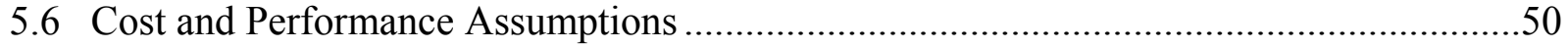


5.7 Incorporating the ComSeM Approach for Modeling Commercial DG Adoption to

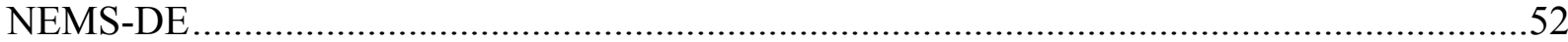

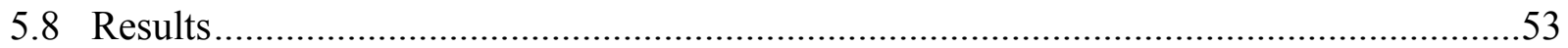

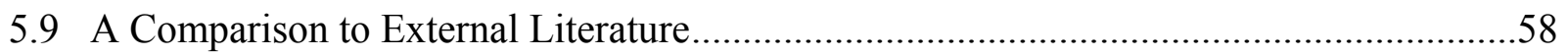

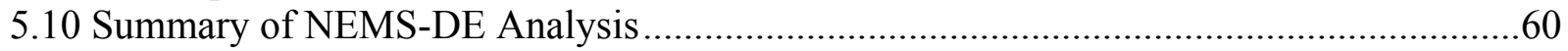

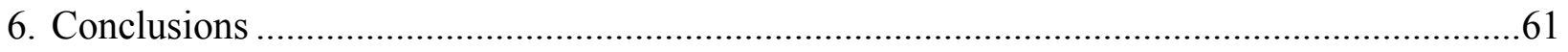

Appendix A. Detailed Treatment of DG in the NEMS Commercial Demand Module..................65

Appendix B. Recent Modifications to DER-CAM …………......................................................69

Appendix C. Detailed DER-CAM Results ............................................................................

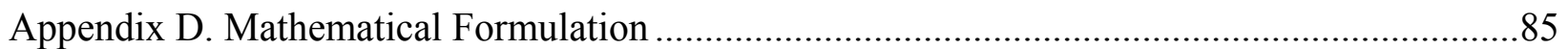




\section{List of Figures and Tables}

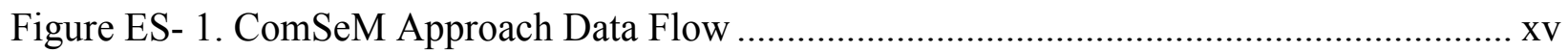

Figure ES- 2. ComSeM Incremental DG Adoption by 2025 .................................................... xvi

Figure ES- 3. ComSeM Program Commercial DG 2025 Adoption as Share of Total Floorspace

.

Figure ES- 4. Incremental Commercial DG Adoption by Building Type by 2025 in ComSeM xviii

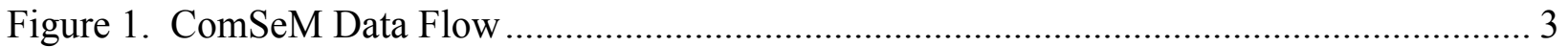

Figure 2. A Comparison of CBECS 1999 and NEMS-DE Total Floorspace by Building Type.... 9

Figure 3. Commercial Floorspace Distribution by Building Peak Load ....................................... 9

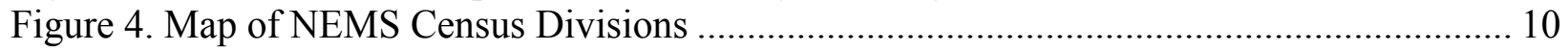

Figure 5. San Francisco Healthcare Building January Electricity Load ........................................ 13

Figure 6. San Francisco Healthcare Building July Electricity Load............................................ 13

Figure 7. San Francisco Healthcare Building January Gas Load ............................................. 13

Figure 8. San Francisco Healthcare Building July Gas Load ................................................ 13

Figure 9. San Francisco Mercantile Building January Electricity Load ....................................... 14

Figure 10. San Francisco Mercantile Building July Electricity Load.............................................. 14

Figure 11. San Francisco Mercantile Building January Gas Load .............................................. 14

Figure 12. San Francisco Mercantile Building July Gas Load ...................................................... 14

Figure 13. San Francisco Office Building January Electricity Load ........................................... 15

Figure 14. San Francisco Office Building July Electricity Load.................................................... 15

Figure 15. San Francisco Office Building January Gas Load .................................................. 15

Figure 16. San Francisco Office Building July Gas Load ........................................................... 15

Figure 17. Chicago Healthcare Building July Electricity Load ....................................................... 16

Figure 18. Chicago Healthcare Building January Gas Load.......................................................... 16

Figure 19. Chicago Mercantile Building July Electricity Load .................................................... 16

Figure 20. Chicago Mercantile Building January Gas Load.......................................................... 16

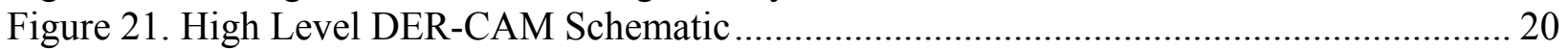

Figure 22. Legend for DER-CAM Bar Chart of Results ............................................................... 25

Figure 23. Installed DG Capacity - Reciprocating Engines (kW) ............................................... 26

Figure 24. Installed DG Capacity - Microturbines (kW) ........................................................... 27

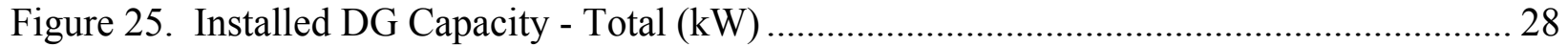

Figure 26. Relative 2004 electricity charges by city.................................................................... 30

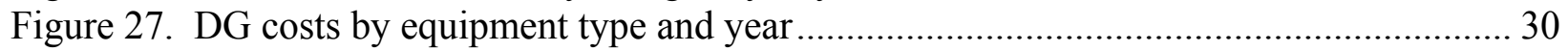

Figure 28. Adoption Curves for New and Existing Buildings................................................ 36

Figure 29. Installed DG Capacity in U.S. Commercial Sector in Baseline and Program Cases . 37

Figure 30. Installed Capacity of Reciprocating Engines and Microturbines in the Program and

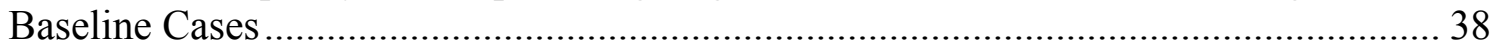

Figure 31. Electricity Produced On-site and Increased Natural Gas Consumption in Program and

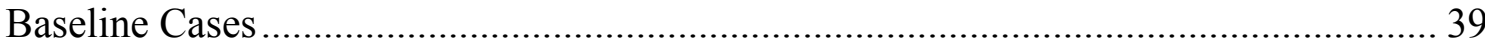

Figure 32. Annual Private Cost Savings from On-site Generation in Program and Baseline Cases

Figure 33. Installed DG Capacity in Census Regions in the Forecast Period in Program and

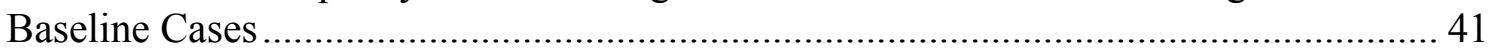


Figure 34. Installed DG Capacity for Building Types in Program and Baseline Cases .............. 42

Figure 35. Overview of the NEMS Modeling Structure .................................................... 45

Figure 36. Installed Cost Assumptions for Three Commercial DER Technologies.................... 51

Figure 37. Electric Heat Rate Assumptions for Three Commercial DER Technologies............. 51

Figure 38. Combined Efficiency Assumptions for Three Commercial DER Technologies........ 52

Figure 39. AEO2005 Commercial DG 2025 Adoption as Share of Total Floorspace ................ 54

Figure 40. ComSeM Baseline Commercial DG 2025 Adoption as Share of Total Floorspace.... 55

Figure 41. ComSeM Program Commercial DG 2025 Adoption as Share of Total Floorspace.... 55

Figure 42. Traditional Approach Baseline Commercial DG 2025 Adoption as Share of Total

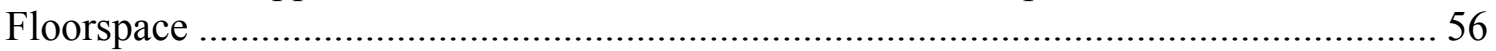

Figure 43. Traditional Approach Program Commercial DG 2025 Adoption as Share of Total

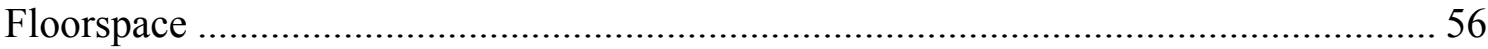

Figure 44. ComSeM Total DG Adoption for Program Case by 2025 ..................................... 58

Figure 45. OnSite Sycom Commercial CHP Potential by Building Type................................ 59

Figure 46. Incremental ComSeM Commercial DG Adoption by Building Type by 2025 .......... 59

Table ES- 1. Summary of 2025 Results Using ComSeM ..................................................... xvi

Table 1. Commercial Building Size Distribution with Corresponding Building Peak Load........ 7

Table 2. Selected Building Size ...................................................................................... 7

Table 3. The Distribution of Total Commercial Floorspace by Building Size ........................... 8

Table 4. The Distribution of Commercial Floorspace as Fraction of Total by Building Size and

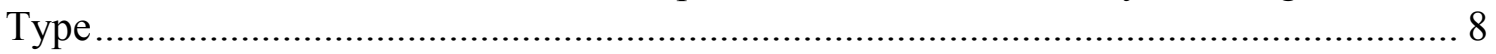

Table 5. Mapping of Four Selected Cities to U.S. Census Divisions ...................................... 10

Table 6. Peak Electricity Load and Total Energy Consumption for 40 Prototype Buildings....... 12

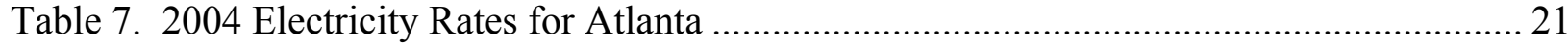

Table 8. 2004 Electricity Rates for Boston.......................................................................... 21

Table 9. 2004 Electricity Rates for Chicago.................................................................... 21

Table 10. 2004 Electricity Rates for San Francisco............................................................. 21

Table 11. Scaling Factors for 2012 and 2022 Electricity and Natural Gas Prices..................... 22

Table 12. AEO2005 Natural Gas Rates in 2004 (\$/kWh, HHV) .......................................... 22

Table 13. 2004 Technology Cost and Performance Data Used in DER-CAM ......................... 23

Table 14. Scaling Factors for 2012 and 2022 DER-CAM Technology Data ........................... 24

Table 15: Description of Indices Used in DER-MaDiM ......................................................... 32

Table 16. Percentage of Buildings Assumed to have DG Potential ........................................ 35

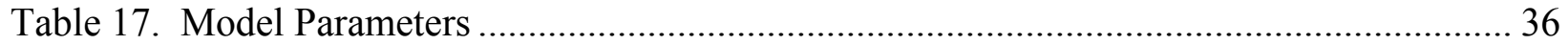

Table 18. Summary of AEO2005 NEMS Commercial DER Technology Types....................... 48

Table 19. Summary of 2025 Results Using ComSeM Approach ........................................... 57

Table 20. Summary of 2025 Results Using Traditional Approach......................................... 57

Figure A- 1. Flow Chart of DG in NEMS Commercial Building Sector ................................. 65

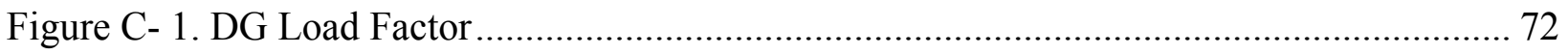

Figure C- 2. Fraction of Electricity Load Met by DG ....................................................... 73

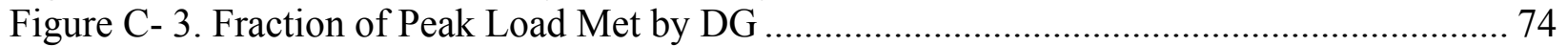

Figure C- 4. Increase in Utility NG Consumption (GWh) ..................................................... 75 


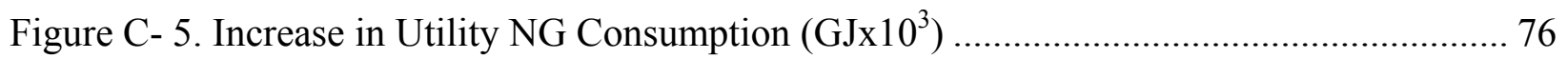

Figure C- 6. Increase in Utility NG Consumption (\% of No-invest) ...................................... 77

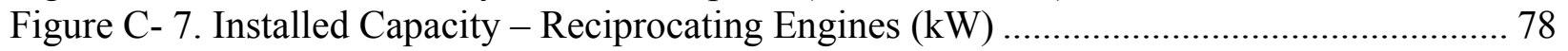

Figure C- 8. Installed Capacity - Microturbines $(\mathrm{kW})$......................................................... 79

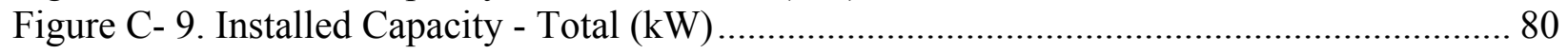

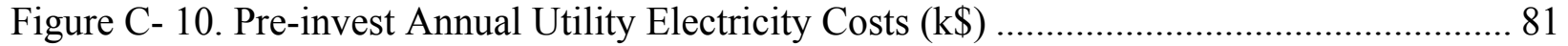

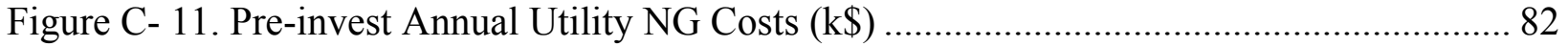

Figure C- 12. Reduction in Annual Utility Electricity Consumption (GWh) ........................... 83 



\section{Acronyms and Abbreviations}

$\begin{array}{ll}\text { AEO } & \text { Annual Energy Outlook } \\ \text { CBECS } & \text { Commercial Buildings Energy Consumption Survey } \\ \text { CHP } & \text { combined heat and power } \\ \text { ComSeM } & \text { Commercial Sector Model } \\ \text { COP } & \text { coefficient of performance } \\ \text { DE } & \text { Distributed Energy Program of DOE } \\ \text { DER } & \text { Distributed Energy Resources refers to technologies used to } \\ & \text { provide on-site generation } \\ \text { DER-CAM } & \text { Distributed Energy Resources Customer Adoption Model } \\ \text { DER-MaDiM } & \text { Distributed Energy Resources Market Diffusion Model } \\ \text { DG } & \text { Distributed Generation } \\ \text { DOE } & \text { U.S. Department of Energy } \\ \text { DOE-2 } & \text { DOE building energy simulation software } \\ \text { EIA } & \text { Energy Information Administration } \\ \text { EMM } & \text { Electricity Market Module } \\ \text { F/E } & \text { fuel to electricity ratio } \\ \text { GAMS } & \text { General Algebraic Modeling System } \\ \text { GW } & 10^{9} \text { (giga)watt } \\ \text { GJ } & 10^{9} \text { (giga)joule } \\ \text { GPRA } & \text { Government Performance and Results Act } \\ \text { HHV } & \text { higher heating value } \\ \text { HVAC } & \text { heating, ventilation, and air conditioning } \\ \text { kW } & 10^{3} \text { (kilo)watt } \\ \text { kWh } & 10^{3} \text { (kilo)watt-hour } \\ \text { LBNL } & \text { Ernest Orlando Lawrence Berkeley National Laboratory (or } \\ \text { MBtu } & \text { Berkeley Lab) } \\ \text { MILP } & \text { million British thermal units } \\ \text { MJ } & \text { mixed integer linear optimization program } \\ \text { MT } & 10^{6} \text { (mega)joule } \\ \text { MW } & \text { microturbine } \\ \text { NEMS } & 10^{6} \text { (mega)watt } \\ \text { NEMS-DE } & \text { National Energy Modeling System } \\ \text { Berkeley Lab version of NEMS used to model DE Program } \\ \text { NG } & \text { benefits } \\ \text { O\&M } & \text { North American Electric Reliability Council } \\ \text { R\&D } & \text { natural gas } \\ \text { operation and maintenance } \\ \text { research and development } \\ \text { typical meteorological year } \\ \text { 10 } & \end{array}$





\section{Acknowledgments}

The work described in this report was funded by the Assistant Secretary of Energy Efficiency and Renewable Energy, Distributed Energy Program (DE) of the U.S. Department of Energy under Contract No. DE-AC02-05CH1 1231. The authors would like to thank our Program Manager, Patricia Hoffman, other members of the DE staff, especially Debbie Haught, and Anne-Marie Borbely-Bartis of the Pacific Northwest National Laboratory, who provides support to DE. Also, a special thank you to Frances Wood of OnLocation, Inc. for providing an exceptionally thorough and insightful review of this report. This work builds on prior work by Afzal Siddiqui, Owen Bailey, Etan Gumerman, Jennifer Edwards, and Michael Stadler. Finally, the authors would also like to thank Judy Lai for her help editing this work. 



\begin{abstract}
Small-scale (100 kW-5 MW) on-site distributed generation (DG) economically driven by combined heat and power (CHP) applications and, in some cases, reliability concerns will likely emerge as a common feature of commercial building energy systems over the next two decades. Forecasts of DG adoption published by the Energy Information Administration (EIA) in the Annual Energy Outlook (AEO) are made using the National Energy Modeling System (NEMS), which has a forecasting module that predicts the penetration of several possible commercial building DG technologies over the period 2005-2025. NEMS is also used for estimating the future benefits of Department of Energy research and development used in support of budget requests and management decisionmaking. The NEMS approach to modeling DG has some limitations, including constraints on the amount of DG allowed for retrofits to existing buildings and a small number of possible sizes for each DG technology. An alternative approach called Commercial Sector Model (ComSeM) is developed to improve the way in which DG adoption is modeled. The approach incorporates load shapes for specific end uses in specific building types in specific regions, e.g., cooling in hospitals in Atlanta or space heating in Chicago offices. The Distributed Energy Resources Customer Adoption Model (DER-CAM) uses these load profiles together with input cost and performance DG technology assumptions to model the potential DG adoption for four selected cities and two sizes of five building types in selected forecast years to 2022. The Distributed Energy Resources Market Diffusion Model (DER-MaDiM) is then used to then tailor the DER-CAM results to adoption projections for the entire U.S. commercial sector for all forecast years from 2007-2025. This process is conducted such that the structure of results are consistent with the structure of NEMS, and can be re-injected into NEMS that can then be used to integrate adoption results into a full forecast.
\end{abstract}





\section{Executive Summary}

This work describes a new approach for modeling distributed generation (DG) adoption in the U.S. commercial sector, which has been implemented as the Commercial Sector Model (ComSeM). It represents a very different method to modeling DG adoption from the method Berkeley Lab has relied on in recent years using only the National Energy Modeling System (NEMS). One fundamental concern is that NEMS relies on a calculation of years to positive cash flow for a limited number of equipment sizes in one building size to determine the economic attractiveness of each potential DG purchase. Also, the analysis does not include waste heat driven cooling technologies, a key potential heat load in warm climates. In contrast, the ComSeM approach uses the Distributed Energy Resources Customer Adoption Model (DERCAM) with detailed information about a given location and building to determine the optimal solution for DG adoption at a given site. This bottom-up approach is then used together with a Distributed Energy Resources Market Diffusion Model (DER-MaDiM) to scale building-bybuilding DG adoption to the likely national penetration. This process is conducted such that the structure of results are consistent with the structure of NEMS, and can be re-injected into NEMS that can then be used to integrate adoption results into a full forecast.

\section{Motivation for This Work}

The Government Performance and Results Act (GPRA) requires each Federal program to annually report the goals of the program and estimate the progress towards achieving them. This work focuses on estimating the benefits that will accrue from the upcoming fiscal year budget request, which is typically two years hence. Working under the auspices of the Distributed Energy (DE) Program office of DOE, Berkeley Lab uses NEMS-DE, a modified version of NEMS tailored to model DE benefits, to assess the potential of DG in the U.S.. NEMS is a large multi-sectoral U.S. energy model designed to forecast 20 years out the behavior of energy markets and their interactions with the U.S. economy, and it produces the influential Annual Energy Outlook (AEO).

GPRA benefits are estimated as the difference between two cases, the Baseline case in which the DE Program does not exist, and the Program case in which it does and meets its stated goals. In this work, DG refers to the entire system including all installed generators at the site as well as any controls or other site-specific components. The goal is to annually estimate the likely beneficial results from DOE research and development (R\&D) programs, as required by GPRA, and to provide input to the management of ongoing planned R\&D.

In the traditional approach, the DE-related GPRA benefit estimates were the result of modifications to cost and performance input technology characteristics of the specific smallscale DER technologies listed, including some changes to DG adoption logic. This included changing the installed cost, heat rate, and combined efficiency of various commercial DER technologies, as well as relaxing the penetration limit to retrofit existing construction from 0.5 percent to 10 percent of the available building stock in any given forecast year. The logistic penetration curve is also modified to reflect a more favorable environment for DG adoption over time. 
However, research has recently found that the NEMS-DE approach to modeling DG has some serious limitations, including arbitrary constraints to the amount of DG allowed for retrofits to existing buildings, a fixed-kW capacity for each technology so installations cannot be optimized for building size, no waste-heat-driven cooling, and no consideration of demand charges or other details of tariffs (LaCommare et al. 2003).

To help address these NEMS-DE modeling limitations, Berkeley Lab has developed an alternative approach called ComSeM, which uses a customer adoption model, DER-CAM, to predict the optimal level of DG adoption for a specific site.

Using load profiles and detailed building characteristic data specific to a particular DG purchase, DER-CAM is able to estimate the optimal level of DG for that site, a level of detail not possible using NEMS-DE. For example, commercial office buildings experience much of their load during weekday business hours, which DER-CAM is able to capture so a potential DG purchase offsets purchased electricity during this peak period. As well, DER-CAM allows sites to properly size the DER technology to their needs and benefit from economies of scale, while NEMS-DE limits each DER technology to generic size, cost, and performance characteristics. Finally, the technology choice available in DER-CAM is arbitrary and endogenous, so the various DG technologies compete against each other and absorption cooling can be properly considered. These improvements improve the accuracy of estimated DE program benefits. Furthermore, the ComSeM approach potentially allows competition between other technologies, as well as between various DE ones. For example, fuel cells, photovoltaics, or other on-site generation is readily added, and competition between energy efficiency improvements and DG can also potentially be incorporated. However, in this work, only the DE technology adoption is estimated using ComSeM.

\section{Overview of ComSeM}

Figure ES-1 illustrates a flow chart of the ComSeM approach. This alternative method begins with the use of a building simulation model, DOE-2, to develop the numerous load profiles necessary as input for DER-CAM. These load profiles represent prototypical commercial building load profiles specific to various representative U.S. locations. Then, using the prototypical load profiles along with cost and performance assumptions of DER technologies and any tariff information are fed into DER-CAM to estimate the economic potential for DG penetration in a given building type and city. The output represents the optimal solution for DG adoption, including operation schedules, energy costs, electricity and natural gas consumption estimates, and bill savings. The DER-MaDiM diffusion model is then used to extrapolate the DER-CAM results to all building types in the U.S for all forecast years. These inflated results are then fed back to NEMS-DE as deterministic changes in energy consumption of the commercial sector. DG adoption not due to cost and performance improvements of reciprocating engines, gas turbines, and microturbines still use the assumptions determined in the traditional approach. 


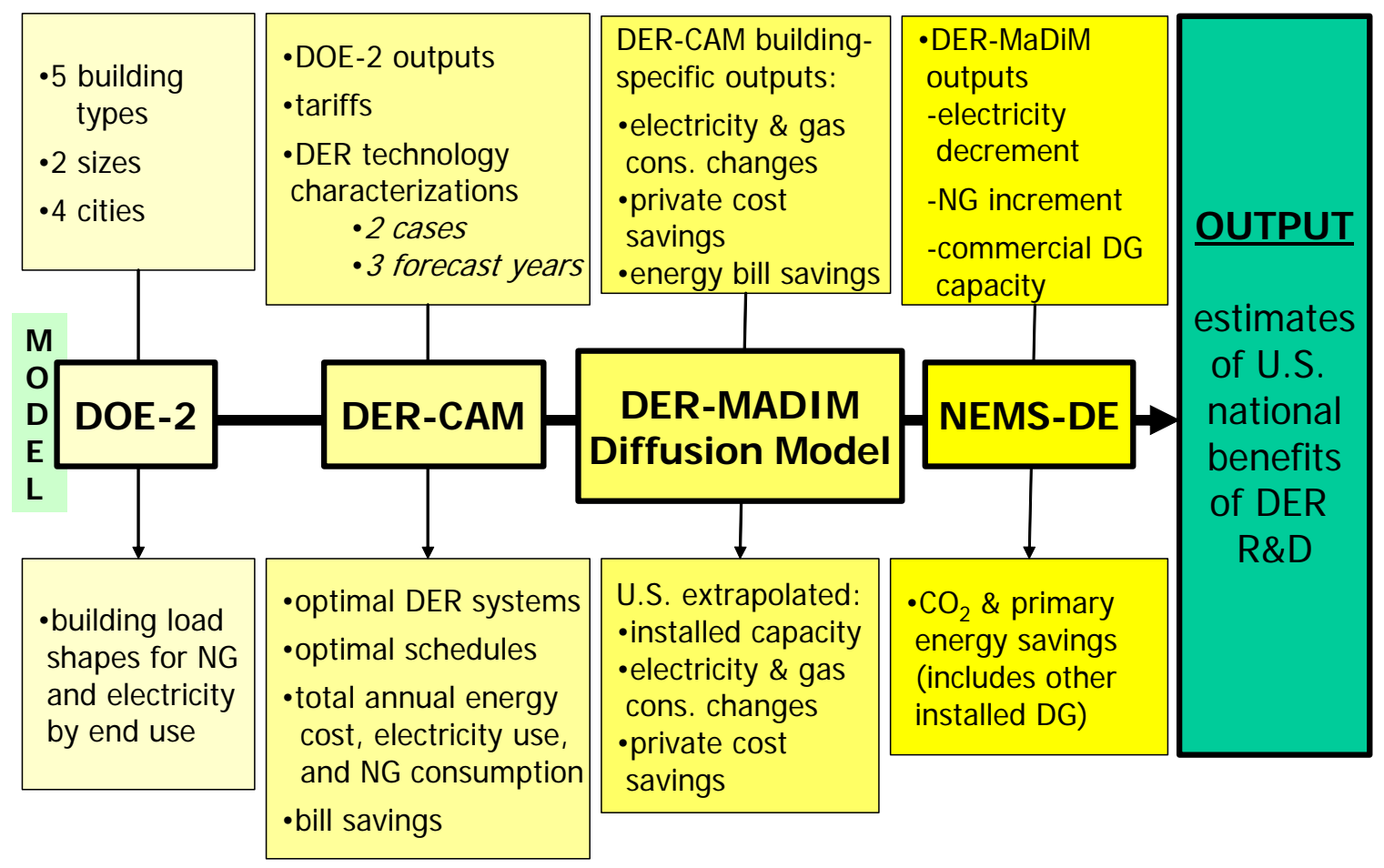

Figure ES- 1. ComSeM Approach Data Flow

\section{Results}

An assessment of the overall DG adoption in NEMS-DE revealed that virtually the entire growth in electricity demand in commercial buildings is met by the traditional centralized power sector. Only in healthcare, where the overall floorspace is relatively small, does DG show a sizeable contribution, serving nearly 50 percent of the forecasted total commercial electricity demand in 2025. Results also indicate that 96 to 97 percent of the commercial DG adoption is from these three selected DER technologies, leaving only three to four percent from other commercial DER technologies such as photovoltaics or fuel cells.

Table ES- 1 shows a summary of the 2025 results from ComSeM. Although not shown, the traditional approach resulted in $61 \mathrm{GW}$ of incremental total DG including CHP compared to the $57 \mathrm{GW}$ suggested using ComSeM. What is interesting to note is that although the incremental 2025 commercial DG adoption is lower using ComSeM, the total commercial DG adoption is significantly higher. For example, the AEO2005 forecasts only $1.8 \mathrm{GW}$ of commercial DG capacity in 2025, while the ComSeM Baseline forecasts $17.0 \mathrm{GW}$, and the Baseline using the traditional approach is only $4.5 \mathrm{GW}$. This is a significant difference of $12.5 \mathrm{GW}$ that is easily overlooked when measuring the DE GPRA benefits as the difference between the Baseline and Program cases. Although no one obvious reason can explain why the ComSeM Baseline results in $12.5 \mathrm{GW}$ more DG because structural differences in the DG modeling are so great. As mentioned earlier, one limitation with the NEMS-DE approach is that the commercial module only allows one $\mathrm{kW}$ size per technology. The incremental DG adoption is not a significantly different among building types between these two approaches. Also shown in this table is the 
percentage change in the program case relative to the baseline case, where the negative values seen for $\mathrm{CO}_{2}$ emissions and primary energy consumption indicate reductions in these levels.

Table ES- 1. Summary of 2025 Results Using ComSeM

\begin{tabular}{|c|cccccc|}
\hline & $\begin{array}{c}\text { Primary } \\
\text { Emissions } \\
\text { (Mt/a) }\end{array}$ & $\begin{array}{c}\text { Energy } \\
\text { Consumption } \\
\text { (EJ) }\end{array}$ & $\begin{array}{c}\text { Energy } \\
\text { Expenditures } \\
\text { (billion 2003-\$) }\end{array}$ & $\begin{array}{c}\text { Commercial } \\
\text { DG } \\
\text { Capacity } \\
\text { (GW) }\end{array}$ & $\begin{array}{c}\text { Other } \\
\text { Small- } \\
\text { Scale DG } \\
\text { Capacity } \\
\text { (GW) }\end{array}$ & $\begin{array}{c}\text { Total } \\
\text { DG } \\
\text { (GW) }\end{array}$ \\
\hline $\begin{array}{c}\text { AEO2005 } \\
\text { Reference }\end{array}$ & 8,060 & 133.2 & 1,059 & 1.8 & 92 & 94 \\
Baseline & 8,004 & 132.7 & 1,061 & 17.0 & 107 & 124 \\
Program & 7,903 & 131.6 & 1,065 & 23.6 & 157 & 181 \\
Difference P-B & -101 & -1.1 & 4.0 & 6.6 & 51 & 57 \\
$\begin{array}{c}\text { Difference as } \\
\text { \% of Baseline }\end{array}$ & $-1.3 \%$ & $-0.8 \%$ & $0.4 \%$ & $38.8 \%$ & $47 \%$ & $46.1 \%$ \\
\hline
\end{tabular}

The total DG from ComSeM includes a large share from CHP technologies. Of the $57 \mathrm{GW}$ of incremental DG forecasted under the ComSeM Program case shown in Table ES-1, roughly half $(28 \mathrm{GW})$ is from CHP with the other half $(29 \mathrm{GW})$ made up of non-CHP DG from the utility sector. It is important to note that the ComSeM approach is focused on commercial CHP with projections from industrial $\mathrm{CHP}$ and non-CHP adoption in the utility sector derived using the traditional approach. Changed cost and performance characteristics of these technologies is entered directly into the NEMS modules that derive DG penetration for the industrial and utility sectors. Furthermore, as industrial and commercial sector DG increase, utility sector DG tends to decrease because commercial electricity sales growth is suppressed. Figure ES-2 illustrates the significant share of non-CHP DG in the utility sector.

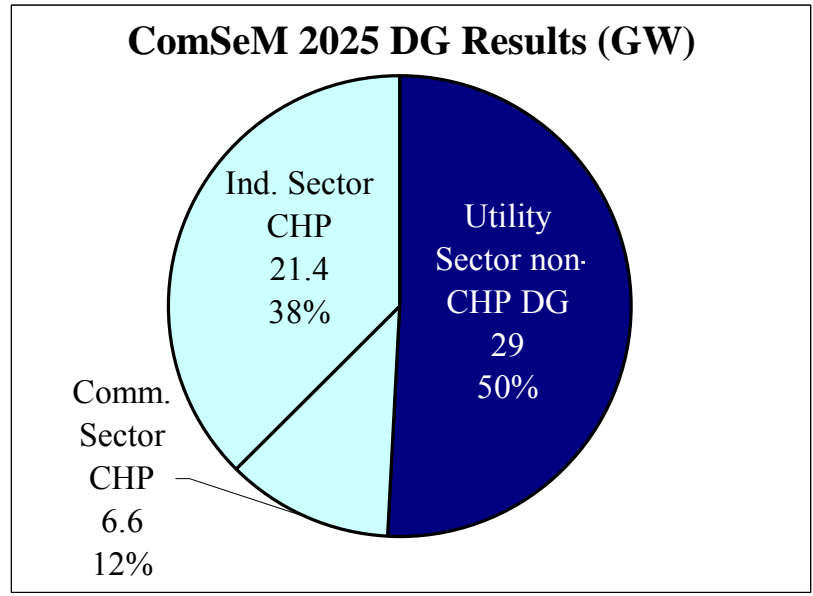

Figure ES- 2. ComSeM Incremental DG Adoption by 2025 
Of the $28 \mathrm{GW}$ CHP increase, only $6.6 \mathrm{GW}$ is from commercial sector DG with the remainder from large scale industrial sector gas turbines. The incremental results highlight the sensitivity of the utility sector DG adoption decision, something that still requires further analysis and understanding.

Figure ES-3 shows the Program case commercial sector DG adoption by building type represented as the share of DG adoption to the total floorspace in year 2025. The size of each pie represents the share of each building's total commercial floorspace relative to the total floorspace across all commercial buildings. The buildings showing the greatest potential for DG are offices and healthcare, and to a lesser extent education and lodging.
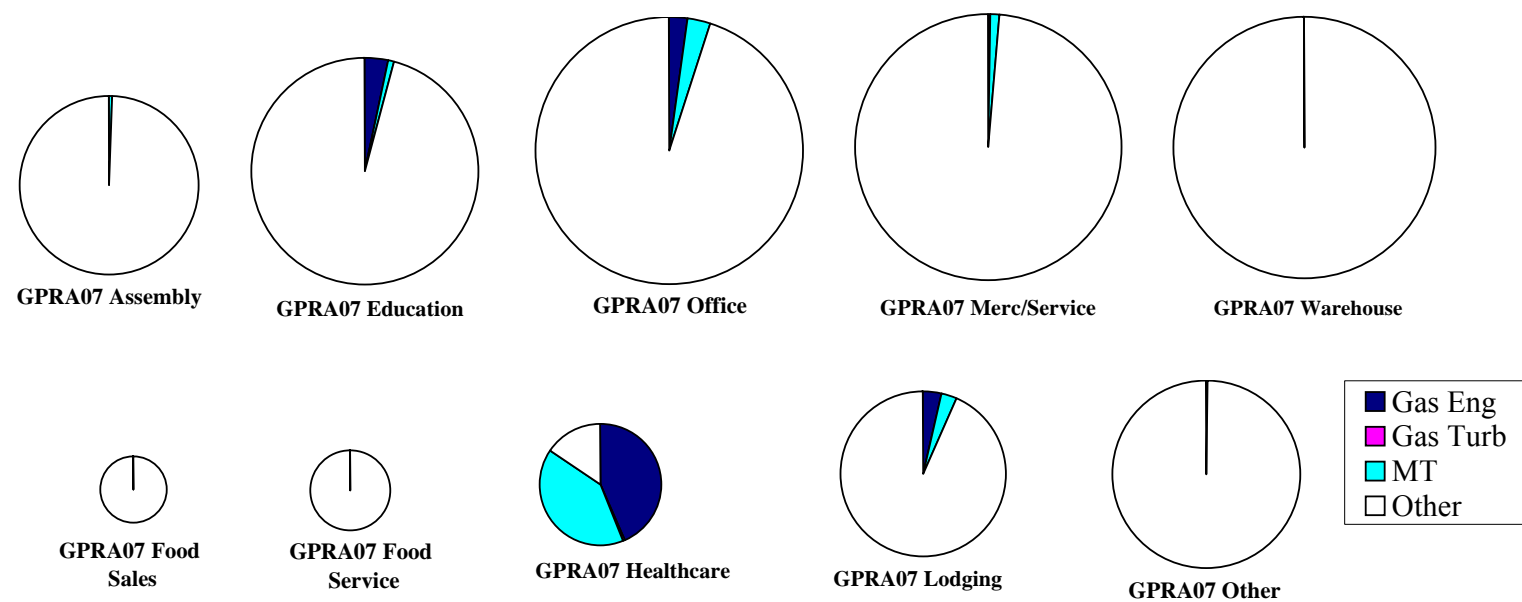

Figure ES- 3. ComSeM Program Commercial DG 2025 Adoption as Share of Total Floorspace

To put the ComSeM results in perspective, Berkeley Lab compared results with those from the external literature. In a study by OnSite Consulting, the total estimated commercial sector CHP potential is $77 \mathrm{GW}$ in year 2005 , of which only $5 \mathrm{GW}$ is currently installed. Almost threequarters of the total are from offices, education, and healthcare buildings, each showing 16-18 GW of potential CHP (Onsite Sycom Energy 2000).

For comparison, Figure ES-4 shows how this CHP potential compares to what ComSeM predicts will be adopted by 2025. This figure breaks down the $6.6 \mathrm{GW}$ of total commercial DG capacity in 2025 by building type. Not surprisingly, office buildings make up a large share of the pie with $1.9 \mathrm{GW}$ of adoption. The mercantile, education, lodging, and healthcare buildings also show notable level of adoption not too different from the OnSite study. 


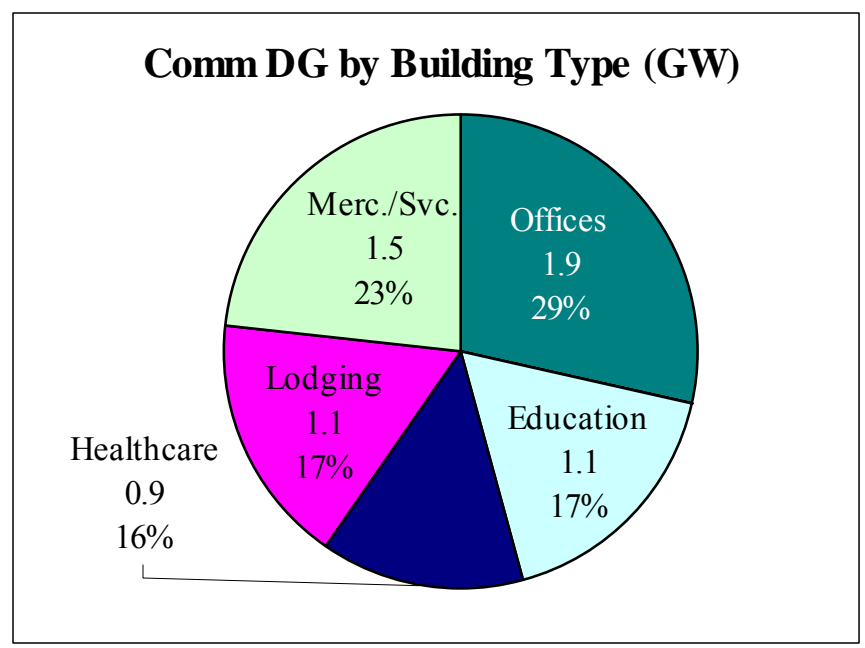

Figure ES- 4. Incremental Commercial DG Adoption by Building Type by 2025 in ComSeM

\section{What Was Learned}

This work revealed a number of interesting findings:

- $1 \mathrm{MW}$ gas turbines are not a viable option for small-scale (100kW-5MW) commercial DG adoption because they are too expensive at this small size to compete with reciprocating engines and microturbines.

- The West and Northeast regions of the U.S. are where most of the DG expansion is expected, with office and mercantile buildings playing a key role in realizing the DG potential.

- Mercantile and office buildings have the lowest fuel to electricity ratio, yet can be the most influential buildings in DG market diffusion because they constitute a large share of commercial floorspace and because they can use waste heat to off-set electric cooling, demand charges and on-peak power. These are effects not accounted for in NEMS-DE.

- Educational buildings with the highest fuel to electricity ratio show less market diffusion than expected. This is most likely due to non-coincidence of heat loads, electricity loads and peak electricity prices.

- The non-obvious relationship between DG profitability and generalized load descriptions confirm the need for the detailed load, price and operation modeling provided by DER-CAM.

- DG adoption shows a shift from reciprocating gas engines early in the forecast to microturbines by the end of the forecast.

- DER-CAM results indicate a strong correlation between DG potential and high electricity rates with the greatest potential in San Francisco and Boston and none in Atlanta.

- Although, incremental DG GPRA benefits between the Program and Baseline cases are less using the ComSeM approach than traditional approach, total overall DG adoption is $11 \mathrm{GW}$ more using the new alternative approach by 2025 .

- The ComSeM DG adoption results are within reason when compared with external studies of DG potential in the commercial sector. 
Healthcare buildings, which show a strong DG potential, exhibit a space heating peak during the night due to high occupancy and high space cooling during the day to maintain a high level of air circulation.

\section{Future Work}

This first effort to integrate the customer adoption capability of DER-CAM with NEMS-DE serves as a proof of concept. Now that GPRA DE benefits can be estimated using an alternative approach designed to capture the location and building load characteristics associated with a given customer, further refinements and additions are desired.

The following summarize some next steps Berkeley Lab hopes to address:

- Expand the number of cities considered to represent the nation. Although four cities were deemed the minimum necessary to model the U.S., this number surely ignores a number of micro-climates only accounted for when including more cities into the analysis.

- Increase the number of buildings considered to eventually include all commercial building types.

- Parameterize results in a simplified model that could be embedded directly in NEMS.

- $\quad$ Switch the building energy simulation to a more modern model than DOE-2, e.g. EnergyPlus.

- Expand analysis to consider other fuels. This work focused on natural gas fired technologies, but could expand to include fuel alternatives like biomass and solar power.

- Include more technology options in direct competition, initially alternative on-site generating technologies such as fuel cells and PV, and potentially competition from alternatives such as energy efficiency investments.

- Consider reliability as a motivation for DG adoption by estimating the sensitive loads in the U.S.

- Explore alterative scenarios like a power system constrained case or high fuel price case to determine its impact on the potential for DG adoption. This work focused on a business-asusual forecast consistent with the AEO2005 Reference Case.

- Include the DG adoption potential of the residential sector. 



\section{Introduction}

While pressure on the current power system continues to grow, its expansion in certain regions of the U.S. is constrained and is potentially unlikely to keep pace with the country's seemingly unquenchable thirst for electricity. Also, little compelling evidence exists to suggest that improved power quality and reliability is possible under the traditional electricity structure (Siddiqui et al. 2005). Consequently, small-scale (100 kW-5 MW) thermal on-site distributed generation (DG) economically driven by combined heat and power (CHP) applications and, in some cases, by reliability concerns will likely emerge as a common feature of commercial building energy systems in the U.S. over the next two decades. The primary benefit of thermal energy conversion to electricity closer to loads is the opportunity it creates for utilization of waste heat, which is usually sacrificed by central station generation.

Other possible benefits of DG include direct electricity cost reduction and stability, improved electricity reliability and quality, emission reductions, and a simple feeling of control and/or independence. Recent improvements in small-scale thermal electricity generation and CHP technologies, resulting in part from U.S. Department of Energy (DOE) research, are enabling a dramatic shift from traditional monopolistic electricity supply to empowered, semi-autonomous self-generator. Nonetheless, this transition will require considerable research and confirmation. Because of the significant effect widespread DG adoption could have on the design and operation of building and utility systems, accurate forecasts of DG penetration are vital, and developing them poses a major research challenge. This research effort aims to develop a bottom-up model of economic DG adoption that can deliver reasonable forecasts of technology penetration, and enable estimates of the benefits of alternative possible enhancements to DG equipment.

In the U.S., deployment of the type of small-scale thermal generation that is the focus of this paper is generally analyzed independently of renewable generation or the devolution of grid operations. More generally, there is little agreement on what technologies should be included under the DG label (see (Peperman et al. 2005) for a broader discussion). For the purposes of this work, $D G$ specifically describes a selected list of technologies currently existent in the commercial module of the U.S. Energy Information Administration's (EIA) National Energy Modeling System (NEMS): small ( $<5 \mathrm{MW})$ gas turbines, gas engines, and microturbines. Another related term used in this report is distributed energy resources (DER), which refers to the full suite of DG technologies plus other prime movers, such as fuel cells as well as energy storage.

Each Federal program is required to annually report its goals and demonstrate progress towards achieving them. Further, the likely beneficial results from DOE research and development (R\&D) programs are estimated, as required by the Government Performance and Results Act (GPRA) of 1993, and to provide input to the management of ongoing planned R\&D. This work focuses on estimating the benefits that will accrue from the upcoming fiscal year budget request, which is typically two years hence. Working under the auspices of the Distributed Energy (DE) office of DOE, Berkeley Lab uses NEMS to assess the potential of DG in the U.S. commercial sector. 
In prior work, Berkeley Lab has assessed the capabilities of NEMS for forecasting DG market penetration (LaCommare et al. 2003). The GPRA-DE benefit estimates are the result of modifications to cost and performance input technology characteristics of the specific smallscale DG technologies listed above, including some changes to the DG adoption logic. This includes changing the installed cost, heat rate, and combined efficiency of various commercial DG technologies, as well as relaxing the penetration limit to retrofit existing construction from the lesser of 0.5 percent or two percent of the market share for new construction to 10 percent of the available building stock in any given forecast year. The logistic penetration curve is also modified to reflect the more optimistic behavior of DG adoption over time that should be fostered by funded market transformation efforts. This research explores an alternative to the way NEMS models DG adoption that uses the same cost and performance technology assumptions in an exogenous customer adoption model that estimates the appropriate level of DG penetration in representative buildings in representative cities. These results are then inflated to national levels and fed back into NEMS as deterministic changes in energy consumption of the commercial sector.

This pilot effort was completed in parallel with the GPRA-07 process and so GPRA-07 results from both approaches are presented.

This alternative approach can be viewed as the following four-stage process, which collectively is called the Commercial Sector Model (ComSeM) approach:

1. development of prototypical commercial building load profiles specific to various representative U.S. locations, including data collection of tariffs and DER technology cost and performance data for present of future years;

2. use of the Distributed Energy Resources Customer Adoption Model (DER-CAM) to estimate the economic attractiveness of DG in a given building type, city, and forecast year;

3. application of the Distributed Energy Resources Market Diffusion Model (DER-MaDiM) to estimate the likely DG penetration for building types, cities, and years in which adoption is attractive, and to then extrapolate these results to all comparable building types in the U.S for all forecast years.; and finally

4. use of NEMS-DE, the Berkeley Lab version of NEMS, to model the DE GPRA benefits, thereby estimating the consequences of DG adoption on the U.S. energy economy. 


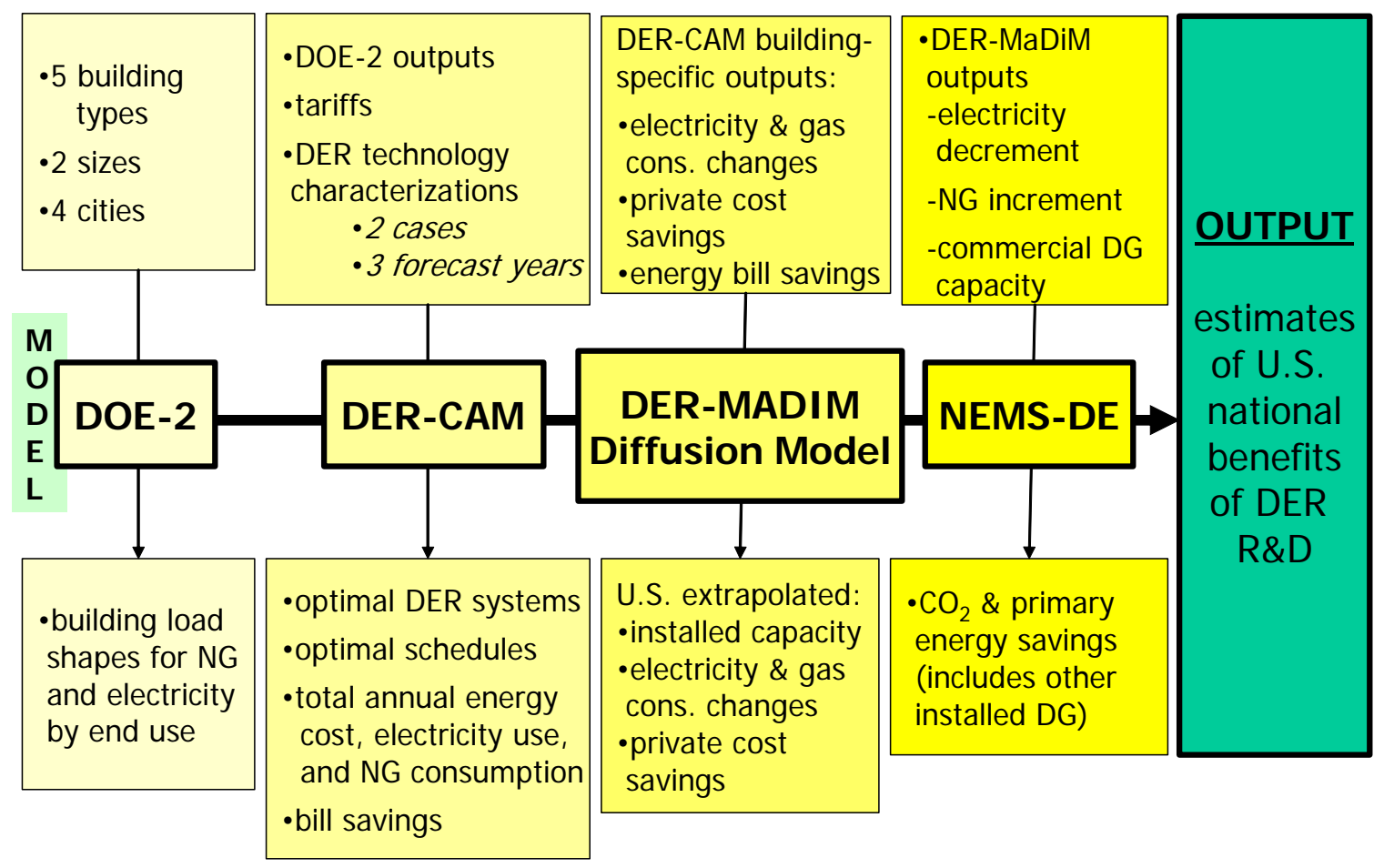

Figure 1. ComSeM Data Flow

The ComSeM approach, as shown in Figure 1, begins by estimating energy use profiles for selected building types and cities. The buildings are based both on the ones existent in NEMS and on a prior Berkeley Lab study (Huang et al. 1991). Five building types were selected (mercantile, lodging, education, healthcare, and office) with small and large versions defined for each building type. Building specifications from the Huang et al study and the same cost and performance data assumed in the NEMS DG module are used in DER-CAM. This current study focuses on selected buildings thought to have the greatest potential for DG adoption. The operations of these buildings were simulated in four representative cities: San Francisco, Chicago, Atlanta, and Boston. A total of 40 load profiles were estimated for a number of end uses as inputs to DER-CAM.

DER-CAM is a mixed integer linear program model written in GAMS (General Algebraic Modeling System) to minimize the annual cost of providing energy services to a given site through utility electricity and gas purchases and/or purchase and operation of DER equipment. The objective function estimates the annual costs of electricity purchases, gas purchases (for direct use and as generating fuel), operating and maintenance (O\&M) costs, and the annualized capital costs of DER equipment (Bailey and Marnay 2005). ${ }^{1}$ Appendix D discusses in detail the mathematical optimization problem that is addressed in this paper. The capital cost annualization uses a simple amortization function, similar to the PMT function in Excel, so financial

1 The annualized cost of capital is defined as $\operatorname{Cap} \operatorname{Cos} t \times\left(\frac{i}{\left.1-(1+i)^{-n}\right)}\right)$ where

CapCost is the upfront capital cost of equipment (including design and installation),

$\mathrm{i}$ is the annual discount rate (here assumed to be $5 \%$ ), and

$\mathrm{n}$ is the lifetime (in years) of equipment (here assumed to be 20 for reciprocating engines, heat exchangers, and absorption chillers, and 10 for microturbines). 
representation is rudimentary, but could be enhanced. The program output is an idealized set of DER technologies to install; however, even if DER is highly economically desirable, it will only be gradually adopted. Therefore, DER-MaDiM is necessary to predict the likely technology diffusion across the entire market of diverse building stock and building owner behavior. The DER-MaDiM model uses the optimal DER-CAM results from 2004, 2012 and 2022 to predict annual results for the period 2005 to 2025 for the entire U.S. commercial building stock. DER$\mathrm{CAM}$ and DER-MaDiM runs were performed for both Baseline and Program cases defined below:

- The Baseline Case is a scenario that assumes no DE Program exists. Without DE R\&D, improvements are slower than EIA's NEMS Reference Case. It is assumed that the baseline catches up to the Program case in 10 years, or by 2022.

- The Program Case is a scenario assuming all current DE Program goals are met and achieved by 2012 .

DER-CAM and DER-MaDiM results are passed as input to NEMS-DE in the form of commercial sector electricity use decrements and natural gas use increments by building type, region, and year. DE benefits are estimated as the difference between the Program and Baseline cases to ensure consistent learning progress and reporting. The estimated additions of DG capacity are also input by region and year.

This report sequentially details each of the four stages involved in performing the ComSeM approach:

- Section 2 presents an overview of the sources and assumptions used to derive the hourly load profiles input to DER-CAM.

- Section 3 explains how DER-CAM works, including an overview of the various model assumptions used in this study and an assessment of the results.

- Section 4 discusses how DER-CAM results are used to forecast real-world U.S. DG adoption using DER-MaDiM.

- Section 5 presents an overview of NEMS and the assumptions made to incorporate penetration results into NEMS-DE along with an analysis of results. 


\section{DOE-2 Analysis}

As a first step in the ComSeM process, Berkeley Lab develops a mix of load profiles to represent multiple representative building types and regions with varying potential for DG adoption. Hourly energy loads of a limited number of end uses and cities are required as inputs to DER-CAM. Using this building load data, DER-CAM finds the optimal technologies, equipment capacities, and operating schedules that minimize cost, as will be discussed in Section 3.

Building information from a prior Berkeley Lab study and DOE-2 simulations were used to develop the suite of load profiles necessary for DER-CAM (Huang et al. 1991). In all, Berkeley Lab developed 40 sets of load profiles for each of five end uses. These represent the load of two sizes of each of five building types in four cities.

\subsection{Overview of DOE-2}

To generate the load profiles, the widely used building energy simulation model, DOE-2, which was developed and is maintained by Berkeley Lab, was used. DOE-2 is a public domain computer program written in FORTRAN77 designed to aid in the analysis of energy usage in buildings. DOE-2 estimates the hourly energy use of a building given hourly weather information and descriptors of the building.

Logistically, it is impossible to simulate a broad enough range of buildings to characterize the U.S. commercial sector using DOE-2 and DER-CAM. The data and computational demands would be simply too burdensome; therefore, judicious selection of representative buildings in representative locations is necessary. Based on the availability of weather data and a desire to include a representative range of climates and fuel cost environments, the cities of San Francisco, Chicago, Atlanta, and Boston were chosen. In the future, Berkeley Lab will automate this stage of the ComSeM process to allow more cities and buildings to be considered in the analysis.

The DOE-2 simulation requires the following input data:

Building Description

$>$ Envelope Characteristics

Operational

Characteristics

\section{Equipment Characteristics}

location, building type, building size, and number of floors vintage, construction, insulation, window to wall ratio, window pane type, and shading coefficient average hot water intensity, peak lighting intensity, peak gas cooking load, and peak electric cooking load, hours of equipment operation, equipment control strategies, and thermostat set points

vintage, system type, and plant type

Basic input data such as building size are obtained from the Commercial Building Energy Consumption Survey (CBECS) 1999, as will be discussed in Section 2.3. The data are chosen to be consistent with the building definitions used in NEMS. Location of the building is defined by typical meteorological year (TMY) data sets derived from the 1961-1990 National Solar Radiation Data Base. ${ }^{2}$ The physical building characteristics are taken from Huang et al.

\footnotetext{
2 The TMY2 data sets are produced by the National Renewable Energy Laboratory's (NREL's) Analytic Studies Division under the Resource Assessment Program, which is funded and monitored by the U.S. Department of Energy's Office of Solar Energy Conversion.
} 
A number of additionally assumptions are needed. The following three subsections discuss in detail how building types, building sizes, and representative cities are chosen.

\subsection{Selection of Building Types}

Huang et al. collected building characteristic and energy usage data to develop a number of building prototypes. This study defined 13 prototype commercial buildings with different sizes in 13 regions. From this, a total of 481 prototypical buildings were simulated, including hospitals, schools, prisons, hotels, restaurants, offices, supermarkets, apartments, and retail stores in each region. As a result, standard building profiles with the aforementioned characteristics were defined, and a large database of hourly load profiles was established. For this analysis, five of the most promising building types for DG were chosen along with the standard buildings defined in Huang et al.

Conventional wisdom suggests that buildings with high thermal to electricity ratios are the best CHP adoption candidates considering waste heat utilization for both heating and cooling. Also, onsite generation tends to be most attractive for buildings with relatively constant electricity demand. Based on these insights, the five building types selected for this study are:

- mercantile

- lodging

- education

- healthcare

- office

More building types could be added in future work.

\subsection{Selection of Building Size}

DG potential tends to vary with building size. Unfortunately, the NEMS building data does not include a size distribution for each building type rather just one size is considered for each type. CBECS data was used to provide this missing data. To determine which building sizes to model in DER-CAM, Berkeley Lab conducted a simple analysis to estimate the peak loads of each selected building type in Boston. CBECS categorizes each building type by area and also reports the energy intensity of each building type $\left(\mathrm{kW} / \mathrm{m}^{2}\right)$ and these data were used to estimate building electricity peaks.

Berkeley Lab did not analyze the peak loads for all four cities, Boston being selected for ease of data availability. Table 1 presents the peak load by building type and size and the selected range of building size for candidate small scale DG. Small-scale DG is in the range of the smallest DG systems currently being installed, i.e. the low 100's of kW, to the largest sites where reciprocating engines are still preferable to turbines, i.e. 1-2 MW. Motivated by this, buildings with peak demand in the range $300-2,000 \mathrm{~kW}$ are considered as attractive DG sites. Within the attractive size range, two buildings, one large and one small, corresponding to the midpoints in the smallest size bin and the largest size bin in the CBECS size distribution respectively, were selected for analysis in DER-CAM (see Table 1). The peak loads shown in bold indicate the small and large sizes considered for each building type. 
Table 1. Commercial Building Size Distribution with Corresponding Building Peak Load

\begin{tabular}{|c|c|c|c|c|c|c|c|c|}
\hline $\begin{array}{l}\text { Building Size } \\
\left(\mathrm{m}^{2}\right) \\
\text { Median Size } \\
\left(\mathrm{m}^{2}\right) \\
\text { Peak Loads } \\
(\mathrm{kW})\end{array}$ & $93-465$ & $465-930$ & $930-2,325$ & $2,325-4,650$ & $4,650-9,300$ & $9,300-18,600$ & $18,600-46,500$ & $>46,500$ \\
\hline Healthcare & 18.25 & 54.75 & 127.75 & 273.75 & 547.5 & 1095 & 2555 & 4745 \\
\hline Lodging & 7 & 21 & 49 & 105 & 210 & 420 & 980 & 1820 \\
\hline Mercantile & 8.75 & 26.25 & 61.25 & 131.25 & 262.5 & 525 & 1225 & 2275 \\
\hline Education & 11.5 & 34.5 & 80.5 & 172.5 & 345 & 690 & 1610 & 2990 \\
\hline Office & 10.75 & 32.25 & 75.25 & 161.25 & 322.5 & 645 & 1505 & 2795 \\
\hline \multicolumn{5}{|c|}{ Below DG attractive size range (less than $200 \mathrm{~kW}$ ) } & & & & \\
\hline \multicolumn{5}{|c|}{ Below DG attractive size range (200 to $300 \mathrm{~kW}$ ) } & & & & \\
\hline \multicolumn{5}{|c|}{ Selected DG attractive size range (300 to $2,000 \mathrm{~kW}$ ) } & & & & \\
\hline \multicolumn{5}{|c|}{ Over DG attractive size range (greater than $2,000 \mathrm{~kW}$ ) } & & & & \\
\hline
\end{tabular}

For each building type, the small and large size subsequently modeled in each of four cities are shown in Table 2. The set of two building sizes for each of the five building types make up 10 buildings for which load profiles were needed as input to DER-CAM. The small buildings typically have peak electricity loads on the order of a few hundred kilowatts, the smallest commercial buildings likely to install DG. The large buildings have peak electricity loads in the range of 1-2 MW, the largest loads typically being met by microturbines and reciprocating engines.

Table 2. Selected Building Size

\begin{tabular}{lcr} 
& \multicolumn{2}{c}{ Building Size $\left(\mathrm{m}^{2}\right)$} \\
\hline Building Type & Small & Large \\
Healthcare & 7,200 & 13,900 \\
Lodging & 13,900 & 32,500 \\
Mercantile & 13,900 & 60,400 \\
Education & 7,200 & 32,500 \\
Office & 7,200 & 32,500 \\
\hline
\end{tabular}

\subsubsection{Distribution of Building Size}

The 1999 CBECS data used for this study are shown in Table 3. The size distributions show how much of the existing commercial floorspace exists in various-sized buildings, and therefore, how much of the total floorspace is in buildings large enough to be considered good candidates for DG. This table presents the floorspace distribution by binning it for each building type and indicates that the distribution varies considerably. For example, office buildings appear to have a relatively even distribution of floorspace across all building sizes, whereas all other building types show a clear predominance of floorspace in the medium to large building sizes. Note that a dominant share of all healthcare floorspace exists in very large buildings, one of the reasons this sector contains particularly attractive DG hosts. 
Table 3. The Distribution of Total Commercial Floorspace by Building Size

\begin{tabular}{|l|c|c|c|c|c|c|c|c|c|}
\hline & \multicolumn{7}{c|}{ Building Size } \\
\hline $\begin{array}{c}\mathrm{m}^{2} \\
\left(1000 \mathrm{ft}^{2}\right)\end{array}$ & $\begin{array}{c}93-465 \\
(1-5)\end{array}$ & $\begin{array}{c}465-930 \\
(5-10)\end{array}$ & $\begin{array}{c}930-2,325 \\
(10-25)\end{array}$ & $\begin{array}{c}2,325-4,650 \\
(25-50)\end{array}$ & $\begin{array}{c}4,650-9,300 \\
(50-100)\end{array}$ & $\begin{array}{c}9,300-18,600 \\
(100-200)\end{array}$ & $\begin{array}{c}18,600-46,500 \\
(200-500)\end{array}$ & $\begin{array}{c}>46,500 \\
(500)\end{array}$ \\
\hline & \multicolumn{7}{|c|}{ Total Commercial Floorspace $\left(10^{6} \mathrm{~m}^{2}\right)$} \\
\hline Healthcare & 18 & $\mathrm{Q}$ & 13 & 25 & 24 & 29 & 70 & 71 \\
\hline Lodging & $\mathrm{Q}$ & 26 & 41 & 106 & 70 & 49 & 74 & $\mathrm{Q}$ \\
\hline Mercantile & 86 & 97 & 198 & 93 & 139 & 164 & 40 & 149 \\
\hline Education & 31 & 41 & 82 & 168 & 199 & 138 & 122 & $\mathrm{Q}$ \\
\hline Office & 113 & 99 & 138 & 111 & 181 & 160 & 145 & 173 \\
\hline
\end{tabular}

$\mathrm{Q}=$ Data withheld because the relative standard error was greater than 50 percent, or fewer than 20 buildings were sampled

1 Square Feet $=0.093$ Square Meters

Source: 1999 Commercial Building Energy Consumption Survey, 1999

Table 4 shows the floorspace distribution from Table 3 as the fraction of total floorspace for each size bin and each selected building type. This table confirms that total healthcare floorspace is clearly dominated by large-sized healthcare buildings or hospitals. Education and lodging facilities tend appear in the mid-range sizes, while office buildings again show a relatively even distribution of floorspace across all building sizes.

Table 4. The Distribution of Commercial Floorspace as Fraction of Total by Building Size and Type

\begin{tabular}{|l|c|c|c|c|c|c|c|c|c|}
\hline & \multicolumn{7}{c|}{ Building Size } \\
\hline \multicolumn{1}{|c|}{$\mathrm{m}^{2}$} & $\begin{array}{c}93-465 \\
(1-5)\end{array}$ & $\begin{array}{c}465-930 \\
(5-10)\end{array}$ & $\begin{array}{c}930-2,325 \\
(10-25)\end{array}$ & $\begin{array}{c}2,325-4,650 \\
(25-50)\end{array}$ & $\begin{array}{c}4,650-9,300 \\
(50-100)\end{array}$ & $\begin{array}{c}9,300-18,600 \\
(100-200)\end{array}$ & $\begin{array}{c}18,600-46,500 \\
(200-500)\end{array}$ & $\begin{array}{c}>46,500 \\
(500)\end{array}$ \\
\hline & \multicolumn{7}{|c|}{ Fraction of Floorspace in Size Bin for Building Category (\%) } \\
\hline Healthcare & 6.6 & $5.7^{*}$ & 4.7 & 9.6 & 9.2 & 11.0 & 26.4 & 26.8 \\
\hline Lodging & $2.2^{\star}$ & 6.3 & 9.6 & 25.3 & 16.8 & 11.7 & 17.6 & $10.6^{\star}$ \\
\hline Mercantile & 8.9 & 10.1 & 20.5 & 9.6 & 14.4 & 17.0 & 4.1 & 15.4 \\
\hline Education & 3.5 & 4.6 & 9.1 & 18.6 & 22.1 & 15.3 & 13.5 & $13.5^{\star}$ \\
\hline Office & 10.1 & 8.8 & 12.3 & 9.9 & 16.2 & 14.3 & 13.0 & 15.5 \\
\hline
\end{tabular}

${ }^{*}$ Assumed value. Data withheld because the relative standard error was greater than 50 percent, or fewer than 20 buildings were sampled

1 Square Feet $=0.093$ Square Meters

Source: 1999 Commercial Building Energy Consumption Survey, 1999

According to the NEMS documentation, the floorspace data used in NEMS-DE is from CBECS. To validate the floorspace data in NEMS-DE, Berkeley Lab compared the total floorspace data obtained from CBECS. Figure 2 below shows that the 1999 CBECS total floorspace is reasonably consistent with the floorspace assumptions in NEMS-DE for year 2004, the first reported year of the current NEMS-DE forecast. As expected, the NEMS-DE floorspace values are slightly higher with the exception of the healthcare building, reflecting growth in commercial floorspace over the intervening five-year period, 1999-2004. The one exception is the mercantile category, which has much higher total floorspace in NEMS than in CBECS. This is because the NEMS Mercantile category includes service buildings that CBECS does not. 


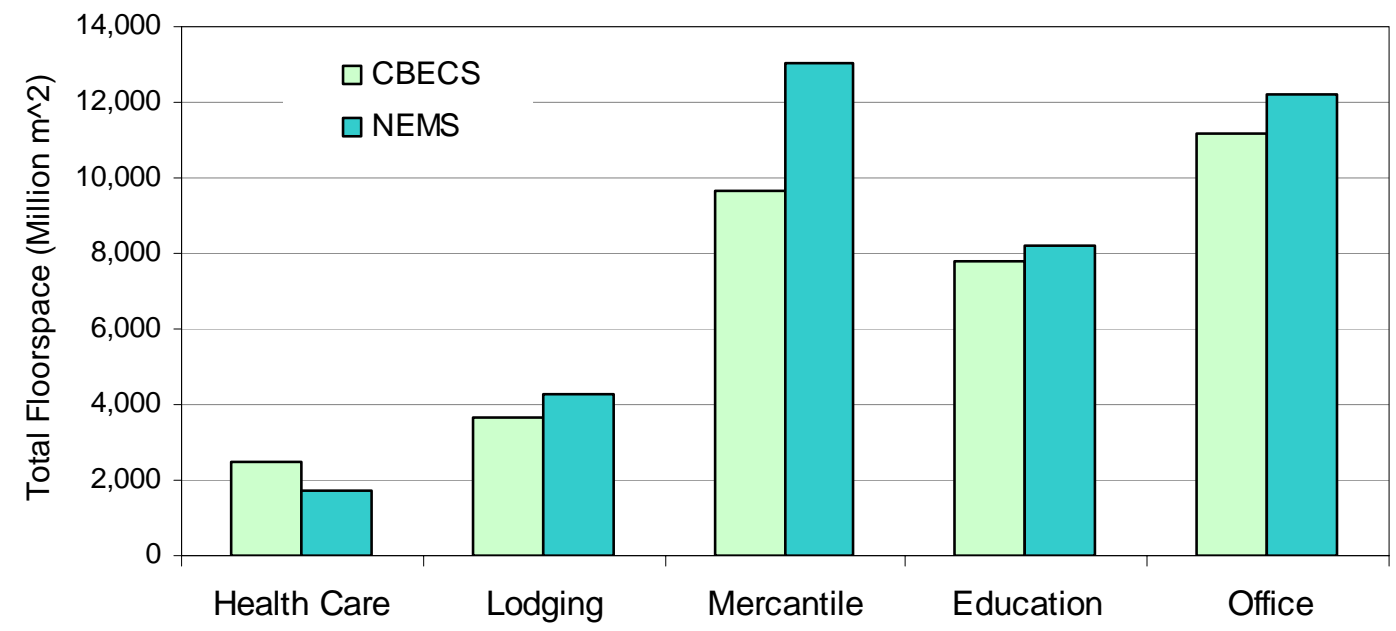

Figure 2. A Comparison of CBECS 1999 and NEMS-DE Total Floorspace by Building Type

The peak demand intensity is the building peak load (in $\mathrm{kW}$ ) divided by the total building size (in $\mathrm{m}^{2}$ ). This peak demand intensity was multiplied by the median building size in each of the eight building size categories shown in Table 1 to approximate a total building peak electricity load. Figure 3 shows the results of this calculation. The $\mathrm{x}$-axis shows the peak load of a single building (displayed on a log scale for visual clarity) and the y-axis shows how much U.S. commercial floorspace is contained in buildings of that size. A floorspace value of " 0 " corresponds to a " $Q$ " entry in Table 3 above. Buildings with peak loads ranging from $300 \mathrm{~kW}$ to 2,000 kW were selected for this project with two building sizes that correspond to the minimum and maximum attractive peak load, respectively (see Table 1).

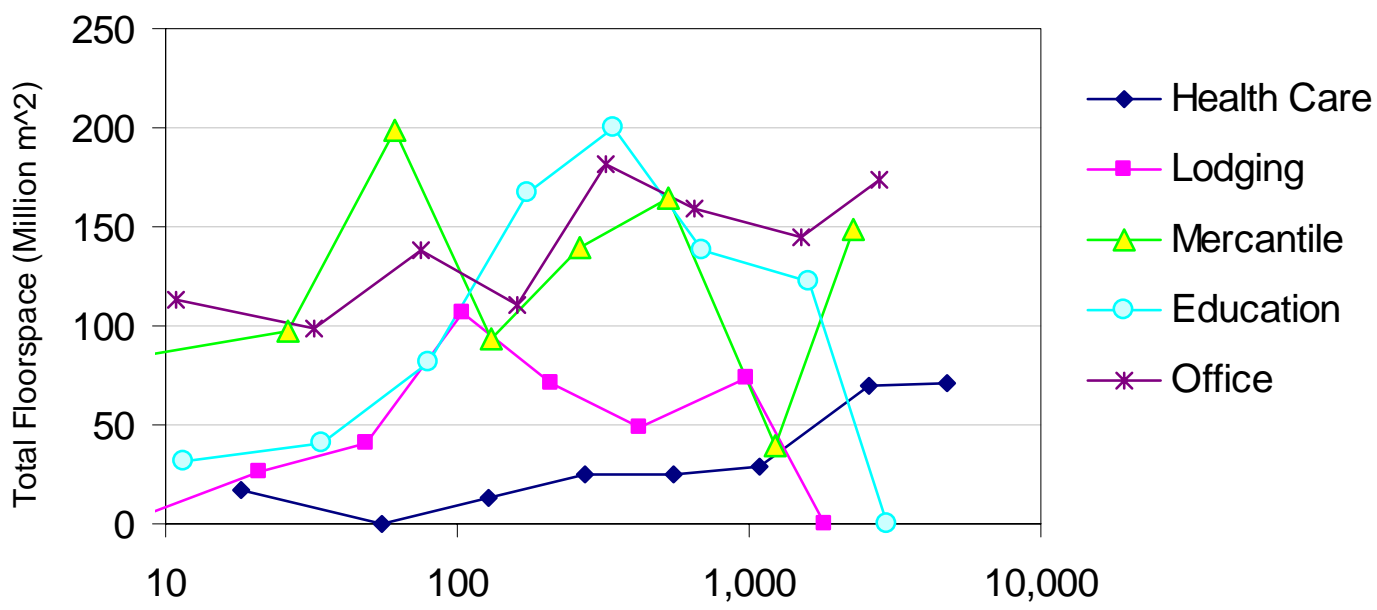

Building Peak Load (kW)

Log Scale

Figure 3. Commercial Floorspace Distribution by Building Peak Load

\subsection{Selection of Cities}

As mentioned earlier, computational restrictions limit the number of regions considered in this effort. Four cities were considered believed to be the minimum number of cities to adequately reflect the various energy usage patterns across the U.S. Each city was chosen to represent a given region. 


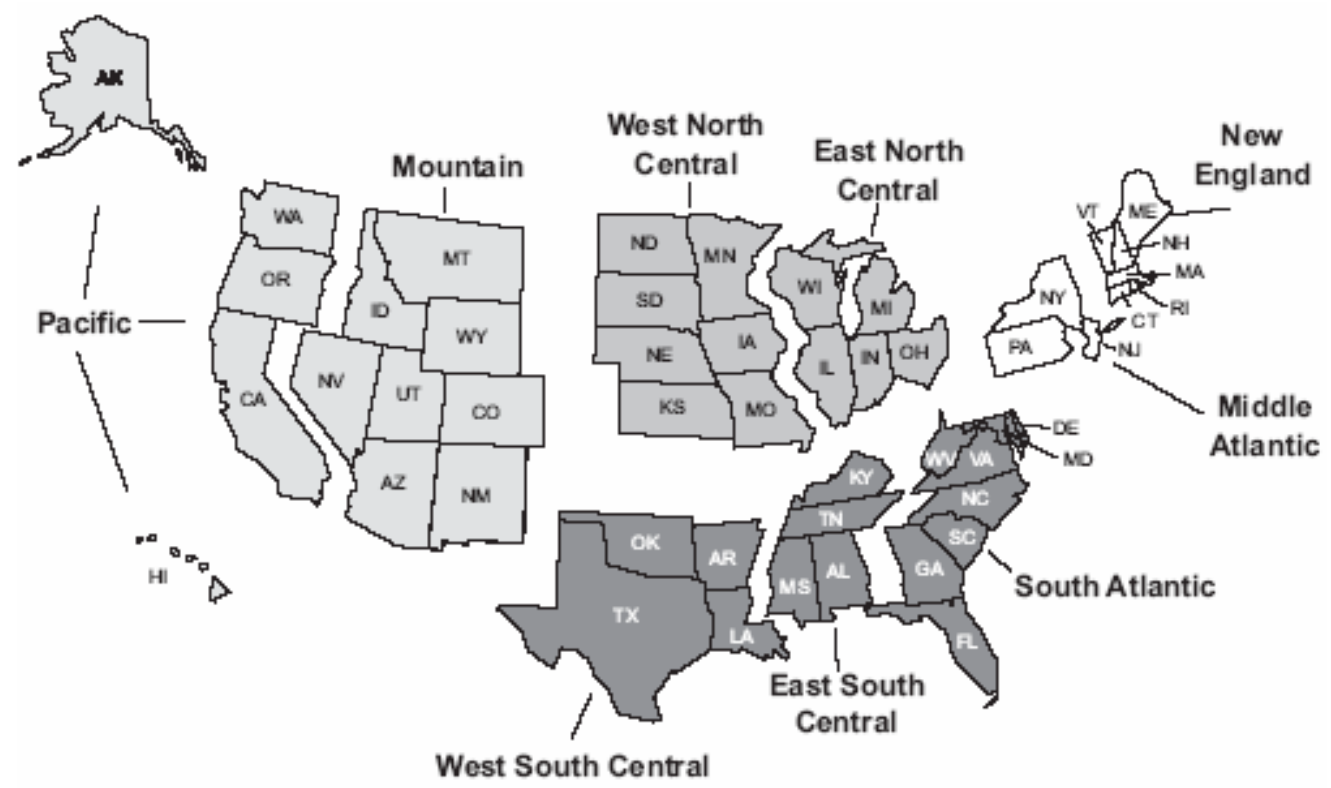

Figure 4. Map of NEMS Census Divisions

The Commercial Demand Module of NEMS uses the nine Census Divisions as shown in Figure 4 to represent the U.S. commercial sector demand. Table 3 represents the mapping of the four selected cities to each of the nine U.S. Census Divisions. The four broad regional divisions of the U.S. are used when displaying regional results from the DER-MaDiM diffusion modeling in Section 4.

Table 5. Mapping of Four Selected Cities to U.S. Census Divisions

\begin{tabular}{|l|l|l|}
\hline Region & Census Division & City \\
\hline \multirow{3}{*}{ Mortheast } & New England & Boston \\
\cline { 2 - 3 } & Middle Atlantic & Boston \\
\hline \multirow{3}{*}{ South } & East North Central & Chicago \\
\cline { 2 - 3 } & West North Central & Chicago \\
\hline \multirow{2}{*}{ West } & South Atlantic & Atlanta \\
\cline { 2 - 3 } & East South Central & Atlanta \\
\cline { 2 - 3 } & West South Central & Atlanta \\
\hline & Mountain & San Francisco \\
\cline { 2 - 3 } & Pacific & San Francisco \\
\hline
\end{tabular}

\subsection{Summary of DOE-2 Load Profile Results}

The load profiles were generated using DOE-2, then the hourly end-use energy results were configured into a DER-CAM friendly format. For each month, three day types were used to represent the annual load: peak day, weekday, and weekend.

- peak day: average hourly load for the three non-holiday weekdays of the month with the highest electricity peak

- weekday: average hourly load for the remaining non-holiday weekdays in the month

- weekend: average hourly load for the weekend days and holidays in the month 
The DOE-2 output representing the hourly energy use patterns of the 40 prototypical buildings selected is processed into an hourly data file by the major end use shown below:

This analysis considered the following five end-use loads:

- electricity only: these are loads that can only be met by electricity, e.g. lighting, computing, and are reported in $\mathrm{kWh}$ of electricity required to meet loads.

- space-heating: this is heat required for thermal comfort, i.e. $\mathrm{kWh}$ of thermal energy required to meet winter heating load and assumed to be natural-gas fueled.

- water-heating: this is heat required for hot water heating, i.e. $\mathrm{kWh}$ of thermal energy required to meet load and assumed to be natural-gas fueled.

- cooling: this is the electricity required to meet cooling demand in $\mathrm{kWh}$. If cooling is achieved by absorption chillers, this is the electricity requirement offset by the absorption chiller.

- natural gas only: these are loads that can only be met by natural gas in $\mathrm{kWh}$ of natural gas, typically this consists of only cooking in commercial buildings.

The outputs from the DOE-2 simulations are:

- hourly loads by end-use in each building zone, consisting of heating load (central heating coil, total zone heating coil, total baseboard heating and total preheat coil), cooling load (central cooling coil, total zone cooling, and the latent part of total cooling), domestic hot water load (electricity and fuel), electricity use, fuel use for heating, fuel use for hot water, boiler heating load, boiler electricity use, central chiller electricity use and the cooling tower electricity use,

- monthly building energy consumption by fuel and end-use, peak monthly building loads with coincident temperatures and humidity ratios, and peak monthly electricity use by end-use,

- annual building fuel consumption by end-use, and

- heating and cooling loads on peak days.

\subsubsection{Summary of the Peak Loads of Prototype Buildings}

Comparisons of the peak electricity load, total annual energy use, and fuel to electricity $(\mathrm{F} / \mathrm{E})$ ratio are shown in Table 6 . The $\mathrm{F} / \mathrm{E}$ ratio is highest for the educational building, followed by healthcare and lodging for all four cities. Notice the low F/E ratio for mercantile buildings. 
Table 6. Peak Electricity Load and Total Energy Consumption for 40 Prototype Buildings

\begin{tabular}{|c|c|c|c|c|c|c|c|c|c|c|c|}
\hline & & \multicolumn{2}{|c|}{ Healthcare } & \multicolumn{2}{|c|}{ Lodging } & \multicolumn{2}{|c|}{ Mercantile } & \multicolumn{2}{|c|}{ Education } & \multicolumn{2}{|c|}{ Office } \\
\hline \multicolumn{2}{|c|}{ Building Size } & small & large & small & large & small & large & small & large & small & large \\
\hline \multicolumn{12}{|l|}{ Atlanta } \\
\hline Peak load & $\mathrm{kW}$ & 576 & 1193 & 460 & 1974 & 543 & 1230 & 360 & 1620 & 348 & 1401 \\
\hline total elec & MWh & 3446 & 7082 & 2090 & 9012 & 2562 & 5881 & 627 & 2871 & 1175 & 4809 \\
\hline total Gas & GJ & 7057 & 11934 & 3629 & 15705 & 710 & 1143 & 2142 & 8997 & 1635 & 3826 \\
\hline $\mathrm{F} / \mathrm{E}$ ratio & & 0.6 & 0.5 & 0.5 & 0.5 & 0.1 & 0.1 & 1.0 & 0.9 & 0.4 & 0.2 \\
\hline \multicolumn{12}{|l|}{ Boston } \\
\hline peak load & $\mathrm{kW}$ & 557 & 1150 & 420 & 1804 & 530 & 1202 & 332 & 1502 & 349 & 1385 \\
\hline total elec & MWh & 3224 & 6591 & 1855 & 8027 & 2351 & 5413 & 586 & 2657 & 1100 & 4529 \\
\hline total gas & GJ & 9789 & 17188 & 4967 & 21504 & 1681 & 2867 & 3847 & 16028 & 2551 & 6094 \\
\hline $\mathrm{F} / \mathrm{E}$ ratio & & 0.8 & 0.7 & 0.7 & 0.7 & 0.2 & 0.2 & 1.8 & 1.7 & 0.6 & 0.4 \\
\hline \multicolumn{12}{|l|}{ Chicaco } \\
\hline peak load & $\mathrm{kW}$ & 584 & 1207 & 448 & 1925 & 536 & 1219 & 335 & 1507 & 350 & 1422 \\
\hline total elec & MWh & 3252 & 6656 & 1886 & 8169 & 2373 & 5466 & 603 & 2726 & 1123 & 4615 \\
\hline total gas & GJ & 9920 & 17270 & 5486 & 23758 & 1954 & 3406 & 4345 & 18038 & 2750 & 6533 \\
\hline $\mathrm{F} / \mathrm{E}$ ratio & & 0.9 & 0.7 & 0.8 & 0.8 & 0.2 & 0.2 & 2.0 & 1.8 & 0.7 & 0.4 \\
\hline \multicolumn{12}{|l|}{$\begin{array}{l}\text { San } \\
\text { Francisco }\end{array}$} \\
\hline peak load & $\mathrm{kW}$ & 539 & 1112 & 383 & 1646 & 498 & 1133 & 304 & 1382 & 338 & 1342 \\
\hline total elec & MWh & 3223 & 6597 & 1828 & 7890 & 2293 & 5300 & 559 & 2577 & 1081 & 4457 \\
\hline total gas & GJ & 7731 & 12776 & 3324 & 14404 & 278 & 396 & 1959 & 8322 & 1650 & 3707 \\
\hline $\mathrm{F} / \mathrm{E}$ ratio & & 0.7 & 0.5 & 0.5 & 0.5 & 0.0 & 0.0 & 1.0 & 0.9 & 0.4 & 0.2 \\
\hline
\end{tabular}

\subsubsection{Analysis of Selected Hourly Load Profiles}

The hourly end use load shapes (space heating, cooling, electricity only, and water heating) for the large healthcare and mercantile buildings in Chicago and San Francisco are described in this section. Figure 5 to Figure 8 show the hourly electricity and gas loads for the peak electricity use days in January and July for the San Francisco healthcare building. Consistent with the popular perception of the mild San Francisco climate, no significant difference is evident between summer and winter electricity or gas use. Cooling electricity can be observed even in the winter, while a substantial heating load occurs in July; but nonetheless, these results should be questioned as they highlight the difficulty of building energy simulation, which remains a very inexact science. San Francisco has a unique moderate climate year-round. The peak non-cooling electricity load is 894 $\mathrm{kW}$ in January and $892 \mathrm{~kW}$ in July at $11 \mathrm{am}$, while the peak cooling load occurs at $2 \mathrm{pm}$ and is 175 $\mathrm{kW}$ in July and $85 \mathrm{~kW}$ in January. 


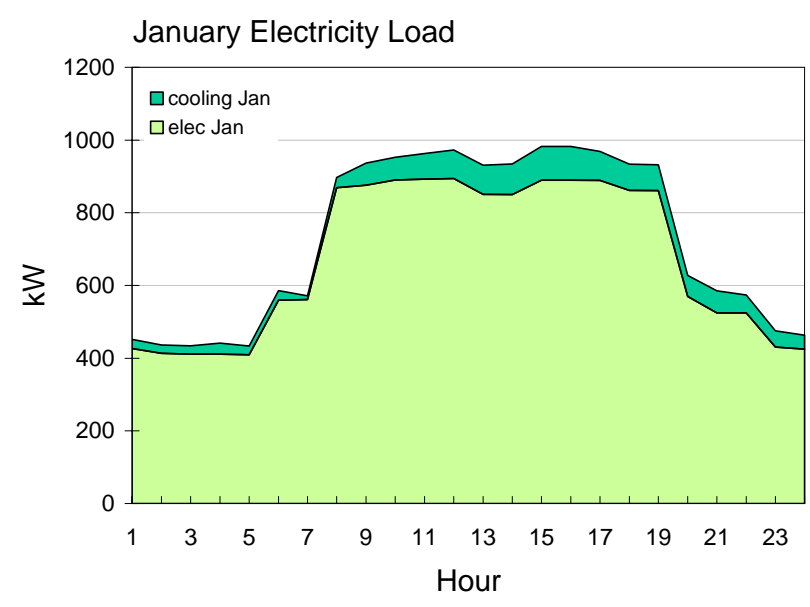

Figure 5. San Francisco Healthcare Building January Electricity Load

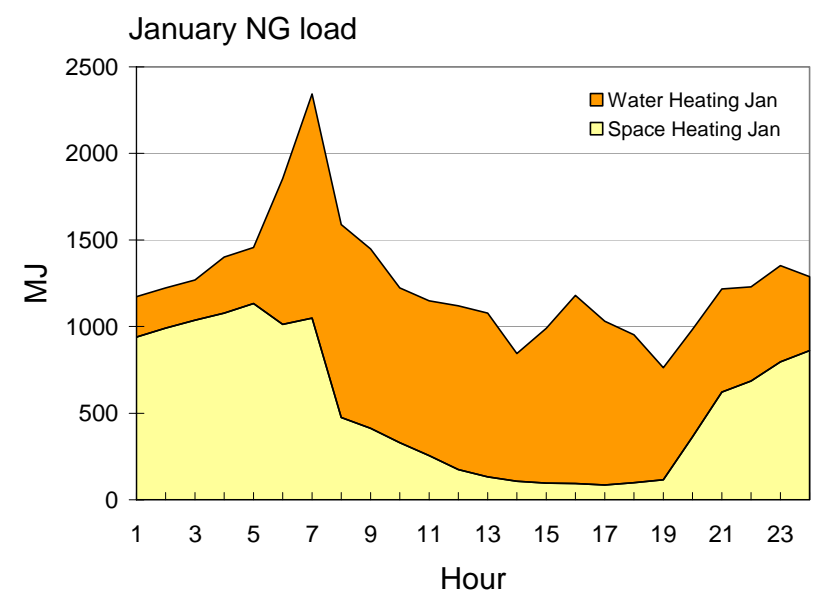

Figure 7. San Francisco Healthcare Building January Gas Load

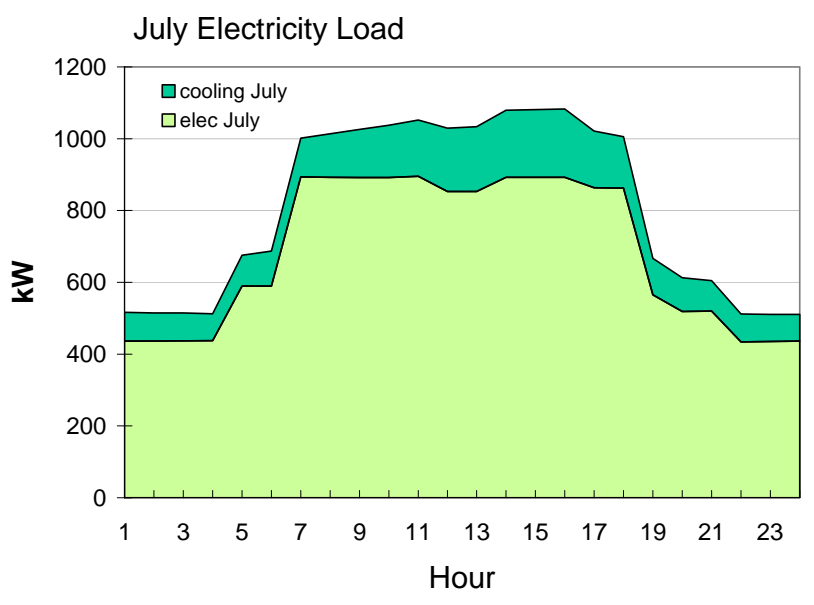

Figure 6. San Francisco Healthcare Building July Electricity Load

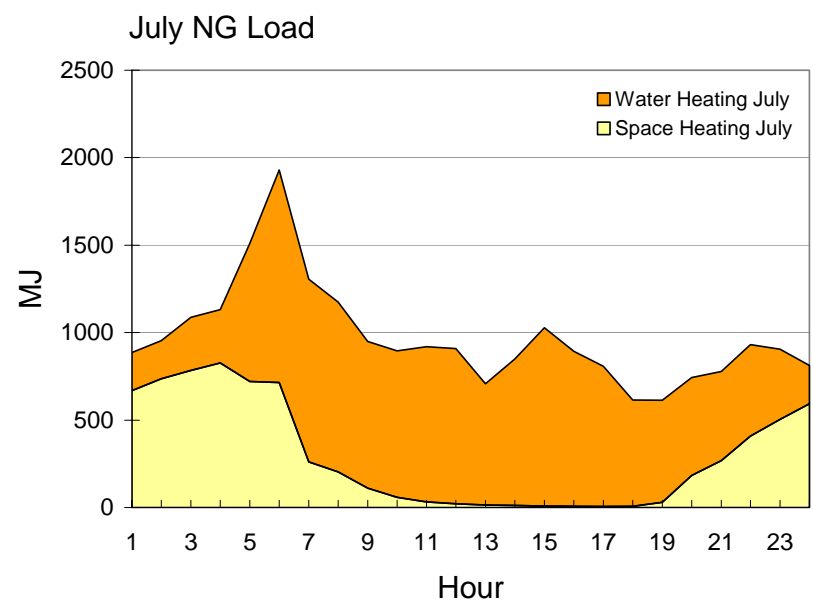

Figure 8. San Francisco Healthcare Building July Gas Load

Healthcare space heating peaks and remains high during the evening and declines in the daytime. This can be attributed to the thermal gain from more occupants and increased outdoor temperature during the daytime. Because hospitals require more air circulation to keep the indoor air clean and has occupants at night, an HVAC system with variable air exchange was applied to maintain air quality. The gas load for heating on January weekdays typically ranges from 85 to $1,048 \mathrm{MJ} / \mathrm{h}$ with a peak load of $1,048 \mathrm{MJ} / \mathrm{h}$ at $7 \mathrm{am}$. There is also significant hot water demand in healthcare buildings. The gas load for hot water ranges from 233 to $1,295 \mathrm{MJ} / \mathrm{h}$, with a peak of 1,295 MJ/h also at $7 \mathrm{am}$.

The load profile for the mercantile building is different from the healthcare building. Figure 9 and Figure 10 show the electrical load for January and July. The load shape is steady during daytime, with small increases in cooling electricity use in the summer. The electrical load remains at 800 $\mathrm{kW}$ from 7 am to $9 \mathrm{pm}$, and the peak cooling load is $181 \mathrm{~kW}$ at $4 \mathrm{pm}$ in July. 


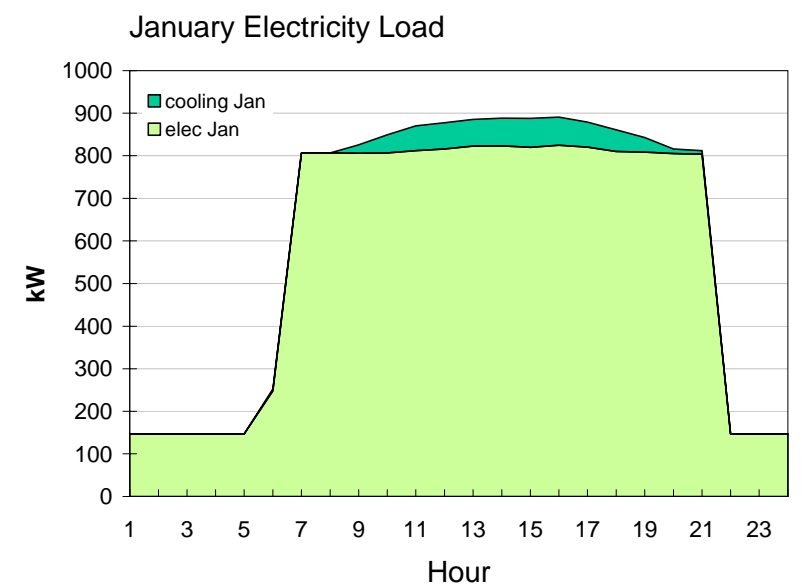

Figure 9. San Francisco Mercantile Building January Electricity Load

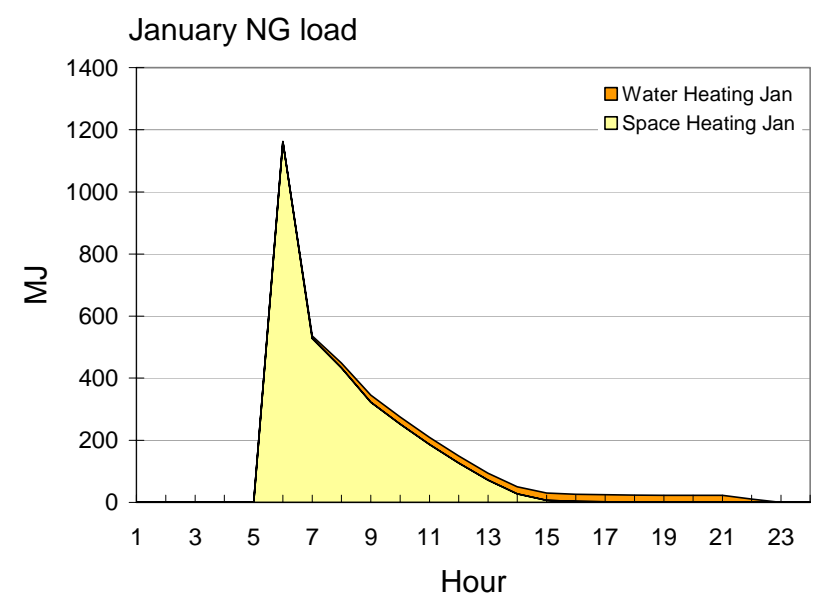

Figure 11. San Francisco Mercantile Building January Gas Load

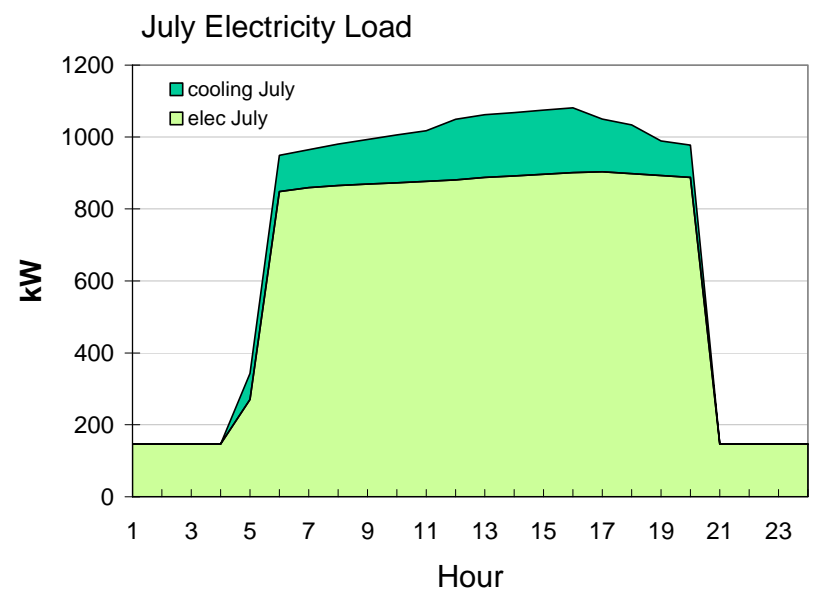

Figure 10. San Francisco Mercantile Building July Electricity Load

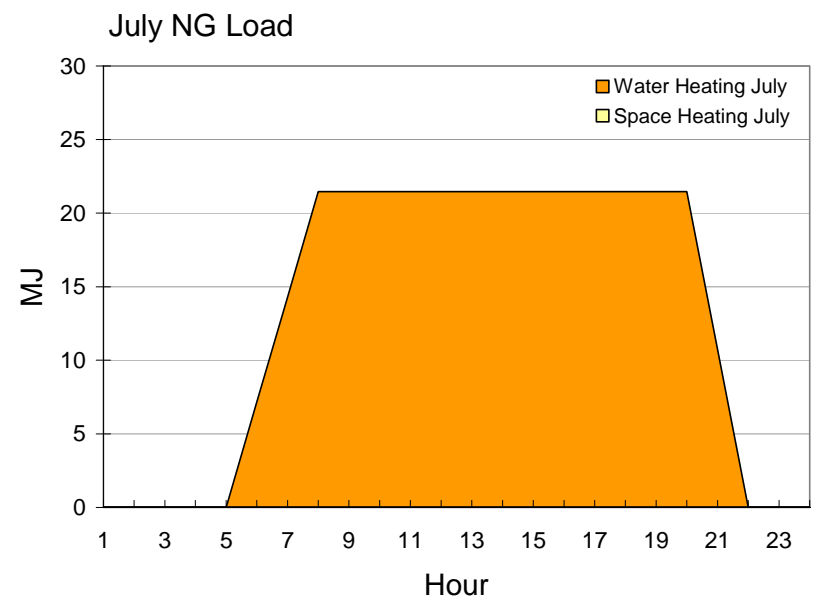

Figure 12. San Francisco Mercantile Building July Gas Load

The gas load profiles seen in Figure 11 and Figure 12 show very different patterns in winter and summer. In January, the space heating load is much higher, with a peak of 1,161 MJ/h at 6 am and decreases sharply throughout the remainder of the morning with no heating load after $3 \mathrm{pm}$. In contrast, hot water demand is only $22 \mathrm{MJ} / \mathrm{h}$ from 7 am to $9 \mathrm{pm}$ in July and is constant throughout the year.

Figure 13 to Figure 16 show the electricity and gas loads in both January and July for the office building. The non-cooling electricity use in January and July is typically $900-1,000 \mathrm{~kW}$ during the business hours of 7 am and $6 \mathrm{pm}$. The cooling electricity load in July increases steadily from 6 am to $4 \mathrm{pm}$ and peaks at $4 \mathrm{pm}$ at $230 \mathrm{~kW}$. The gas use in January is approximately double the use in July, with a peak of 2,236 MJ/h at $7 \mathrm{am}$. 


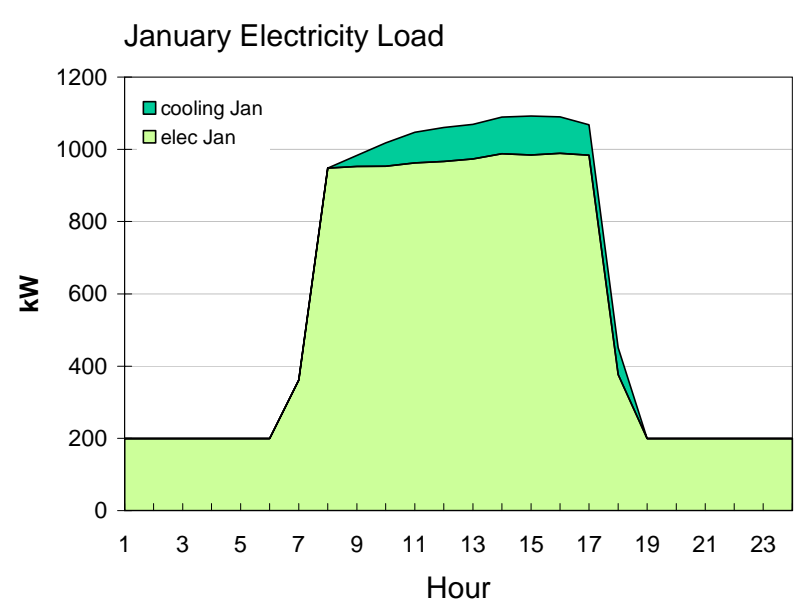

Figure 13. San Francisco Office Building January Electricity Load

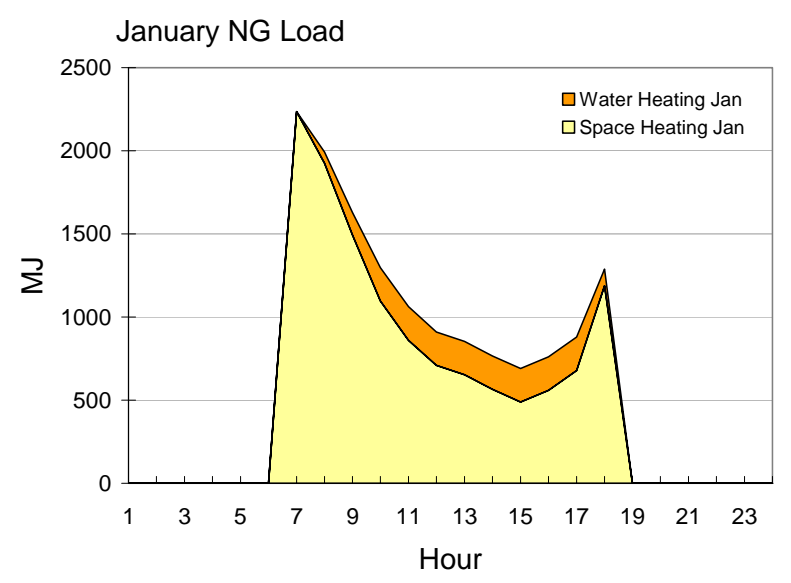

Figure 15. San Francisco Office Building January Gas Load

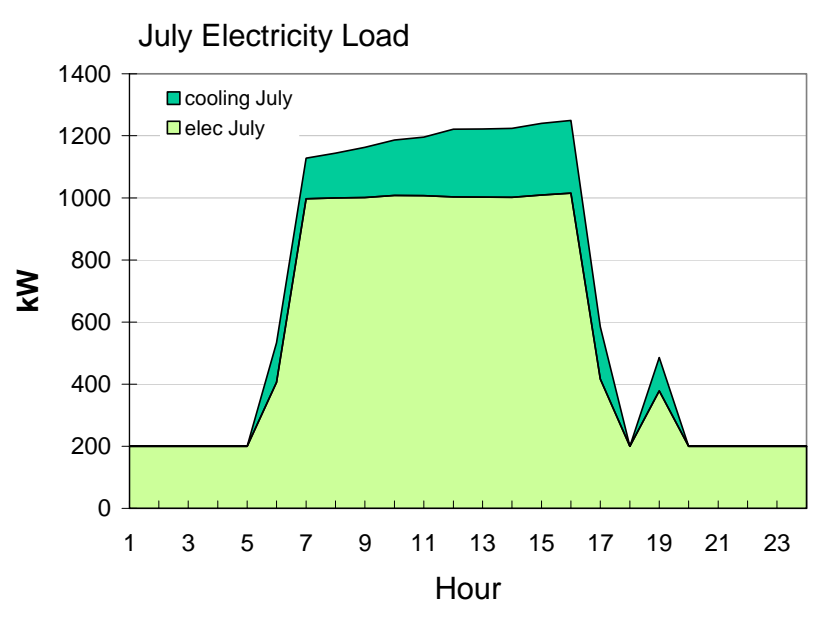

Figure 14. San Francisco Office Building July Electricity Load

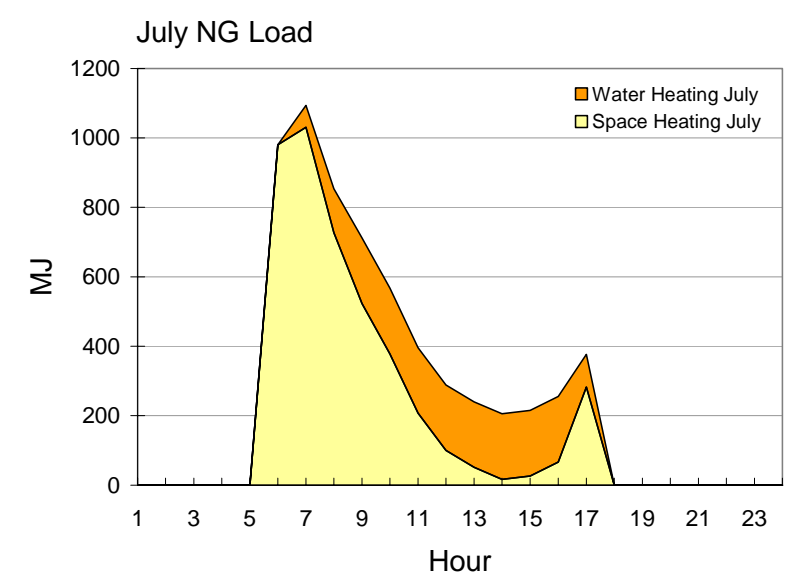

Figure 16. San Francisco Office Building July Gas Load

On the other hand, the heating and cooling demand pattern in Chicago varies significantly between summer and winter in both electricity and gas use. A representative electricity demand on a summer peak day and a gas demand on a winter peak day are presented. Figure 17 and Figure 18 show the electricity load in July and gas load in January for a healthcare building in Chicago. The peak non-cooling electrical load is $914 \mathrm{~kW}$ at $2 \mathrm{pm}$, while the peak cooling load occurs at $4 \mathrm{pm}$ at $260 \mathrm{~kW}$. The space heating load for the healthcare building declines as the day progresses. The gas load for heating on a January weekday typically ranges from 1,021 to 2,481 MJ/h with the peak load of 2,184 MJ/h at $5 \mathrm{am}$. This is much higher than in San Francisco. The gas load for hot water is similar to that of San Francisco, ranging from 267 to $1,484 \mathrm{MJ} / \mathrm{h}$ with a peak of 1,484 MJ/h at 7 am.

Figure 19 shows the electrical load in the mercantile building in Chicago for the month of July. The electrical load remains flat from 6 am to $8 \mathrm{pm}$ at slightly over $800 \mathrm{~kW}$ with the cooling load also stable and minimal during the daytime. Figure 20 shows the gas space heating load in January for the same building peaks at $6 \mathrm{am}$ of $4,061 \mathrm{MJ} / \mathrm{h}$ and declines significantly by $9 \mathrm{pm}$ to $500 \mathrm{MJ} / \mathrm{h}$. No heating load is seen after the closing time of $9 \mathrm{pm}$. There is no space heating demand in the 
summer in Chicago. Hot water demand is very low at around $22 \mathrm{MJ} / \mathrm{h}$ from 7 am to $9 \mathrm{pm}$ and it is constant throughout the year.

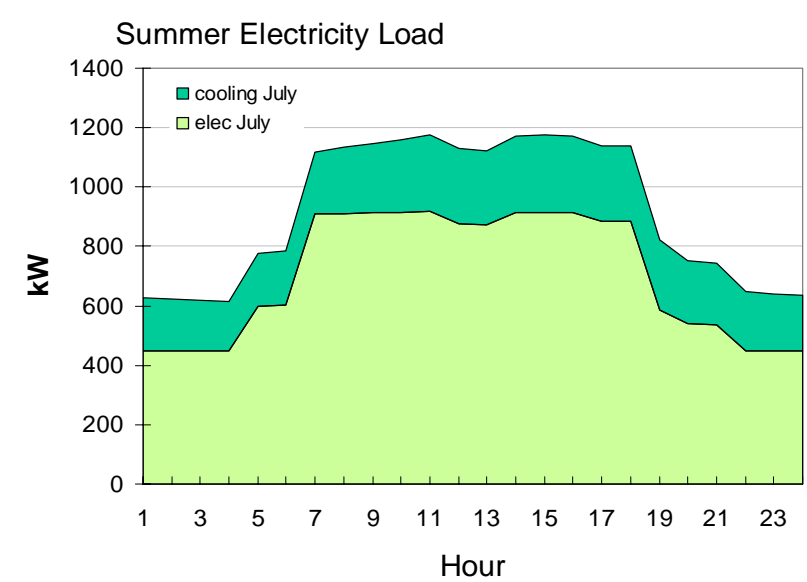

Figure 17. Chicago Healthcare Building July Electricity Load

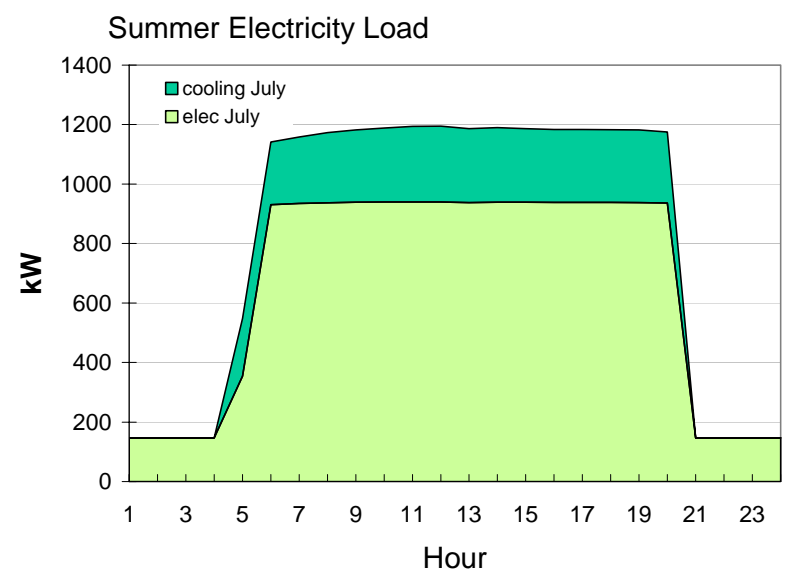

Figure 19. Chicago Mercantile Building July Electricity Load

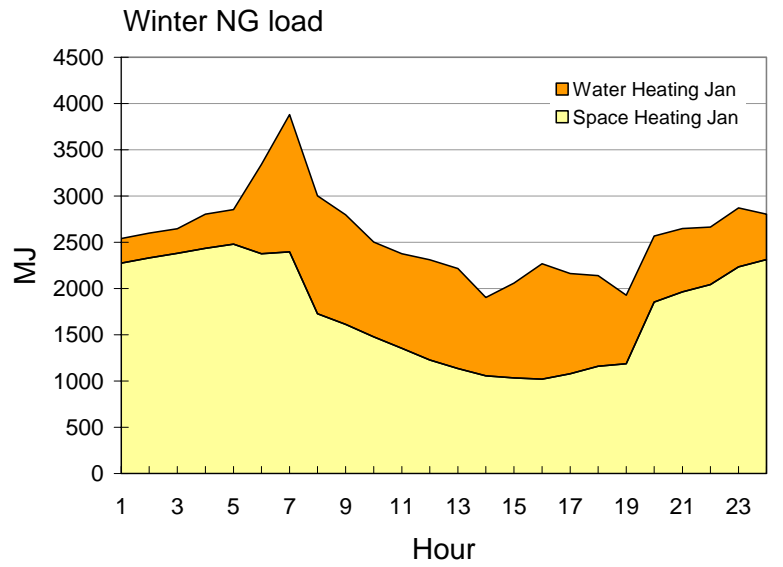

Figure 18. Chicago Healthcare Building January Gas Load

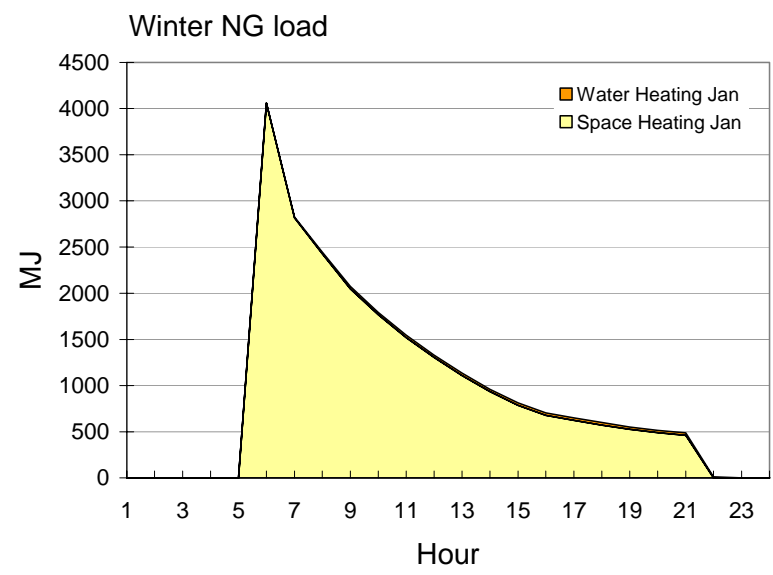

Figure 20. Chicago Mercantile Building January Gas Load

Finally, a summary of findings from this stage of the ComSeM process follows:

- A minimum of four cities was considered necessary to adequately represent the regional variability of building load profiles in the U.S.

- For each of the five building types, Berkeley Lab determined representative sizing based on estimated peak loads, noting that healthcare has larger building sizes than the other types.

- CBECS 1999 floorspace agrees well with the NEMS-DE projected floorspace.

- Space heating and cooling demand in healthcare buildings in some cities occur in the same season, and the load shape can be very flat in moderate climates. Both loads vary significantly between seasons under a typical northern U.S. weather regime such as in Chicago, with no heating demand in the summer and no cooling demand in the winter.

- Peak space heating and cooling demands in San Francisco are lower than those of other regions. 
- The space heating load for healthcare buildings peak at night and water heating requirements are large.

- The office building uses twice the amount of energy for heating in the winter as it does in the summer.

- The winter space heating load in the mercantile building shows a sharp peak in the morning and decreases sharply thereafter. No heating demand is seen at night.

Load shapes and peak loads show different patterns in different regions, which is a crucial factor that will affect potential of DG installation, and determine the optimal operating schedule. 



\section{Distributed Energy Resources Customer Adoption Model (DER-CAM) Analysis}

The load profiles developed by DOE-2 and discussed in the previous section are provided as input to the Distributed Energy Resources Customer Adoption Model (DER-CAM). This section describes the adoption model and how it is used to determine the optimal DG levels as the second step of the ComSeM approach.

\subsection{Overview of DER-CAM}

Through prior efforts, the Berkeley Lab developed the DER-CAM software to determine the economically optimal DER investment for a given site. The DER-CAM solution also provides an economically optimal operating schedule for DG equipment. The key inputs are the site hourly end-use energy demand, electricity and natural gas tariffs, and DG technology characterizations. Available technology options are specified as a discrete set of devices, from which this model picks the cost-minimizing combination. In this study, DER-CAM is used to model the 40 commercial buildings described in Section 2.

The prime mover DG technology options for this project are gas-fired reciprocating engines, microturbines, and turbines. Additional options in DER-CAM are heat exchangers, which can be used to convert the waste heat from generators to useful thermal energy, and absorption chillers, which can convert the waste heat to cooling load offsets.

DER-CAM is a mixed integer linear optimization program (MILP) written and executed in the General Algebraic Modeling System (GAMS). The objective is to minimize annual energy costs for the modeled site, including utility electricity and natural gas costs, amortized capital costs for DG investments, and maintenance costs for installed DG equipment. A key constraint is a limit on the acceptable simple payback period, which mimics typical investment decision making in practice. This makes the financial decision two pronged. First, the cost minimizing equipment purchase and operating schedule is chosen, and second, if new equipment is chosen, it must meet or better a fixed payback target to be accepted. For a detailed mathematical description of the optimization problem, please see Appendix D.

The outputs of DER-CAM include the optimal DG system and an hourly operating schedule, as well as the resulting costs, fuel consumption, and carbon emissions. Figure 21 shows a high-level schematic of DER-CAM. References to detailed descriptions of DER-CAM and recent modifications are included in Appendix B. 


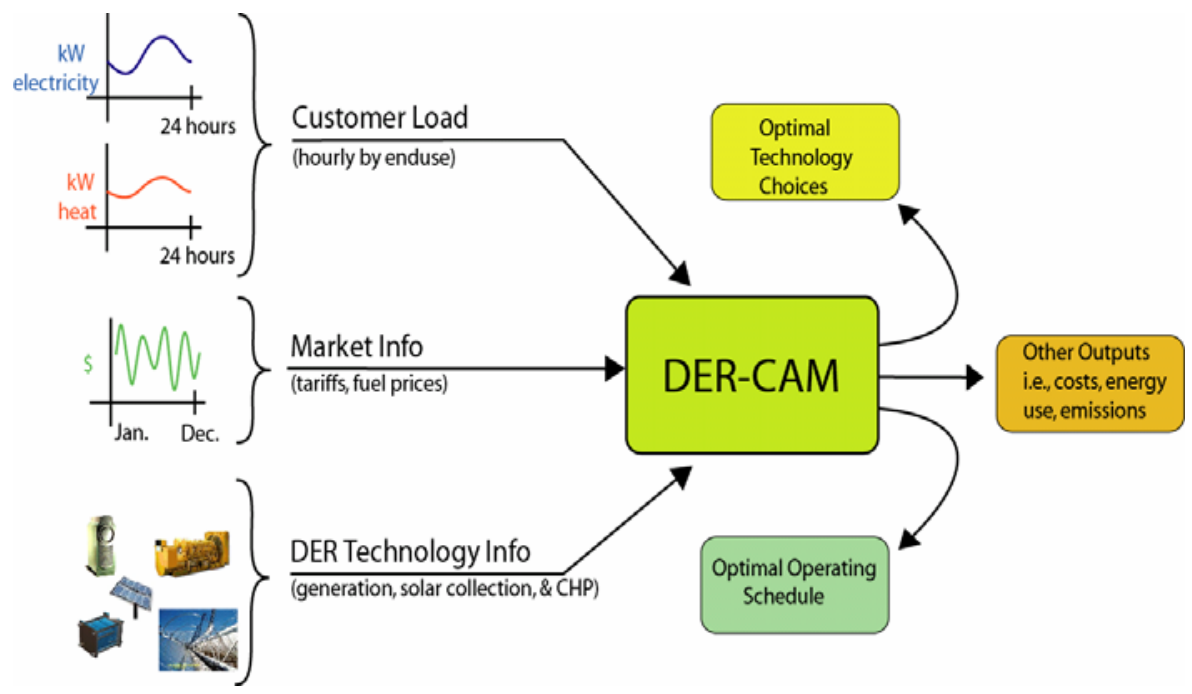

Figure 21. High Level DER-CAM Schematic

\subsection{Tariff Data}

\subsubsection{Electricity}

The 2004 electricity tariffs for electric utilities serving the four cities of consideration were obtained from the Tariff Analysis Project's database of U.S. electricity rates (Energy Efficiency Standards Group 2005). The three main components of a typical electricity tariff are volumetric charges, demand charges, and monthly fees. Volumetric charges are in proportion to the electricity consumed each month; there are often different rates for different times of the day. Demand charges are in proportion to the maximum power of electricity consumption during the month, regardless of how often the maximum rate occurs. There are often different rates for different times of the day, as well as occasionally a non-coincident rate which is applicable to all hours of the day. The monthly fee is a fixed charge each month. 
Table 7 through Table 10 show the 2004 electricity rates for all four cities.

Table 7. 2004 Electricity Rates for Atlanta

\begin{tabular}{|c|c|c|}
\hline \multicolumn{2}{|c|}{ Volumetric (\$/kWh) } & winter* \\
\hline on-peak ${ }^{\star *}$ & 0.061 & 0.061 \\
\hline mid-peak ${ }^{\star \star}$ & 0.061 & 0.061 \\
\hline off-peak ${ }^{\star \star}$ & 0.061 & 0.061 \\
\hline \multicolumn{3}{|l|}{ Demand (\$/kW) } \\
\hline on-peak ${ }^{\star \star}$ & $\mathrm{N} / \mathrm{A}$ & $\mathrm{N} / \mathrm{A}$ \\
\hline mid-peak** & $\bar{N} / \mathrm{A}$ & $\bar{N} / \mathrm{A}$ \\
\hline \begin{tabular}{|l} 
non-coincident \\
\end{tabular} & $\bar{N} / \mathrm{A}$ & $\mathrm{N} / \mathrm{A}$ \\
\hline \multicolumn{3}{|c|}{ Monthly fee ${ }^{\star \star \star}(\$)$} \\
\hline & 2750 & 2750 \\
\hline
\end{tabular}

*Rates do not depend on the season

${ }^{*}$ Rates do not depend on the time of day

***In actuality, the volumetric rates are

in a block structure. To model this

within the constraints of the DER-CAM

linear program, the marginal cost (the

last block) of electricity is used as the

sole volumetric price and the

additional volumetric costs of earlier

blocks are included in the monthly

fixed cost.

Table 8. 2004 Electricity Rates for Boston

\begin{tabular}{|c|c|c|}
\hline \multicolumn{3}{|c|}{ Volumetric $(\$ / k W h)$} \\
\hline on-peak ${ }^{\star \star \star}$ & 0.0815 & 0.0693 \\
\hline mid-peak & $\mathrm{N} / \mathrm{A}$ & $\mathrm{N} / \mathrm{A}$ \\
\hline off-peak ${ }^{\star \star \star \star}$ & 0.0594 & 0.056 \\
\hline \multicolumn{3}{|l|}{ Demand (\$/kW) } \\
\hline on-peak ${ }^{\star \star \star}$ & $\mathrm{N} / \mathrm{A}$ & $\mathrm{N} / \mathrm{A}$ \\
\hline mid-peak & $\mathrm{N} / \mathrm{A}$ & $\mathrm{N} / \mathrm{A}$ \\
\hline non-coincident & 24.72 & 11.54 \\
\hline \multicolumn{3}{|c|}{ Monthly fee $e^{\star \star *}(\$)$} \\
\hline & 166.67 & 166.67 \\
\hline
\end{tabular}

*summer months: June - September

** winter months: October - May

${ }^{* \star *}$ on-peak hours: summer: weekdays,

9 a.m. to 6 p.m., winter weekdays 8

a.m to 9 p.m.

****off-peak hours: all non-peak

weekday hours and all weekend hours
Table 9. 2004 Electricity Rates for Chicago

\begin{tabular}{|c|c|c|}
\hline Volumetric (\$/k & summer* & winter ${ }^{\star \star}$ \\
\hline on-peak ${ }^{\star \star \star}$ & 0.056 & 0.056 \\
\hline mid-peak & N/A & $\mathrm{N} / \mathrm{A}$ \\
\hline off-peak ${ }^{\star \star \star \star}$ & 0.0234 & 0.0234 \\
\hline \multicolumn{3}{|l|}{ Demand (\$/kW) } \\
\hline on-peak ${ }^{\star \star \star}$ & 14.24 & 11.23 \\
\hline mid-peak & N/A & N/A \\
\hline non-coincident & $\bar{N} / \mathrm{A}$ & $\mathrm{N} / \mathrm{A}$ \\
\hline \multicolumn{3}{|c|}{ Monthly fee ${ }^{\star * \star}(\$)$} \\
\hline & 39.93 & 39.93 \\
\hline
\end{tabular}

*summer months: June - September

**winter months: October - May

***on-peak hours: year-round:

weekdays 9 a.m. to 10 p.m.

****off-peak hours: all non-peak

weekday hours and all weekend hours

Table 10. 2004 Electricity Rates for San Francisco

\begin{tabular}{|c|c|c|}
\hline Volumetric (\$/kWh) & summer* & winter ${ }^{\star \star}$ \\
\hline on-peak ${ }^{\star \star \star}$ & 0.1647 & $\mathrm{~N} / \mathrm{A}$ \\
\hline mid-peak ${ }^{\star \star \star \star}$ & 0.1 & 0.1083 \\
\hline off-peak ${ }^{\star \star \star \star \star}$ & 0.0891 & 0.0891 \\
\hline \multicolumn{3}{|l|}{ Demand (\$/kW) } \\
\hline on-peak ${ }^{\star \star \star}$ & 11.8 & $\mathrm{~N} / \mathrm{A}$ \\
\hline mid-peak ${ }^{\star \star \star \star}$ & 2.65 & 2.65 \\
\hline non-coincident & 2.55 & 2.55 \\
\hline \multicolumn{3}{|l|}{ Monthly fee (\$) } \\
\hline & 175 & 175 \\
\hline
\end{tabular}

*summer months: June - September

${ }^{*}$ winter months: October - May

***on-peak hours: summer: Monday -

Sunday 12 p.m. - 6 p.m.

****mid-peak hours: summer: Monday -

Sunday 9 a.m. to 12 p.m. and 6 p.m. to

10 p.m., winter: Monday - Sunday 9 a.m

to 10 p.m.

${ }^{* * * *}$ off-peak hours: all other hours 
The AEO2005 Reference Case was used to estimate the electricity tariffs for years 2012 and 2022. The average commercial electricity rates by region and year were examined to determine the percentage change of rates from 2004 in each of the four cities of consideration. The scaling factors derived for which to multiply the 2004 prices by are shown in Table 11. All components of the electricity tariff are multiplied by these scaling factors to obtain the future electricity tariffs used in DER-CAM. As is apparent from the fact all multipliers are below 1.0, both electricity and natural gas prices are expected to stay under 2004 levels in all regions and all time periods. Natural gas fueled DG profitability depends on the difference between natural gas and electricity prices, implying that falling prices do not necessarily mean less favorable DG market conditions.

Table 11. Scaling Factors for 2012 and 2022 Electricity and Natural Gas Prices

\begin{tabular}{l|c|c|c|c|c|c|} 
& \multicolumn{2}{|c|}{ Electricity } & \multicolumn{2}{c|}{$\begin{array}{c}\text { Natural Gas } \\
\text { (standard) }\end{array}$} & \multicolumn{2}{c|}{ Natural Gas (DG) } \\
& $\mathbf{2 0 1 2}$ & $\mathbf{2 0 2 2}$ & $\mathbf{2 0 1 2}$ & $\mathbf{2 0 2 2}$ & $\mathbf{2 0 1 2}$ & $\mathbf{2 0 2 2}$ \\
\hline Atlanta & 0.89 & 0.95 & 0.82 & 0.92 & 0.80 & 0.93 \\
\hline Boston & 0.76 & 0.84 & 0.83 & 0.91 & 0.81 & 0.92 \\
\hline Chicago & 0.88 & 0.98 & 0.81 & 0.93 & 0.77 & 0.93 \\
\hline San Francisco & 0.84 & 0.83 & 0.87 & 0.97 & 0.86 & 0.93 \\
\hline
\end{tabular}

\subsubsection{Natural Gas}

The 2004 natural gas rates for the regions containing the four cities of consideration were obtained from the AEO2005 Reference Case (Energy Information Administration 2005a) and are shown in Table 12. The rate used for non-DG natural gas consumption is the average commercial rate for each respective region. The rate for DG consumption is the average of the commercial rate and the core electricity generator rate. This reflects the lower volumetric cost of natural gas when it is consumed in the higher quantities and more consistent rates of prime power DER rather than typical commercial building consumption. The AEO2005 (Energy Information Administration 2005a) was also used to estimate natural gas prices for 2012 and 2024. The scaling factors used to convert 2004 natural gas rates to 2012 and 2022 rates are shown in Table 11 .

Table 12. AEO2005 Natural Gas Rates in $2004\left(\$ / \mathbf{k W h} \mathrm{HHV}^{3}\right)$

\begin{tabular}{|l|c|c|}
\hline & $\begin{array}{c}\text { basic and } \\
\text { absorption } \\
\text { cooling }\end{array}$ & DG \\
\hline Atlanta & 0.037 & 0.029 \\
\hline Boston & 0.040 & 0.029 \\
\hline Chicago & 0.032 & 0.027 \\
\hline San Francisco & 0.032 & 0.029 \\
\hline
\end{tabular}

${ }^{3}$ HHV refers to higher heating value. $1 \mathrm{kWh}$ of natural gas contains 3,412 Btu. 


\subsubsection{DG Cost and Performance}

Three natural gas fired DG technology types were considered: reciprocating engines, gas turbines, and microturbines. Cost and performance data for these technologies in 2004 are interpolated from data provided in a study by the National Renewable Energy Laboratory with additional data provided from work done at the Berkeley Lab (Firestone 2004; Goldstein et al. 2003). Reciprocating engines and microturbines were considered in two sizes. In DER-CAM, each device can be purchased in one of three packages: 1) as an electricity generation unit 2) as an electricity generation unit with heat recovery for space and water heating applications or 3 ) as an electricity generation unit with heat recovery for space and water heating applications and for cooling via an absorption chiller. Cost and performance data for these technologies in 2004 is summarized in Table 13.

Table 13. 2004 Technology Cost and Performance Data Used in DER-CAM

\begin{tabular}{|c|c|c|c|c|c|c|c|c|}
\hline DG Option & Lifetime & & pital costs & & Maintena & ance costs & Energy & output \\
\hline & & $\begin{array}{c}\text { electricity } \\
\text { generation } \\
\text { only }\end{array}$ & $\begin{array}{c}\text { with heat } \\
\text { recovery } \\
\text { for heating }\end{array}$ & $\begin{array}{c}\text { with heat } \\
\text { recovery } \\
\text { for heating } \\
\text { and } \\
\text { cooling }\end{array}$ & $\begin{array}{l}\text { fixed annual cost } \\
\text { for units with } \\
\text { absorption chilling }\end{array}$ & variable costs & $\begin{array}{l}\text { electrical } \\
\text { efficiency }\end{array}$ & $\begin{array}{l}\text { heat to } \\
\text { electricity } \\
\text { ratio }\end{array}$ \\
\hline & (years) & & W installed) & & (\$/kW installed) & (\$/kWh generated) & & \\
\hline 1 MW turbine & 20 & 1403 & 1910 & 2137 & 11.9 & 0.010 & 0.219 & 2.45 \\
\hline $100 \mathrm{~kW}$ microturbine & 10 & 1700 & 1980 & 2419 & $\overline{17.1}$ & 0.015 & 0.260 & 2.29 \\
\hline $250 \mathrm{~kW}$ microturbine & 10 & 1400 & 1650 & 1976 & 12.8 & 0.015 & 0.280 & 2.29 \\
\hline $200 \mathrm{~kW}$ reciprocating engine & 20 & 900 & 1225 & 1629 & 15.9 & 0.015 & 0.308 & 1.88 \\
\hline $500 \mathrm{~kW}$ reciprocating engine & 20 & 795 & 1065 & 1339 & 11.0 & 0.012 & 0.332 & 1.55 \\
\hline
\end{tabular}

NEMS estimates of technology cost and performance in 2004 and 2022 were used to estimate the percentage improvements in cost and performance from 2004 to 2022. These percentage improvements were then applied to the 2004 technology data to obtain the 2022 data for both the Baseline and Program cases.

For the Baseline case, technology improvement from 2004 to 2022 is assumed to be linear; data for 2012 are interpolated from the beginning and end years. For the Program case, the technology is assumed to reach maturation in 2012, so that cost and performance data for 2022 is also used for 2012. The scaling factors used to convert 2004 cost and performance data to 2012 and 2022 data are provided in Table 14. Note that microturbines are predicted to improve in electrical efficiency and capital cost to a much greater extent than reciprocating engines, while gas turbine improvement is intermediate to these two technologies. Cost and performance characteristics are discussed further in Section 5.6. 
Table 14. Scaling Factors for 2012 and 2022 DER-CAM Technology Data

\begin{tabular}{|c|c|c|c|c|}
\hline & $\begin{array}{l}\text { Electrical } \\
\text { Efficiency }\end{array}$ & $\begin{array}{c}\text { Electricity } \\
\text { Ratio }\end{array}$ & $\begin{array}{c}\text { Capital } \\
\text { Cost }\end{array}$ & $\begin{array}{c}\text { Maintenance } \\
\text { Cost }\end{array}$ \\
\hline \multicolumn{5}{|c|}{ Scaling Factors for 2012 Base Case } \\
\hline Reciprocating Engines & 1.045 & 0.994 & 0.882 & 0.928 \\
\hline Microturbines & 1.324 & 0.892 & 0.737 & 0.907 \\
\hline Gas Turbines & 1.112 & 1.017 & 0.890 & 0.834 \\
\hline \multicolumn{5}{|c|}{ Scaling Factors for 2012 Program and 2022 Base and Program Cases } \\
\hline Reciprocating Engines & 1.080 & 1.011 & 0.807 & 0.800 \\
\hline Microturbines & 1.389 & 0.950 & 0.479 & 0.773 \\
\hline Gas Turbines & 1.215 & 1.043 & 0.837 & 0.834 \\
\hline
\end{tabular}

\subsubsection{Other Technologies}

For this project, heat exchangers used to convert waste heat from DG equipment to useful enduse heat are assumed to be 80 percent efficient, as are combustors used to convert natural gas to useful end-use heat. The coefficient of performance (COP) of electric chillers is assumed to be 5 and that of absorption chillers to be 0.7 .

\subsection{Running DER-CAM}

For each of the 40 buildings modeled in this study (five building types each with two sizes and four cities), DER-CAM runs were done for each of the three test years for both the Baseline and Program cases. ${ }^{4}$ For each examination (building type, building size, region, year, Baseline and Program case) DER-CAM was run twice: first with no DG investment allowed in order to determine the annual energy cost and consumption data without DG investment, and then with DG investment allowed to determine the economically optimal DG system and subsequent cost and energy consumption. The first simulation was done to determine the annual energy cost without investment. This cost is needed to determine the payback period, which is constrained when DG investment is allowed.

For each DER-CAM examination, the following output results were collected.

- Annual Energy Cost (\$)

- Pre-DG Annual Peak Electricity (kW)

- Annual Utility Electric Cost (\$)

- Annual Utility Natural Gas Cost (\$)

- Annualized Capital Costs (\$)

- Annual Maintenance Costs (\$)

- Installed Capacity - All Technologies (kW)

- Installed Capacity - Reciprocating Engines (kW)

- Installed Capacity - Reciprocating Engines with Heat Exchangers (kW)

\footnotetext{
${ }^{4}$ Note that results for the Baseline and Program cases are identical in 2004 and in 2022 . It is only in 2012 that there is a difference in the technology cost and performance data between the two cases. However, the automation procedure for running DER-CAM made this approach most convenient.
} 
- Installed Capacity - Reciprocating Engines with Heat Exchangers and Absorption Chillers $(\mathrm{kW})$

- Installed Capacity - Microturbines (kW)

- Installed Capacity - Microturbines with Heat Exchangers (kW)

- Installed Capacity - Microturbines with Heat Exchangers and Absorption Chillers (kW)

- Installed Capacity - Turbines (kW)

- Installed Capacity - Turbines with Heat Exchangers (kW)

- Installed Capacity - Turbines with Heat Exchangers and Absorption Chillers (kW)

- Annual Utility Electric Consumption (kWh)

- Annual Utility NG Consumption (kWh)

- Annual Electricity Generated Onsite (kWh)

Figure 23. Figure 24, and Figure 25 show the installed capacities of reciprocating engines, microturbines, and total DG, respectively. Gas turbines do not appear in any of the optimal DG investment solutions because gas turbine cost and performance was inferior to reciprocating engines and microturbines at the small turbine size ( $1 \mathrm{MW})$ considered in this study. If buildings with larger electrical loads were considered and if larger turbines were considered, turbines would have appeared more favorable.

Each figure consists of DER-CAM results for years 2004, 2012, and 2022. Results are shown for both the Baseline (top row) and Program (bottom row) cases. Each column of charts is for a different building type, and within each chart, results for the four cities are shown. The following abbreviations are used to denote each of the four cities:

- Chic: Chicago

- Bost: Boston

- Atla: Atlanta

- S.F.: San Francisco

For all of the bar charts, the following legend applies.

small building

$\square$ large building

Figure 22. Legend for DER-CAM Bar Chart of Results 

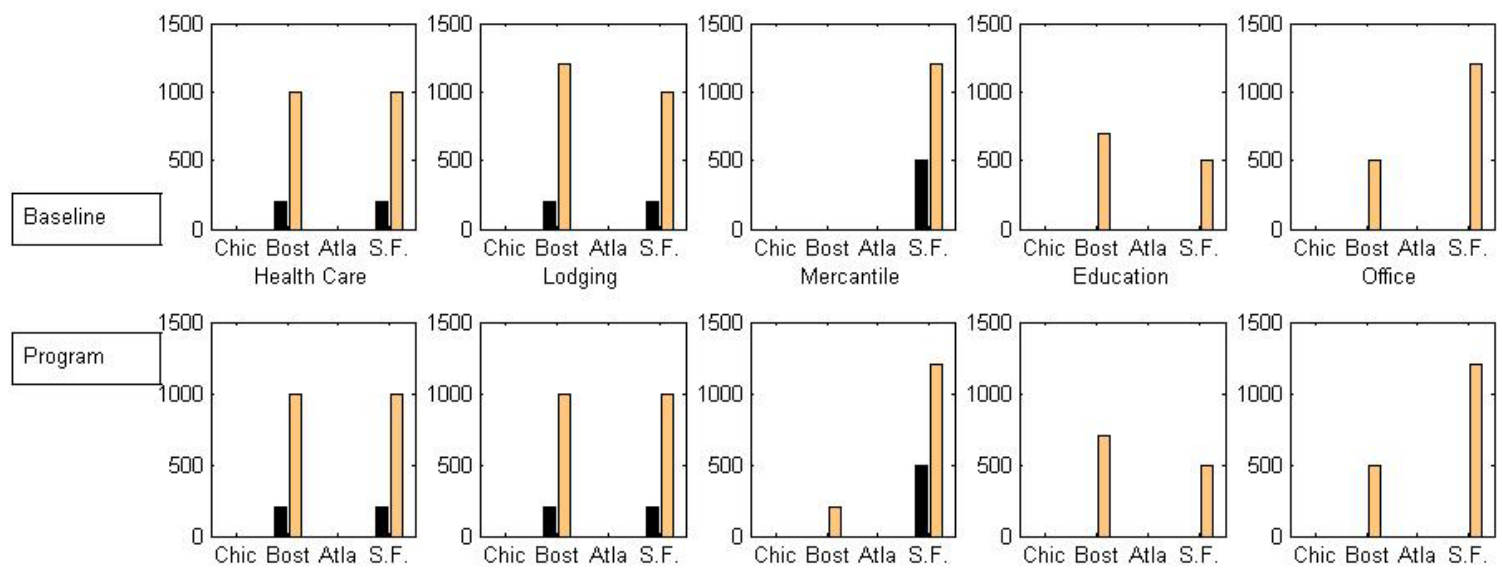

2012
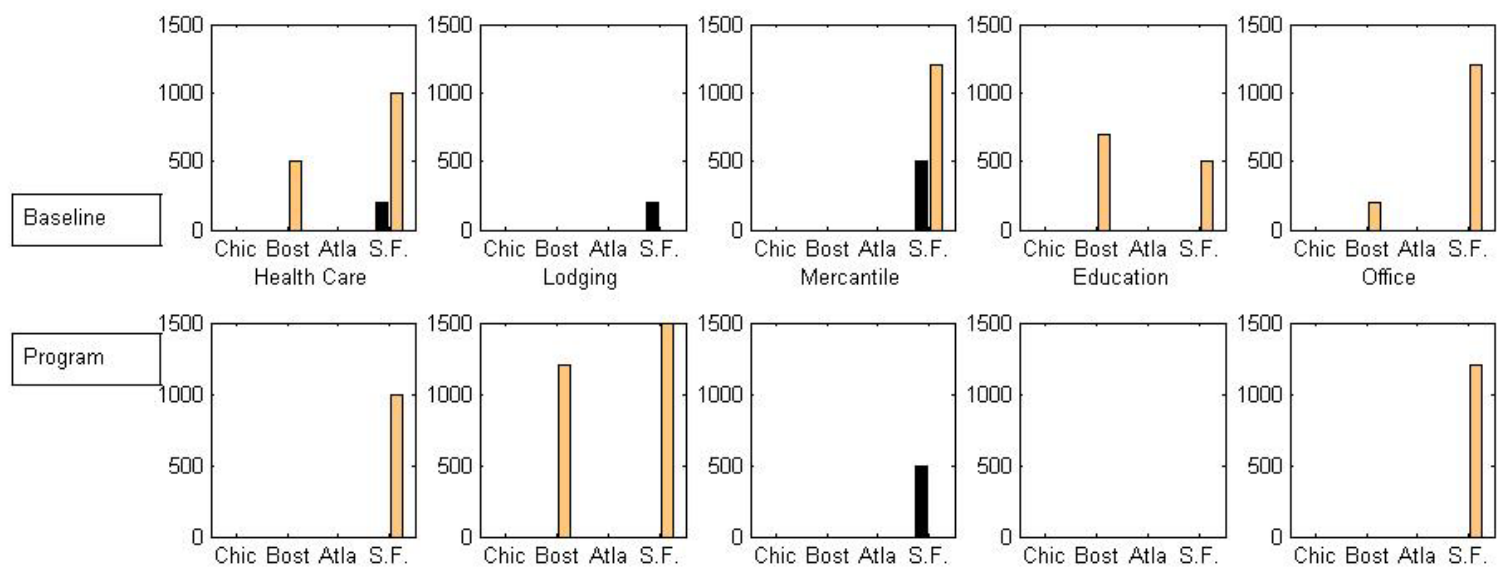

2022
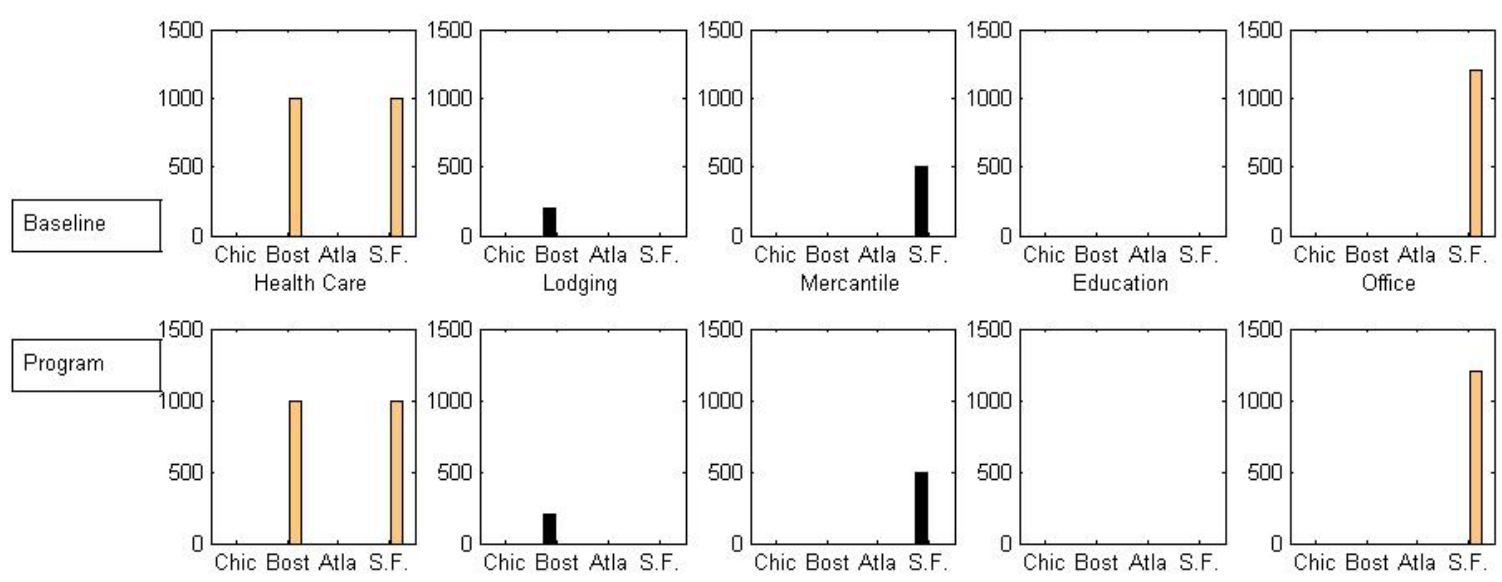

Figure 23. Installed DG Capacity - Reciprocating Engines (kW) 

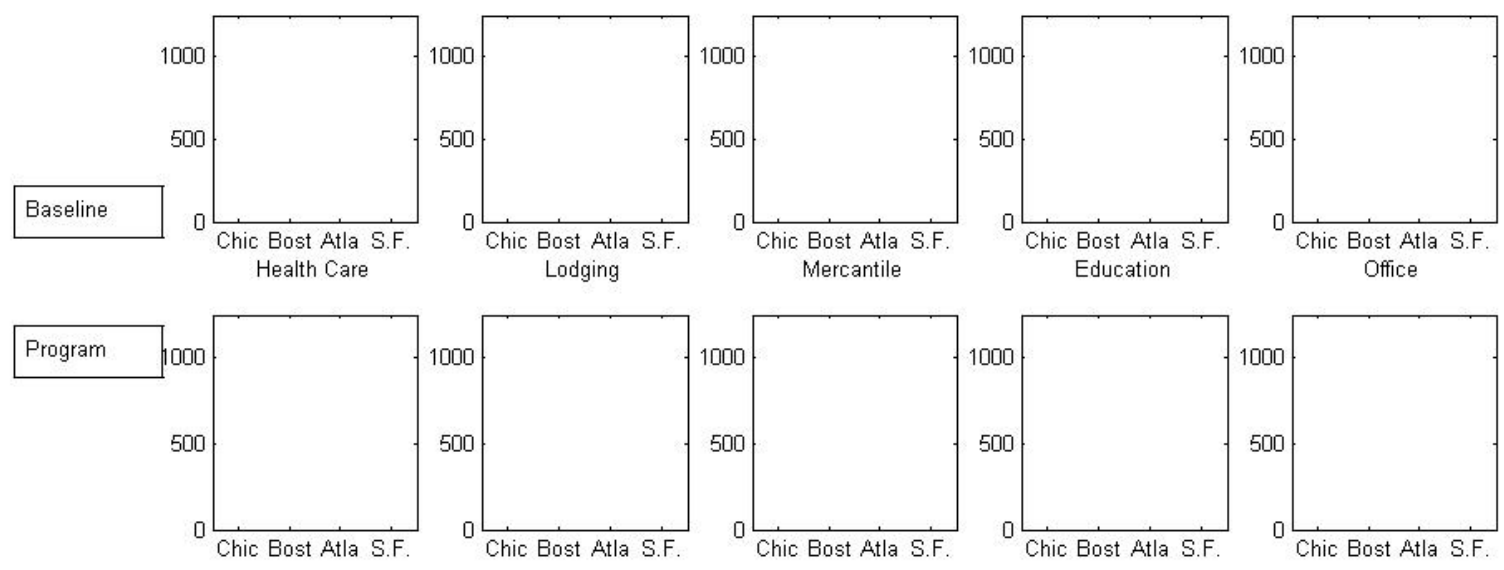

2012
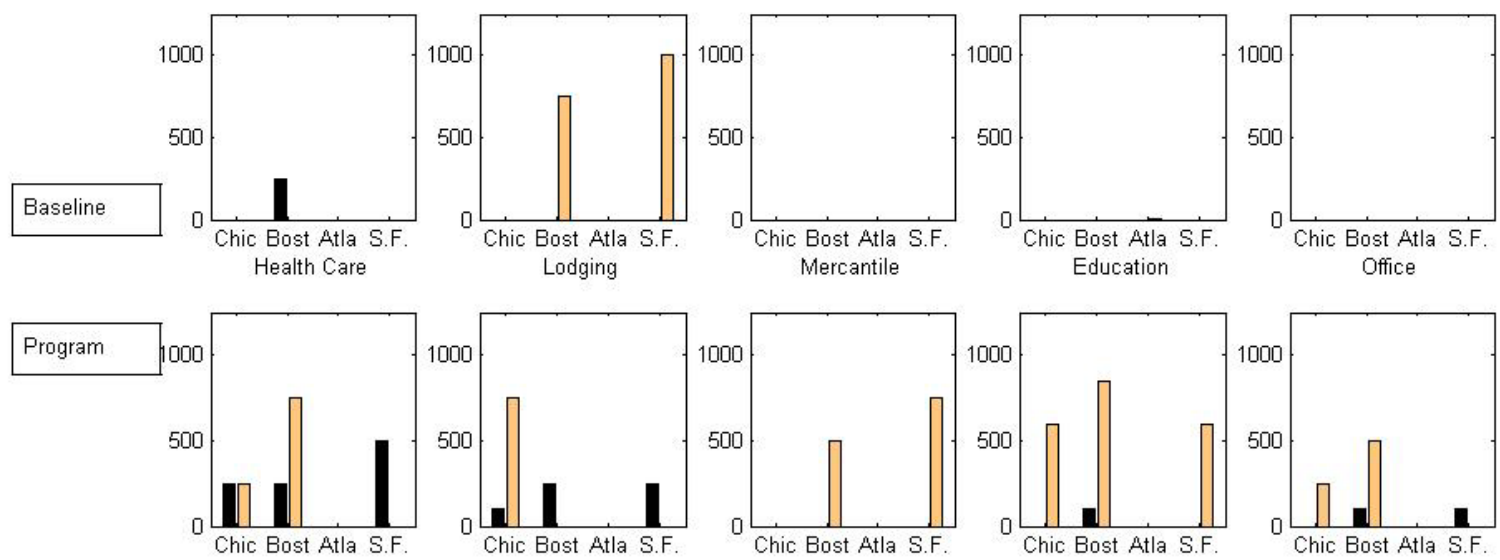

Office

2022

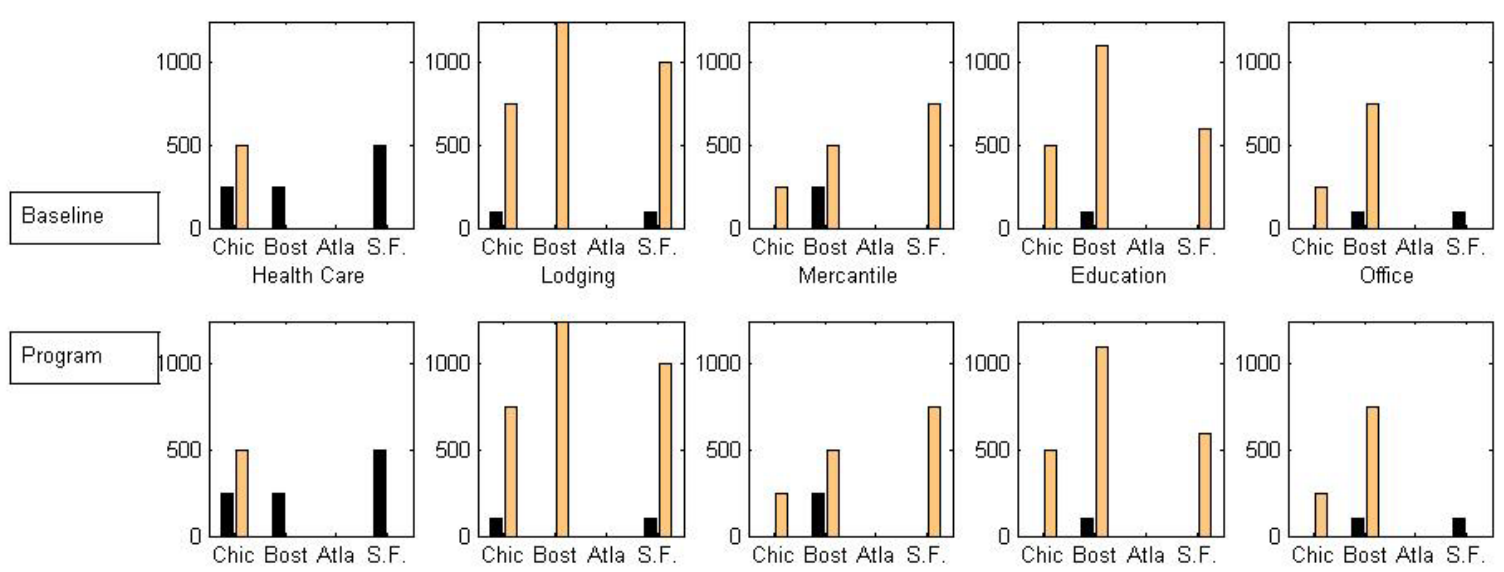

Figure 24. Installed DG Capacity - Microturbines (kW) 
2004
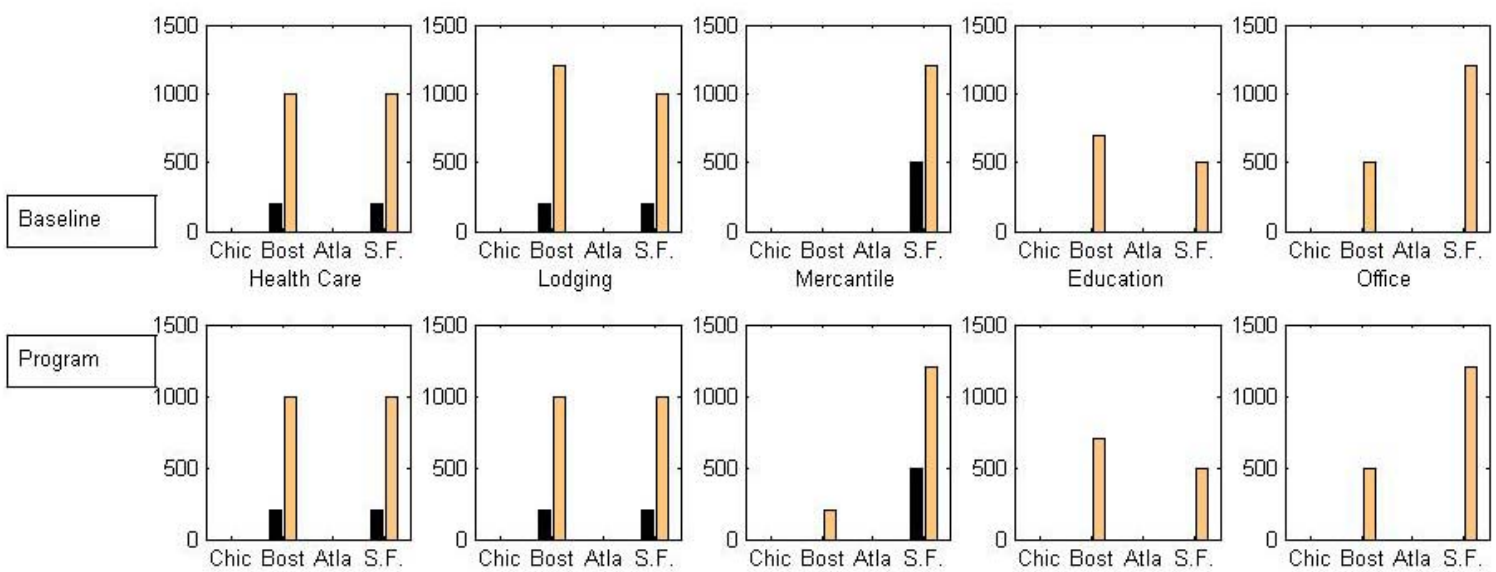

2012
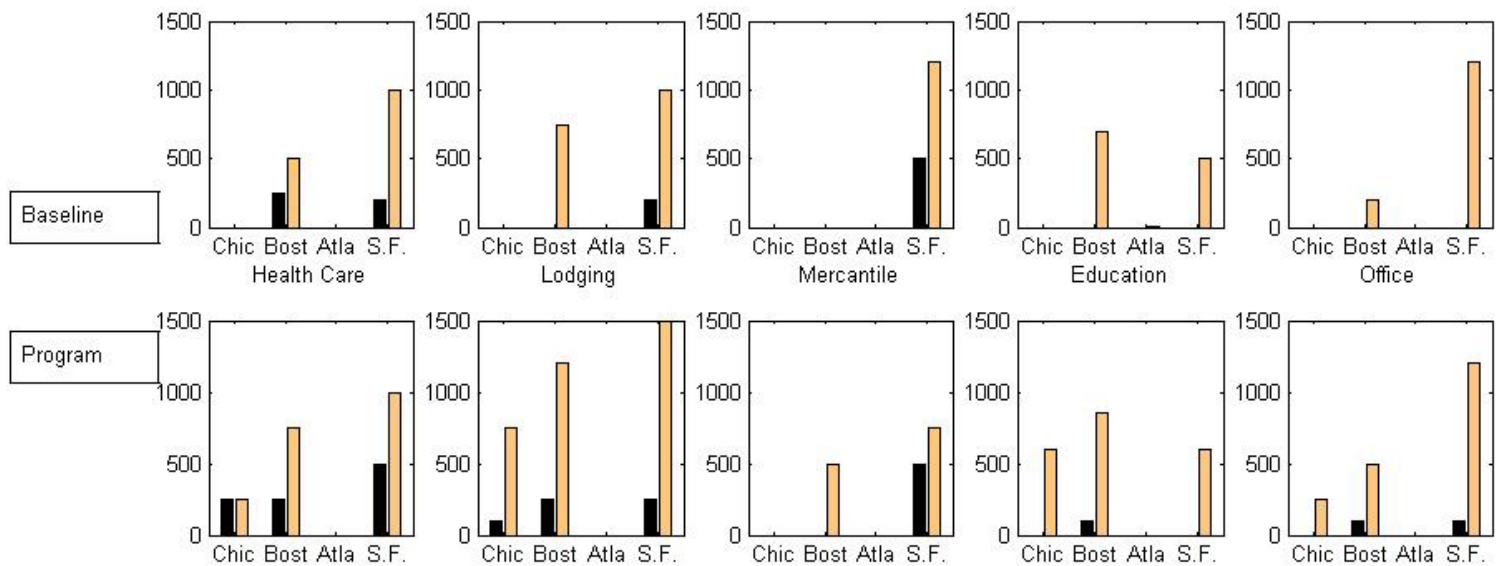

2022
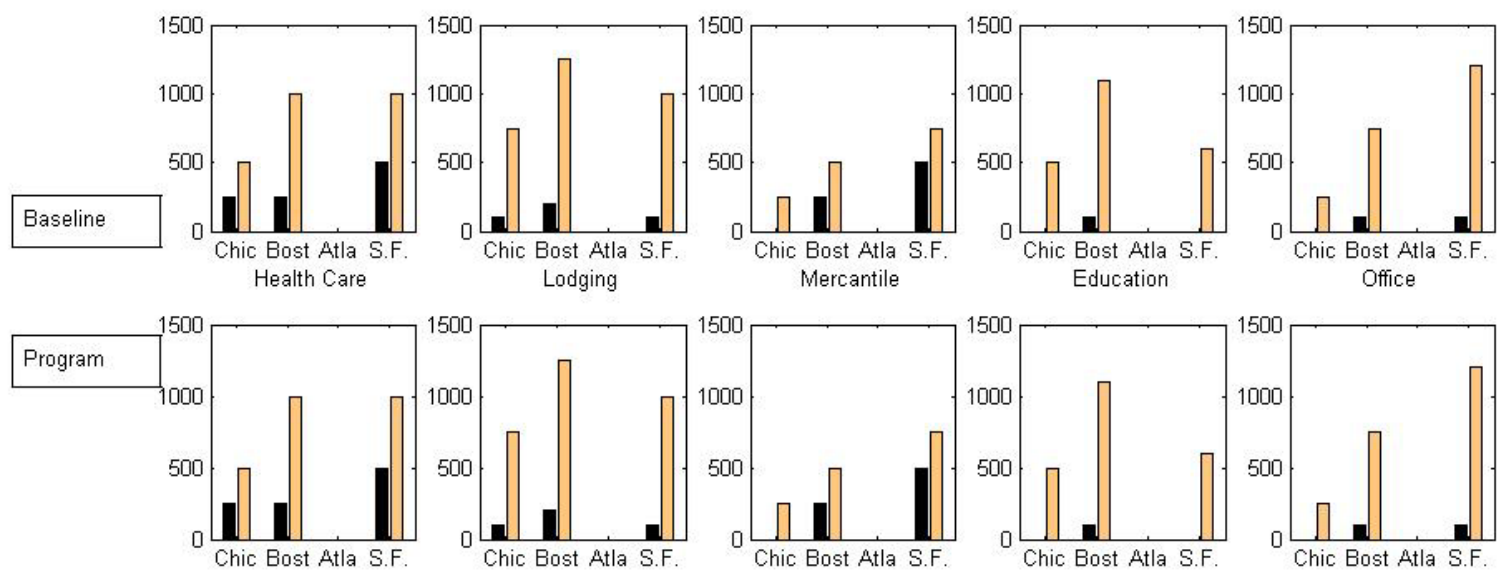

Figure 25. Installed DG Capacity - Total (kW) 
Two general, straightforward trends are observed from these figures. The first is the correlation between high electricity rates and high DG adoption. Nearly all San Francisco buildings adopt DG in each modeled year, six to ten Boston buildings adopt (depending on the year and case), Chicago buildings only adopt in the 2012 Program and 2022 Baseline and Program cases, and no Atlanta buildings adopt (Figure 25). Figure 26 plots the relative electricity prices in the four cities. The vertical axis is the relative demand charge ${ }^{5}(\$ / \mathrm{kW})$ and the horizontal axis is the relative volumetric charge ${ }^{6}(\$ / \mathrm{kWh})$ of electricity. The placement of cities on this plot and DG adoption patterns together suggest lines of isometric DG adoption potential going from the top left to bottom right of the plot.

The second general trend is an increase in DG adoption, with a cross-over from reciprocating engines to microturbines over time. DG is adopted in only 14 buildings in 2004, but in 26 buildings in 2022. Reciprocating engines are selected in 14 buildings in 2004, but only in 5 buildings in 2022. Microturbines are not selected at all in 2004, but in 21 buildings in 2022. In 2012, the year in which Baseline and Program case equipment parameters differ, results are intermediate of the two end years, with reciprocating engines favored in the Baseline case and microturbines in the Program case, and with more total DG installation in the Program than the Baseline case. Figure 27 plots the capital and operating costs of reciprocating engines (labeled "ICE"), microturbines (labeled "MT") and turbines (labeled "Turb") for all three test years". The dramatic improvement in microturbines relative to reciprocating engines and gas turbines is clearly seen in this plot.

Additional results, including utility electricity and natural gas consumption, are displayed in Appendix C. In order to estimate national DG penetration and resulting fuel consumption, these results were projected to entire building classes and regions using the DER-MaDiM model described in the next section.

\footnotetext{
${ }^{5}$ Relative demand charges are defined as

Total demand price during on - peak hours (city) $\overline{\max (\text { Total des }}$ (emand price during on - peak hours (city))

based on 2004 prices.

${ }^{6}$ Relative volumetric prices are defined as $\quad$ Total volumetric price during on - peak hours (city) based on 2004 prices. $\max _{\text {cities }}($ Total volumetric price during on - peak hours (city))

${ }^{7}$ For this plot, the following assumptions are made: reciprocating engine cost and performance is based on the $500 \mathrm{~kW}$ engine, microturbine cost and performance is based on the $250 \mathrm{~kW}$ microturbine, and turbine cost and performance is based on the $1 \mathrm{MW}$ turbine. All costs are for units without heat recovery. Capital costs are over the lifetime of the equipment, using a discount rate of 7.5 percent. Marginal costs assume natural gas prices of $\$ 0.03 / \mathrm{kWh}, \mathrm{HHV}$ (equivalent to $\$ 8.80 / \mathrm{MMBTU}$ by dividing the $\$ / \mathrm{kWh}$ by 0.003409 to get $\$ / \mathrm{MMBTU})$.
} 


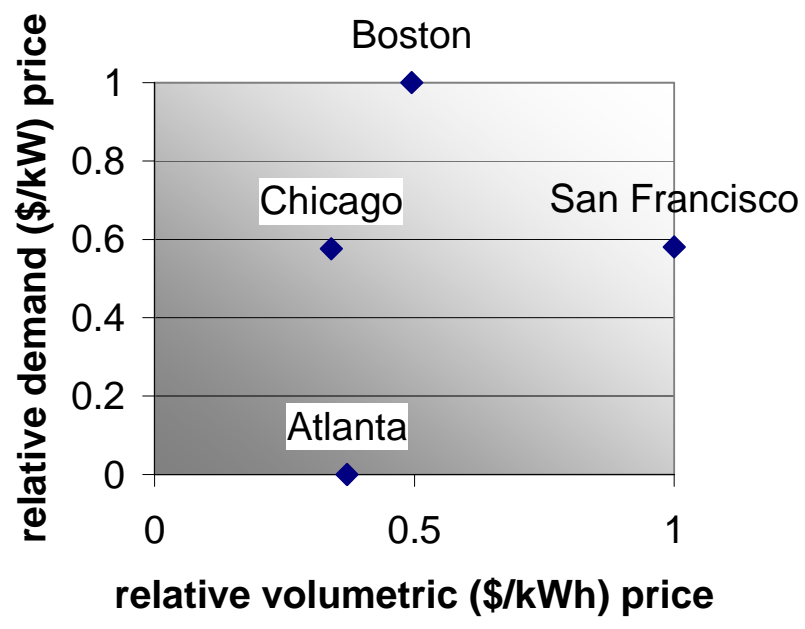

Figure 26. Relative 2004 electricity charges by city

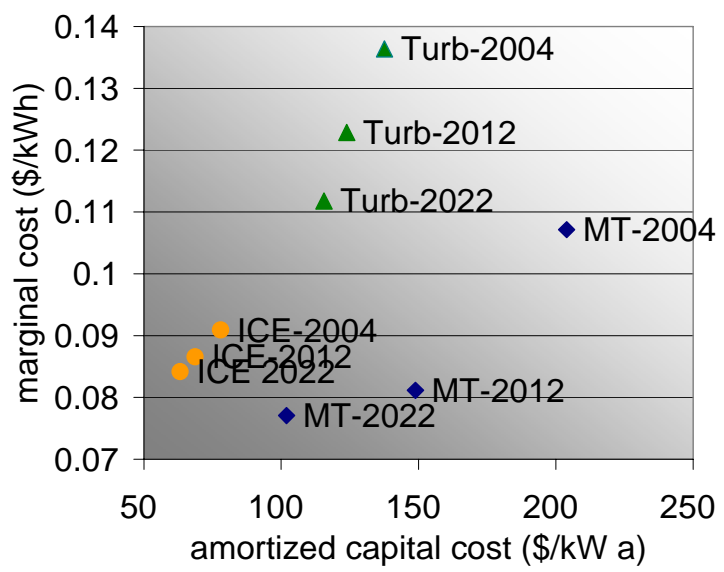

Figure 27. DG costs by equipment type and year 


\section{Distributed Energy Resource Market Diffusion Model (DER-MaDiM) Analysis}

With the use of DER-CAM in Section 3 to determine which of the representative buildings (discussed in Section 2) are attractive for DG adoption, further analysis is necessary to scale these results to levels of likely adoption for all buildings in the U.S. and for all forecast years from 2007-2025. One of the goals of the ComSeM approach is to forecast the likely diffusion of gas reciprocating engine and microturbine DG adoption in the U.S. commercial sector. To do this, Berkeley Lab developed a DER diffusion model called DER-MaDiM to conduct this third step in the ComSeM approach.

The diffusion process contains two basic parts. First, it is necessary to determine how representative the selected prototype buildings are of the entire commercial sector. This step provides a sense of how well the DER-CAM results represent the U.S. Second, DG diffusion into all buildings is needed, based on the varying levels of DG attractiveness over time as defined by the DER-CAM results.

The diffusion technique used in this work was based on a study by Paul Geroski on technology diffusion modeling (Geroski 2000). In accordance with the Geroski study, the introduction of a technology into a market is not only dependent on the cost attractiveness but also the level of knowledge and trust in the technology.

\subsection{Nomenclature}

The various indices, variables and parameters involved in the DER-MaDiM diffusion modeling are presented below:

\section{Indices}

$i$

$j$

$k$

l

time period (years)

$\{1 \ldots 20\}$

census division

$\{1 \ldots 9\}$

building type

$\{1 \ldots 5\}$

building size

$\{1 \ldots 2\}$

results type

\section{Variables}

$A D G E x_{t, i, j, k}$

$A D G N e w_{t, i, j, k}$

$A D G_{t, i, j, k}$

$\mathrm{Fr}_{t}$

FSTot $_{t, i, j, k}$

FSNew $w_{t, i, j, k}$

$C D G_{t, i, j, k}$

$A R_{t, i, j, k, l}$

$C R_{t, i, j, k, l}$ annual existing floorspace that adopts DG

annual net new floorspace that adopts DG

annual total floorspace that adopts DG

fraction of floorspace in commercial buildings with potential and installed systems

floorspace without DG but with economic potential to install

net new floorspace with DG economic potential

cumulative floorspace with DG

annual change in result metrics

cumulative results 


\section{Parameters}

$\alpha$

$\beta$

$S Z_{j, k}$

$S_{t, i, j, k}$

$a_{E}$

$b_{E}$

$c_{E}$

$a_{N}$

$b_{N}$

$c_{N}$

$A R D C_{t, i, j, k, l}$ constant fraction of buildings without DG that has knowledge from outreach programs

parameter deciding speed of word of mouth process

building size

percentage savings on energy bill

parameter for adoption function for existing buildings

parameter for adoption function for existing buildings

parameter for adoption function for existing buildings

parameter for adoption function for new buildings

parameter for adoption function for new buildings

parameter for adoption function for new buildings

annual DER-CAM results

Table 15: Description of Indices Used in DER-MaDiM

\begin{tabular}{|c|l|l|c|l|}
\hline & \multicolumn{1}{|c|}{ Census Division } & $\begin{array}{c}\text { Building } \\
\text { Type }\end{array}$ & $\begin{array}{c}\text { Building } \\
\text { Size }\end{array}$ & \multicolumn{1}{|c|}{ DER-MaDiM results } \\
\hline $\begin{array}{c}\text { Index } \\
\text { Value }\end{array}$ & \multicolumn{1}{|c|}{$j$} & $j$ & $k$ & $l$ \\
\hline 1 & New England & healthcare & small & total installed capacity \\
\hline 2 & Middle Atlantic & lodging & large & $\begin{array}{l}\text { total installed capacity reciprocating } \\
\text { engines }\end{array}$ \\
\hline 3 & East North Central & mercantile & & total installed capacity microturbines \\
\hline 4 & West North Central & education & & change in electricity purchases \\
\hline 5 & South Atlantic & office & & change in natural gas purchases \\
\hline 6 & East South Central & & & annual private cost savings \\
\hline 7 & West South Central & & & \\
\hline 8 & Mountain & & & \\
\hline 9 & Pacific & & & \\
\hline
\end{tabular}

The introduction of a new technology in a market usually follows an S-curve. Two competing ways for addressing this logistic function are through epidemic models and probit models (Geroski 2000). An epidemic model tries to explain the introduction of new technologies with the way information of the technology propagates to potential users. One version assumes a central source from where information is transmitted to a constant percentage of the potential users each year. However, this model fails to produce the commonly observed S-curve. A second epidemic model assumes that information is spread by word of mouth. This model produces an S-curve but fails to explain how the successful introduction of a new technology can be explained without initial installations. Geroski suggests using a mixed information source model with both a central source of information and a word of mouth process. Probit models, on the other hand, focus on the customer characteristics as an explanatory factor of why some firms adopt new technologies before others. Customer characteristics will affect the investment profitability, and therefore the decision to adopt the technology. 
The model developed in this work is a combination of all three approaches. First, the central source of information is assumed to be outreach programs and research devoted to increasing the understanding of DG. Second, the word of mouth process is included. Third, individual building characteristics and DG attractiveness are modeled directly as described in the previous sections. The fact that DG systems are more suitable in some buildings than others is reflected in the variability of energy bill savings found from the DER-CAM analysis. Hence, it is reasonable to assume that buildings with a higher percentage of energy bill savings will be more likely to install DG. This assumption is implemented using a logistic adoption function where buildings with large savings are assumed to adopt DG at a faster rate than buildings with marginal savings.

As can be seen in Table 15, all nine Census Divisions and all five selected building types are modeled. Two building sizes for each modeled building type in DER-CAM represent the entire building size distribution. Results for all forecast years are determined as a linear interpolation between the DER-CAM results of each modeled year.

Each year a constant fraction of buildings, $\alpha$, with no DG gain knowledge about DG technologies from outreach programs. The remaining fraction of buildings gains DG knowledge by word of mouth. The factor that decides the strength of the word of mouth process, $\beta$, is modeled proportionally to the fraction of commercial buildings with DG potential that has installed systems. Thus, the word of mouth process is increasing in strength as more users become aware of the technology. Of the buildings with knowledge of DG, only a fraction will actually install systems. This fraction is a function of the percentage of annual energy savings to the total energy bill as seen in Figure 28.

Hence, the existing floorspace that adopts DG each year is the product of the percentage of the market with DG knowledge, the adoption function, and the available floorspace without DG systems as shown below

$$
A D G E x_{t, i, j, k}=\left(\alpha+\beta F r_{t-1}\right) f\left(a_{E}, b_{E}, c_{E}, S_{t, i, j, k}\right)\left(F S T o t_{t-1, i, j, k}-C D G_{t-1, i, j, k}\right)
$$

New floorspace is added each year as new buildings are constructed. Because DER-MaDiM does not include a vintage structure of existing buildings and no buildings were phased out, new buildings were defined as the amount of new floorspace minus the reduction to the existing floorspace due to retirements. New buildings adopt DG systems using a similar process

$$
A D G N e w_{t, i, j, k}=\left(\alpha+\beta F r_{t-1}\right) f\left(a_{N}, b_{N} c_{N} S_{t, i, j, k}\right) F S N e w_{t, i, j, k}
$$

The upper limit or constraint on the parameters $\alpha$ and $\beta$ is that their sum must be lower than one to ensure that less than 100 percent of buildings with DG economic potential have DG information.

The adoption function for both existing and new buildings is a logistical function given as

$$
f(a, b, c, S)=\frac{c}{1+a e^{-b S}}-\frac{c}{1+a}
$$


The floorspace considered in this analysis excludes larger commercial buildings, where competition with gas turbines is assumed to be strong and where there is economic potential as determined by DER-CAM.

Annual total floorspace that adopts DG is the sum of adoption in existing and new buildings

$$
A D G_{t, i, j, k}=A D G E x_{t, i, j, k}+A D G N e w_{t, i, j, k}
$$

Net new floorspace is added to the total floorspace

$$
\text { FSTot }_{t, i, j, k}=\text { FSTot }_{t-1, i, j, k}+\text { FSNew }_{t, i, j, k}
$$

Cumulative floorspace with DG is represented as

$$
C D G_{t, i, j, k}=C D G_{t-1, i, j, k}+A D G_{t, i, j, k}
$$

Fraction of buildings with DG is total floorspace with DG divided by floorspace with potential in U.S. commercial building sector

$$
F r_{t}=\frac{\sum_{i=1}^{9} \sum_{j=1}^{5} \sum_{k=1}^{2} \operatorname{CDG}_{t, i, j, k}}{\sum_{i=1}^{9} \sum_{j=1}^{5} \sum_{k=1}^{2} \text { FSTot }_{t, i, j, k}}
$$

The different result metrics (see index 1 Table 15) in each time period, is defined as the DERCAM results divided by building size multiplied by the floorspace that actually adopts

$$
A R_{t, i, j, k, l}=\frac{A R D C_{t, i, j, k, l}}{S Z_{j, k}} A D G_{t, i, j, k}
$$

Cumulative values of the different results are

$$
C R_{t, i, j, k, l}=C R_{t-1, i, j, k, l}+A R_{t, i, j, k, l}
$$

Cumulative results are obtained by summing over the indices. Results for the U.S. commercial building sector as a whole are obtained as a summation over all Census Divisions, building types and building sizes that the floorspace is allocated to

$$
C R_{t, l}=\sum_{i=1}^{9} \sum_{j=1}^{5} \sum_{k=1}^{2} C R_{t, i, j, k, l}
$$




\subsection{Model Parameters}

Table 1 from Section 2 shows the size distributions in bold that are used in this study and it is assumed that the national size distribution is valid regionally. Reciprocating engines and microturbines have a different potential in different building types and sizes. Buildings with a peak electricity load in the medium-size range of $300-2000 \mathrm{~kW}$ are assumed to be most suitable for reciprocating engines and microturbines. For buildings with a lower peak, the appropriatelysized DG system incurs a high investment costs and a low capacity factor that are not likely to be cost-effective for most buildings. However, some niche markets may exist and some development may come from the introduction of microgrids, where neighboring buildings can add their loads together to become an attractive DG site. For buildings with a peak load over 2 MW, gas turbines can be a strong competitor to reciprocating engines and microturbines. In addition some large buildings already have DG systems installed. At the same time there is a potential market in some buildings where the investment in large gas turbines does not provide a sufficient return. Table 16 shows the percentage of buildings that are assumed to have DG potential by the size of the peak load. These assumptions are currently based only on judgment; however, they could be readily replaced over time by more complete analysis of the various building sizes shown in Table 1.

Table 16. Percentage of Buildings Assumed to have DG Potential

\begin{tabular}{|c|c|c|}
\hline & Existing Buildings (\%) & New Buildings (\%) \\
\hline $\begin{array}{c}\text { Below DG Attractive Size Range } \\
(<300 \mathrm{~kW})\end{array}$ & 16 & 18 \\
\hline $\begin{array}{c}\text { DG Attractive Size Range } \\
(300-2,000 \mathrm{~kW})\end{array}$ & 80 & 90 \\
\hline $\begin{array}{c}\text { Over DG Attractive Size Range } \\
(>2,000 \mathrm{~kW})\end{array}$ & 32 & 36 \\
\hline
\end{tabular}

As described in Section 2, DER-CAM considers two building sizes for each building type, both selected from the medium size peak load group. One building represents the minimum and the other represents the maximum size building likely to have a peak load in the $300 \mathrm{~kW}-2 \mathrm{MW}$ range. Small buildings are assumed to adopt systems at the same capacity and energy consumption changes per floorspace as the marker small building and with the same percentage savings on the energy bill. Similarly, buildings larger than the maximum size building are assumed to adopt systems with a capacity and energy consumption per square meter equal to the large building and with the same percentage annual energy bill savings. For building types with an intermediate size bin installed capacity, changes in energy consumption and the percentage savings on the energy bill is a linear interpolation between the small and the large building. Instead of interpolating the results, an equivalent interpolation where the floorspace is shared between the buildings was performed. Hence, the total floorspace for each building type is allocated to the two building sizes. 
Table 17 summarizes the model parameters used in the analysis. In the Baseline case, two percent of buildings with DG potential are assumed to gain DG information from outreach programs, while in the Program case ten percent are reached. In both cases, the factor determining the strength of the word of mouth process, $\beta$, is at its maximum. The parameters determining the adoption function, which are the percentage of customers with DG information that actually install systems for a given cost-effectiveness, are assumed to be equal in both cases.

Table 17. Model Parameters

\begin{tabular}{|l|c|c|}
\hline Parameter & Baseline Case & Program Case \\
\hline$\alpha$ & 0.02 & 0.1 \\
\hline$\beta$ & 0.98 & 0.9 \\
\hline$a_{E}$ & 200 & 200 \\
\hline$a_{N}$ & 200 & 200 \\
\hline$b_{E}$ & 0.4 & 0.4 \\
\hline$b_{N}$ & 0.6 & 0.6 \\
\hline$c_{E}$ & 60 & 60 \\
\hline$c_{N}$ & 80 & 80 \\
\hline
\end{tabular}

Figure 28 is a plot of the adoption function for existing and new buildings. This figure illustrates a more aggressive DG adoption rate in new buildings. This is based on the assumption that when new buildings are constructed it is more likely that energy considerations are made, and that new buildings can be more flexible in incorporating DG systems. The maximum saturation for new buildings is 80 percent and for existing buildings is 60 percent. Note that the percentage of all considered buildings that adopt systems can be much lower, depending on the current status of DG information in the market.

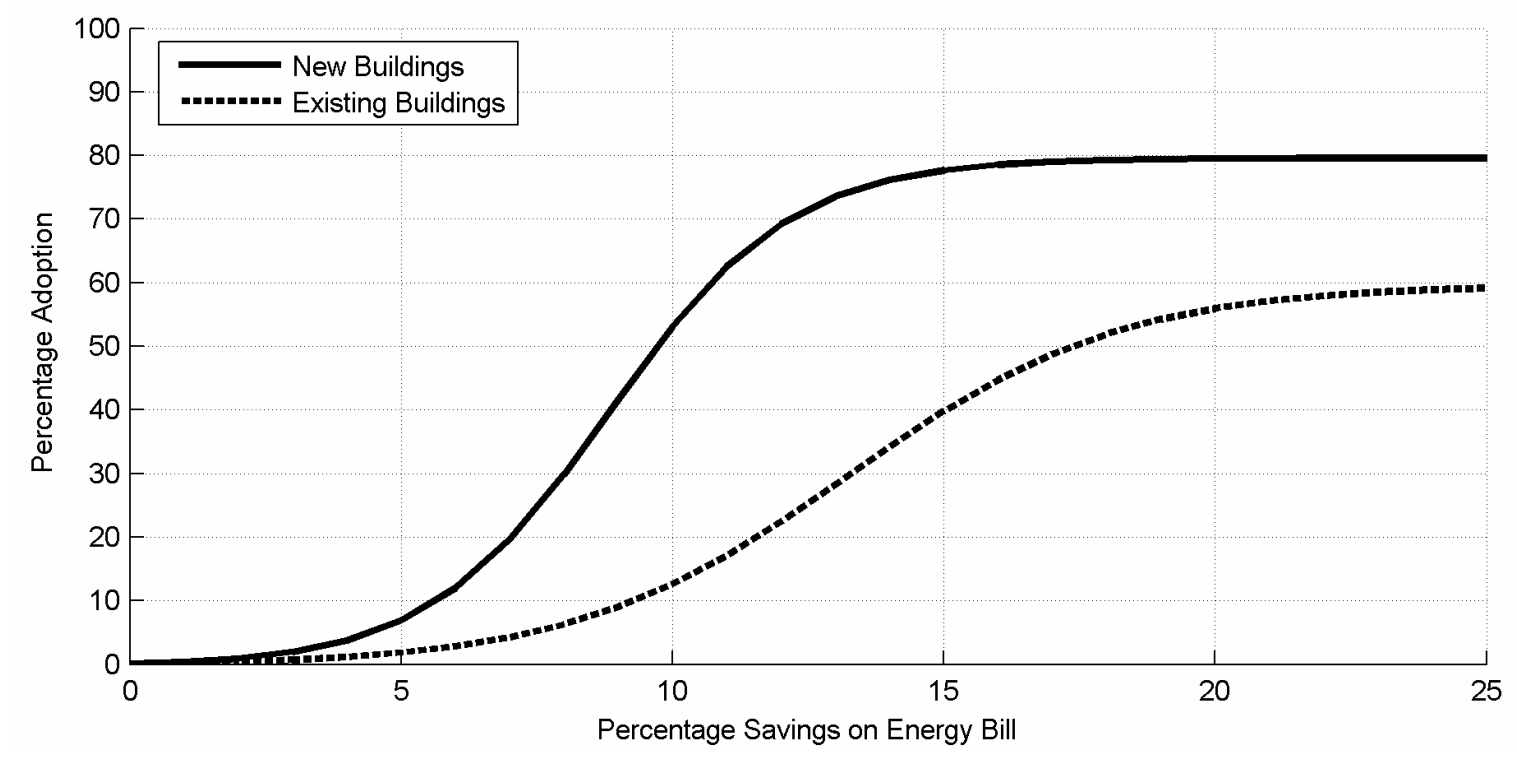

Figure 28. Adoption Curves for New and Existing Buildings 


\subsection{Results}

Figure 29 shows the modeled installed DG capacity in U.S. commercial buildings from 2005 to 2025 for the Baseline and Program cases. The Program case leads to an earlier and wider adoption of DG than the Baseline case. Cumulative capacity follows an S-curve with the highest growth in DG capacity around 2014. In the Baseline case, installed capacity shows exponential growth during the forecast period with a potential inflection point around 2025. The largest difference in installed capacity is in year 2019 at $11.1 \mathrm{GW}$. After 2019, growth is higher in the Baseline case because technological advancements catch up to the Program case and because there is a larger undeveloped potential than in the Program case. Furthermore, observe that there is path dependence in these curves; the difference between the Program and Baseline cases is not only a delayed development, but the path has also changed. This is due to two factors: first, stronger outreach programs create higher growth, and second, increased DG knowledge in periods where prices are favorable for DG can lead to an increase in capacity that will not be made up for later.

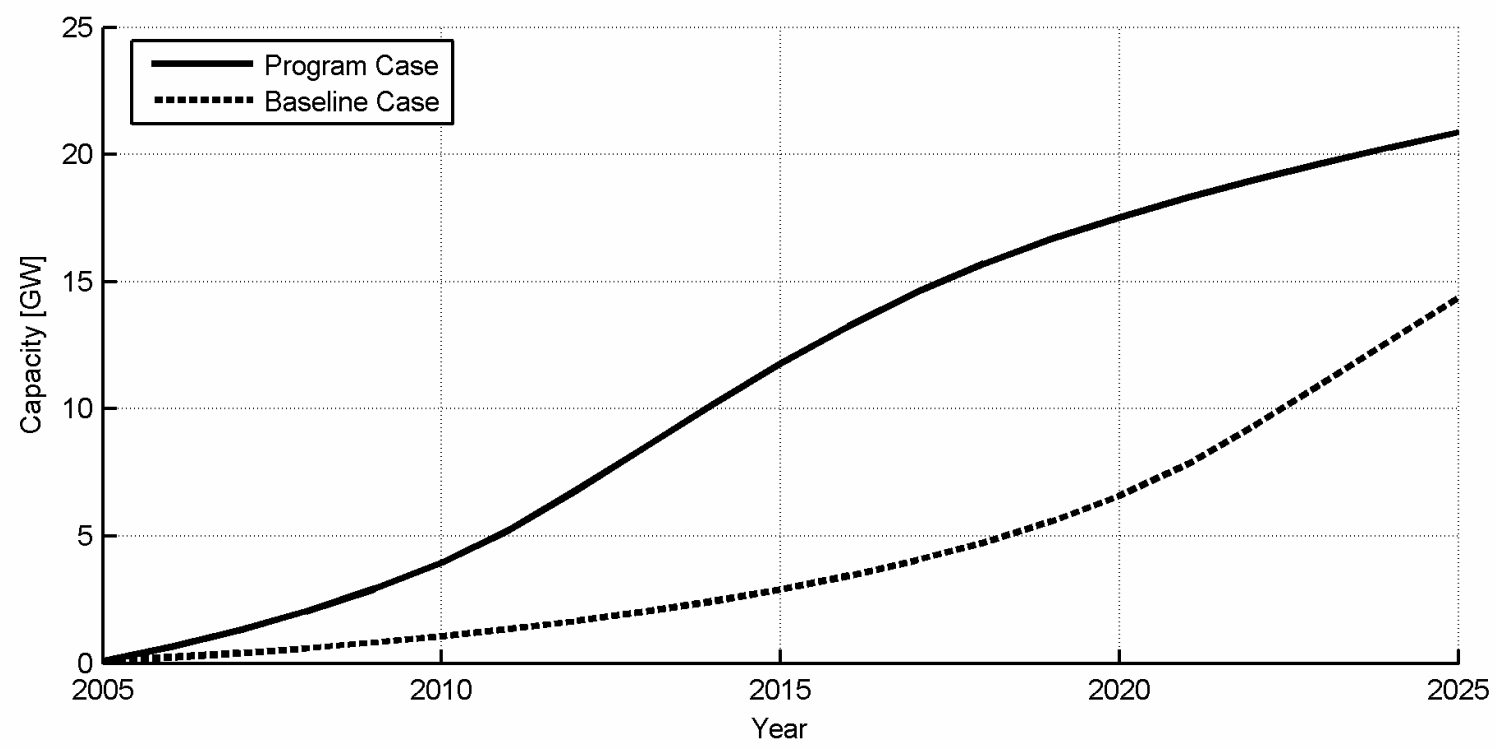

Figure 29. Installed DG Capacity in U.S. Commercial Sector in Baseline and Program Cases

Reciprocating engines are expected to experience marginal improvements in performance during the forecast horizon. However, these improvements combined with a stronger technology outreach program and increased word of mouth from the successful implementation of microturbines leads to a higher installed capacity in the Program case than in the Baseline case (see Figure 30). Microturbines represent a promising technology with expected cost reductions and performance improvements over time. In the Program case, investment in microturbines are expected to grow rapidly from 2010 and exceed the capacity of reciprocating engines by 2017. Notice the difference in the diffusion curves for reciprocating engines and microturbines in the Program case. Reciprocating engine capacity grows fast initially, but as microturbines become more competitive microturbines take a larger share of the market. However, there is still a 
market growth for both, reflected by different buildings suitability to each technology. For example, in the Baseline case reciprocating engines are superior to microturbines.
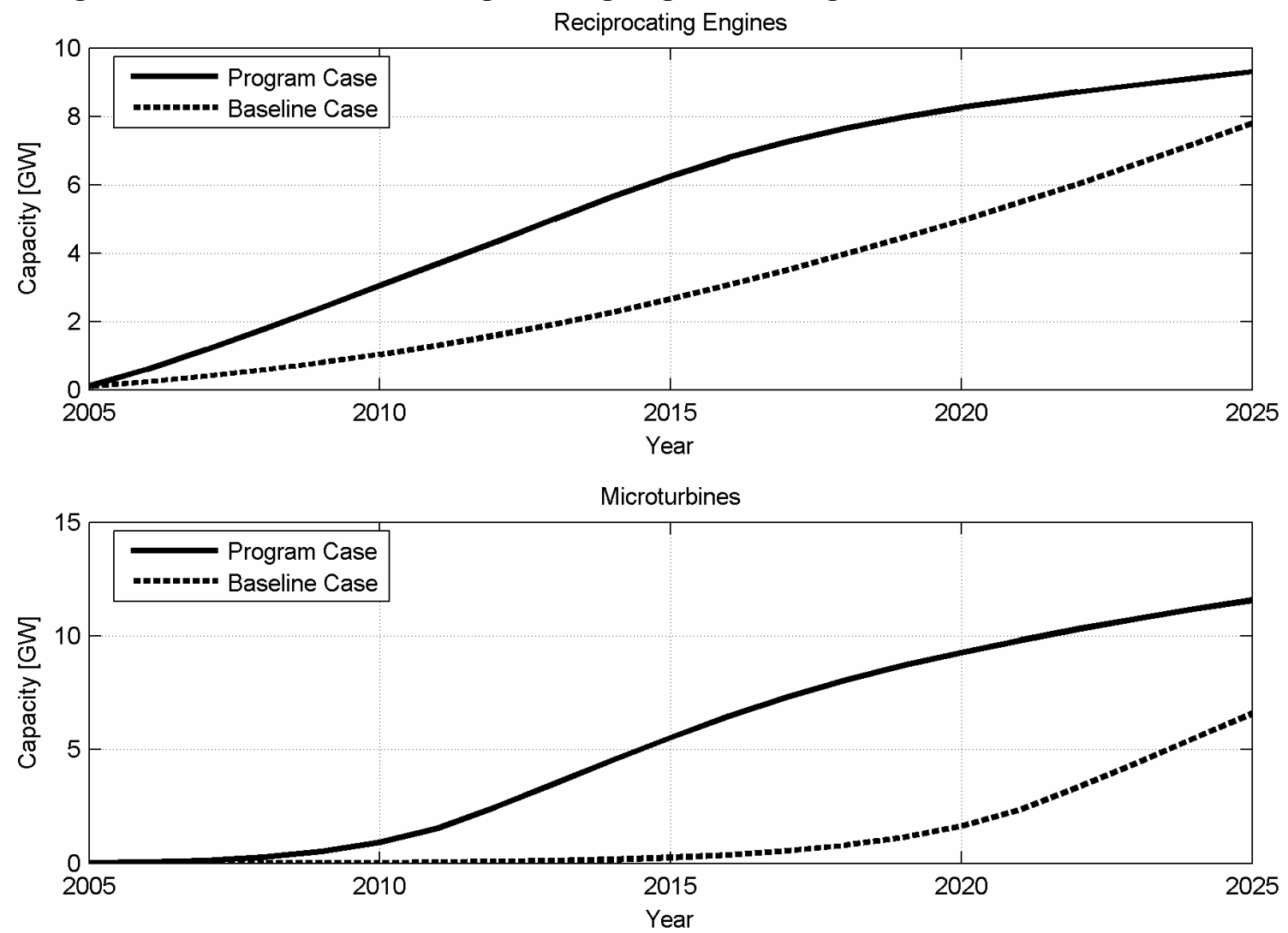

Figure 30. Installed Capacity of Reciprocating Engines and Microturbines in the Program and Baseline Cases

Figure 31 shows that the amount of electricity produced on-site follows the same pattern as installed capacity. In the Program case, 100 TWh of electricity is expected to be produced in commercial buildings. The largest difference in the two graphs is in 2017 when $67 \mathrm{TWh}$ are produced in the Program case and 19 TWh in the Baseline case. Notice that natural gas consumption increases at approximately double the rate of on-site electricity generation, which is due to waste heat use. This is a higher efficiency than the average efficiency of the U.S. thermal generation. CHP systems have the potential to produce higher overall efficiencies. The reason for this discrepancy is that some of the recovered heat is used for cooling, which has a lower efficiency than direct heat use and that the generators are allowed to produce without any heat recovery if the prices justify the operation. A considerable amount of the on-site generation occurs at peak hours when the efficiency is lower and the grid is heavily strained. In comparison to a central system where some electricity will be lost under transmission and distribution, DG provides electricity on-site. The results represent a laissez-faire solution, exclusive of any regulatory policies to improve efficiency, such as a lower bound on efficiency or promotion of the use of waste heat 

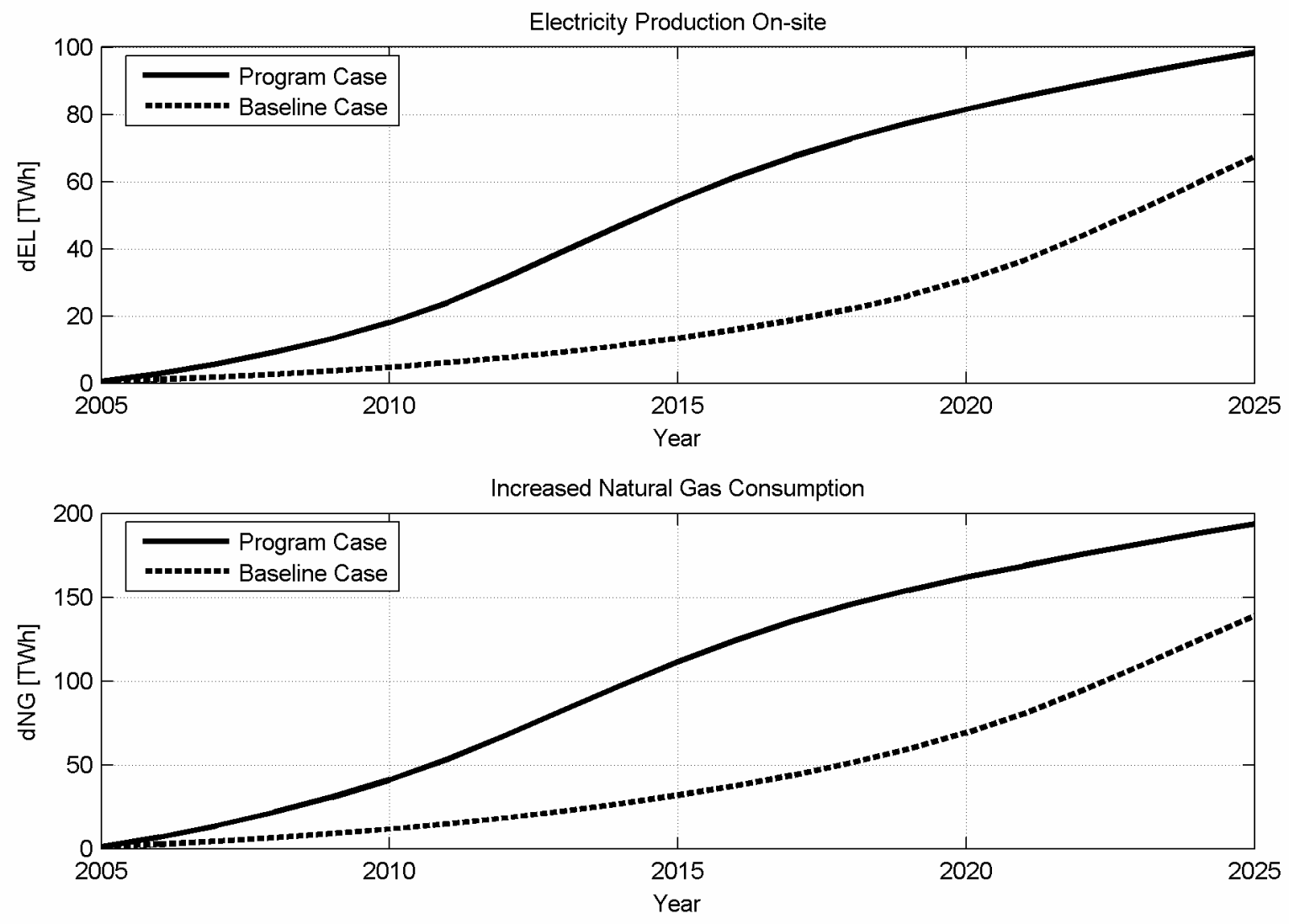

Figure 31. Electricity Produced On-site and Increased Natural Gas Consumption in Program and Baseline Cases

Buildings installed DG systems have reduced energy costs. The cumulative annual private cost savings or cost savings from building energy use for all U.S. commercial buildings with DG is shown in Figure 32. In 2015 the annual savings, which include capital costs, are $\$ 2.0$ billion in the Program case and $\$ 0.5$ billion in the Baseline case ${ }^{8}$. In 2025 the difference in savings is reduced with savings of $\$ 3.5$ billion in the Program case and $\$ 2.3$ billion in the Baseline case. These savings represent the net cost in the energy bill of the buildings, including the cost of investment in DG equipment.

${ }^{8}$ Annual expenditure savings are based on the AEO2005 Reference Case forecast of natural gas and electricity prices. 


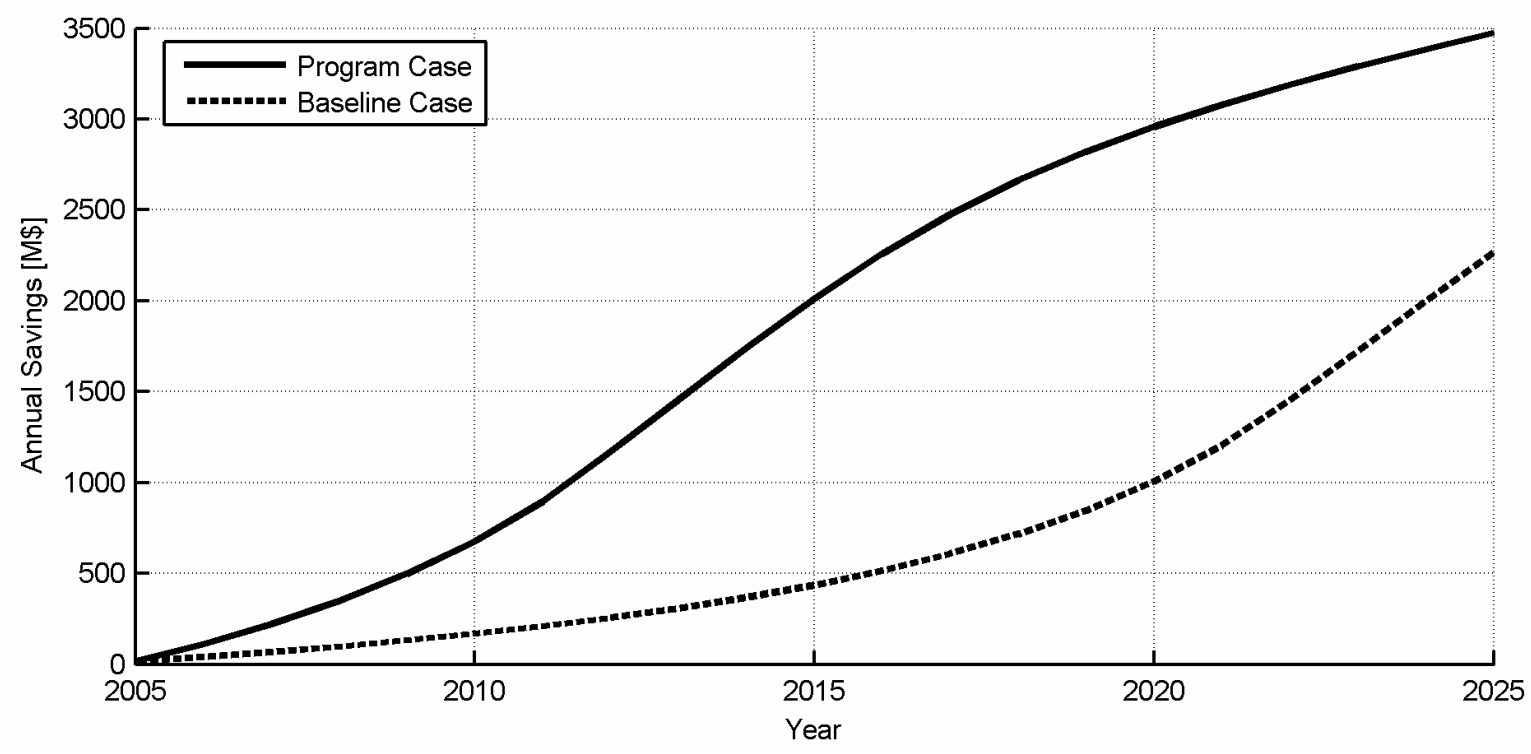

Figure 32. Annual Private Cost Savings from On-site Generation in Program and Baseline Cases

The U.S. consists of regions with diverse climates and electricity and natural gas markets. These differences are of major importance for DG attractiveness. As seen in Figure 33, the West region, which is dominated by the dense population of California and high electricity prices and cooling demand, is in position to be the leader in DG expansion. Also the Northeast seems to be an area suited for DG with a later but significant development. DG expansion in the Midwest is expected to be more modest and the low electricity rates in the South preclude any DG potential. Both the Baseline and the Program cases show the same regional pattern. The West and Northeast are still expected to develop the majority of DG capacity in the Baseline case, but toward the end of the forecast period. In the Midwest, DG development is delayed 10 years and considerably less. Please refer to Table 5 for a summary of how the four cities relate to the broadly defined four regions representing the U.S. 

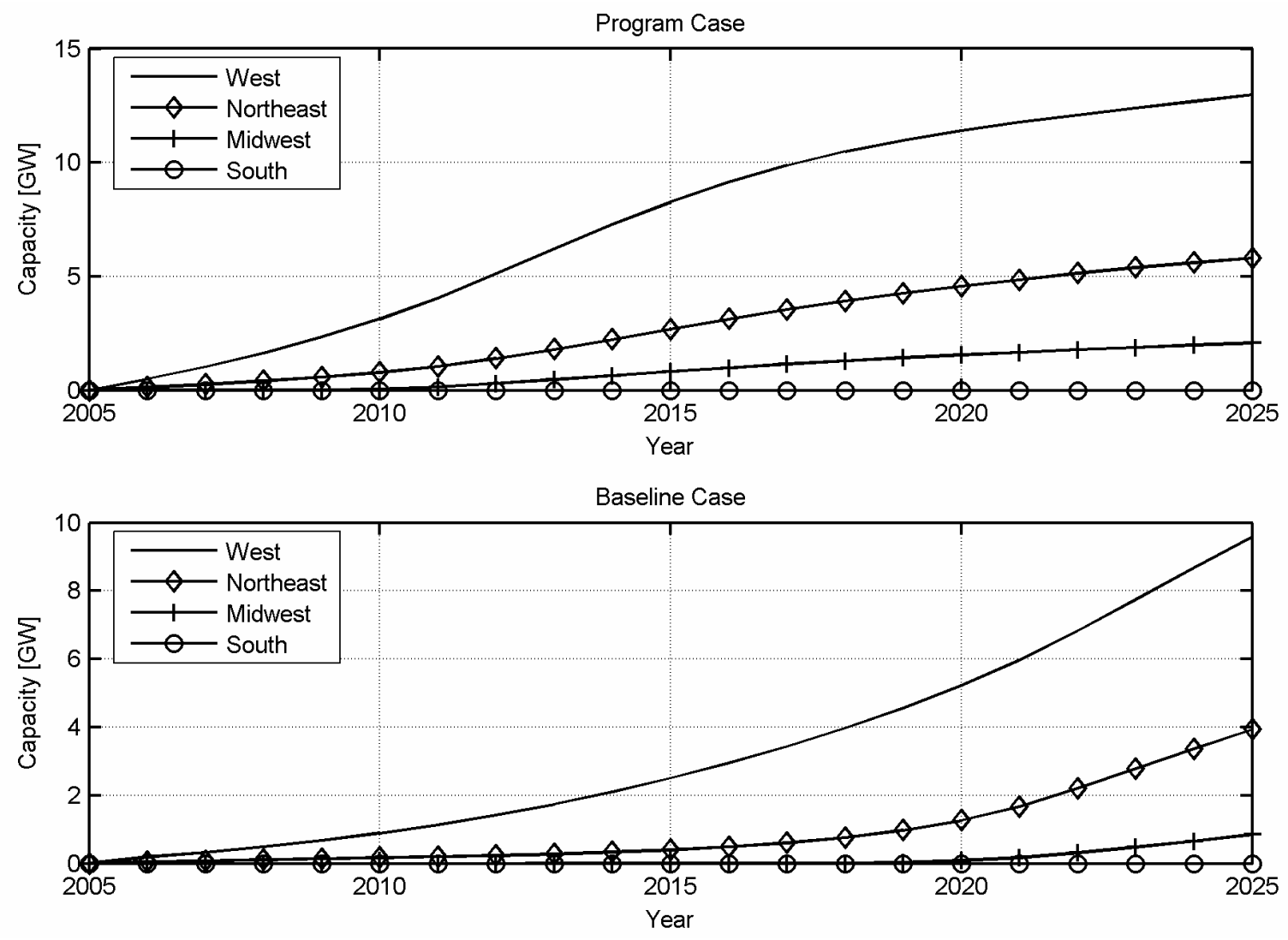

Figure 33. Installed DG Capacity in Census Regions in the Forecast Period in Program and Baseline Cases

In the Program case, DG adoption is expected to be highest in office buildings followed by mercantile buildings (see Figure 34). Although the total floorspace in education buildings is much higher than the healthcare and lodging buildings, the DG capacity is only slightly higher in the education buildings. Healthcare buildings are among the most attractive for DG sites, but they constitute a relatively small portion of U.S. commercial floorspace. Somewhat surprising is the two building types with the lowest fuel to electricity ratio, mercantile and office, are the most important for DG market diffusion (see Table 6). Although these don't have a high heat load, they are good candidates because they can use recovered heat for absorption cooling and reduce demand charges and expensive on-peak power. Further they are important because they constitute a large share of the commercial floorspace. Educational buildings have the highest fuel to electricity ratio but are less important than office and mercantile buildings. This can probably be explained by the non-coincident of electricity loads, heat loads and peak electricity prices for educational buildings. The Baseline case shows a similar but not identical ratio between the building types. Mercantile buildings are leading DG adopters until 2018 when healthcare buildings build more DG than both education and lodging. An explanation for this can be that office buildings are more suited to the improved microturbines than reciprocating engines. 

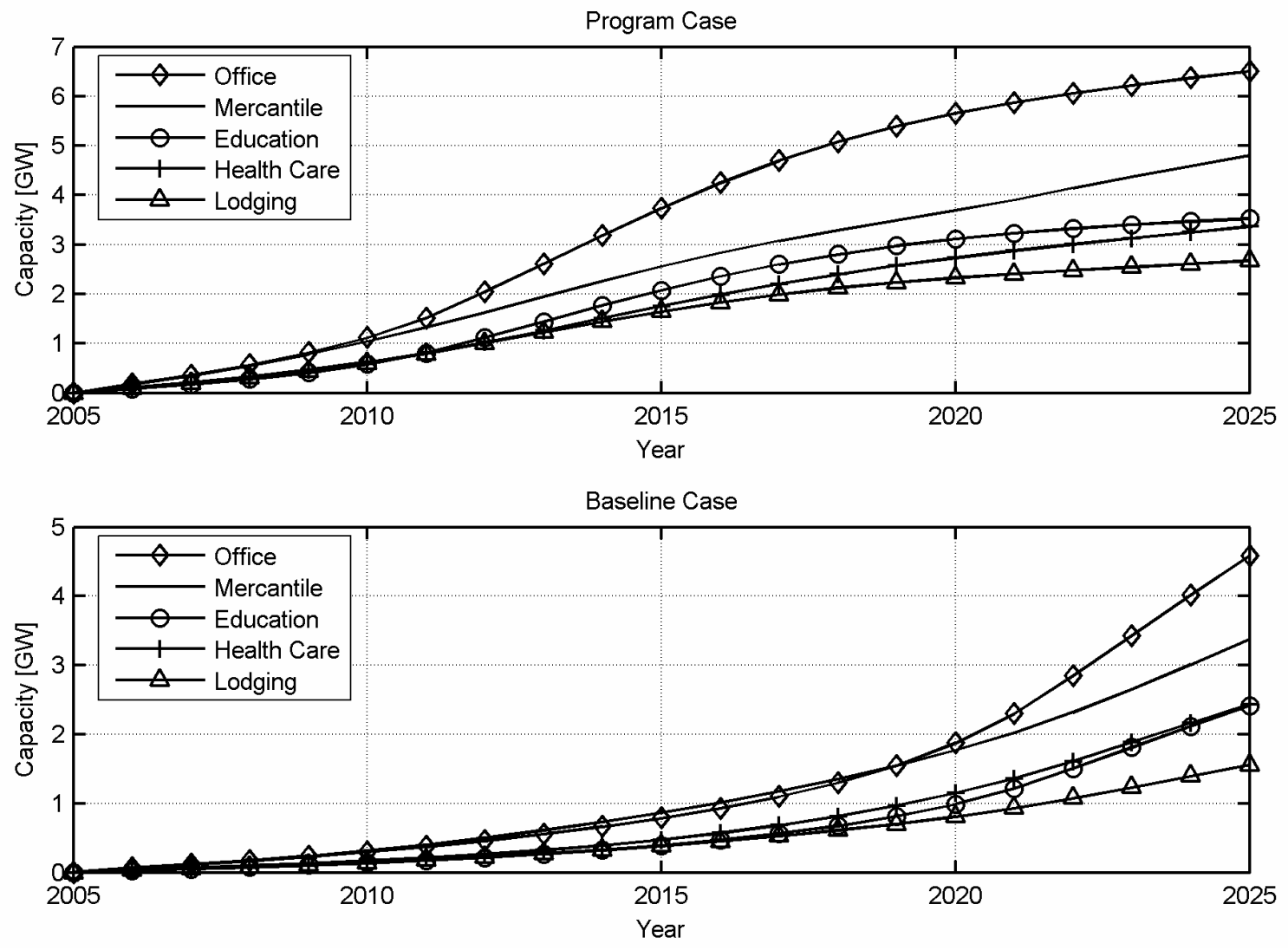

Figure 34. Installed DG Capacity for Building Types in Program and Baseline Cases

The results from the DER-MaDiM model suggest that there can be a large market for DG in U.S. commercial buildings even with only modest outreach program and little technology outreach. It reveals how significant an impact a stronger outreach program combined with more technology research can have on the potential to accelerate and increase DG investments. The investment in the outreach and research programs can be balanced by private savings on the energy bill. Satisfying electricity, heating, and cooling loads with DG leads to a net increase in building natural gas consumption that is approximately double the increase in electricity production onsite. Regulation and incentives have the potential to further improve the environmental benefits of DG. The West and Northeast are the regions where most DG capacity expansion is expected. The office and mercantile buildings can play a key role in wide-scale DG development.

A weakness in the DER-MaDiM modeling approach is that the model does not directly allow for operational changes in the DG systems after they are installed if market conditions change.

Similarly, the investment decision is based only on the prices in a particular year and does not include any expectation of prices in the future. The vintage structure of the existing building stock and the demolition of buildings are not included in the analysis, but only a fraction of the entire building stock is included as potential DG buildings, and most buildings have an expected lifetime far beyond the analysis horizon. Competition from other DER technologies is included to some extent. This is accounted for by reducing the floorspace with DG potential, such as including a low fraction of the floorspace for larger buildings where gas turbines can be a 
competitor. It could also be possible to include more technologies, such as photovoltaic systems, directly as a competing technology if they prove to be more competitive, or if there is strong regulatory support for them.

Predicting market diffusion of new technologies is not straightforward. Therefore, finding the correct parameters for the model is a challenge. Using parameters from the introduction of other technologies could be an option, but each technology is itself unique and has a unique market, which makes comparisons difficult. A possible approach could be to base parameters on empirical data from the introduction of similar technologies such as energy efficiency equipment and on surveys of building developers' willingness to invest under various cost saving levels.

In any case, the model captures the major dynamics of technology diffusion for DG in modeling the spread of information from a central source and from a word of mouth process, combined with the bottom-up DER-CAM approach to decide DG attractiveness for different building types in different regions. The modeling approach can further be used to analyze the effect of other energy market policies in future studies. 



\section{NEMS-DE Modeling Analysis}

The final step of the ComSeM approach is to input the consequences of the estimated DG diffusion derived in Section 4 to NEMS-DE. This section explains how this is done, starting first with an overview of the NEMS model and then detailing the assumptions and inputs necessary to successfully model the exogenous results obtained from DER-MaDiM into NEMS-DE. An explanation of the traditional approach is also provided as a basis for comparison to the new ComSeM approach. Then, results are presented with some focus on the benefits reported for the GPRA filing.

\subsection{Overview of NEMS}

NEMS is a large multi-sectoral U.S. energy model used to produce the influential Annual Energy Outlook (AEO) and designed to forecast the behavior of energy markets and their interactions with the U.S. economy over the next 20 years. NEMS relies on fairly transparent assumptions due to the exposure and scrutiny each AEO receives, but the model is huge and many of its operations are opaque at best. On the other hand, because its scale allows it to measure the interactions between the various energy supply and demand sectors and the economy as a whole, NEMS offers a comprehensive picture of the possible benefits results of technology research programs. Figure 35 illustrates these interactions by showing how NEMS is structured (Energy Information Administration 2003b).

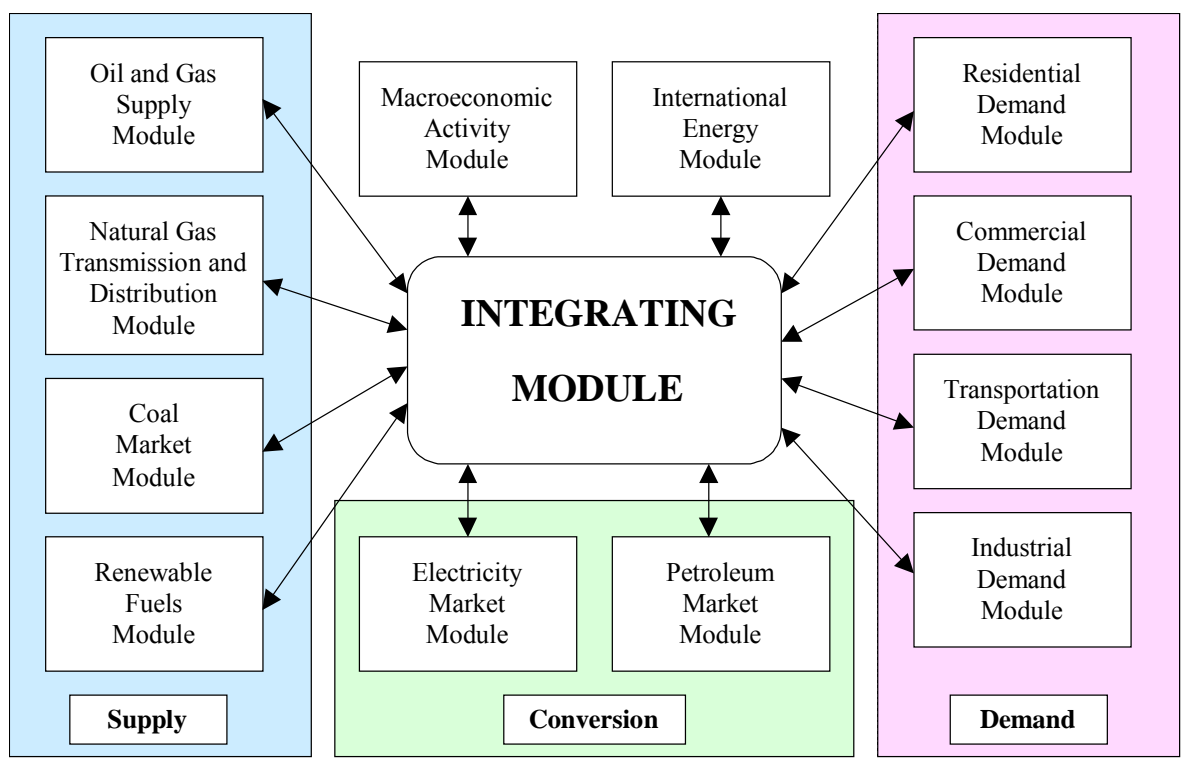

source: Adapted from Energy Information Administration. 2003. The National Energy Modeling System: An Overview 2003. DOE/EIA-0581(2003). March. Washington, DC.

Figure 35. Overview of the NEMS Modeling Structure

Each of the demand modules uses nine U.S. Census Divisions, while electricity supply is represented by 13 regions, and other regional specifications are used elsewhere. Each module is independent of the others, and the integrating module orchestrates iteration towards the overall solution, which represents a partial equilibrium for the entire U.S. energy sector. While description here is limited to the Commercial Demand Module, DG is currently represented in 
the Residential Demand Module, the Electricity Market Module, the Industrial Demand Module, and to a lesser extent elsewhere in the Oil and Gas Supply Module, and the Petroleum Market Module. Additionally, customer-sited renewable technologies appear in the Renewable Fuels Module. This scatter, together with NEMS' diversity, makes an assessment of overall DG potential a major challenge. For example, incorporating waste heat driven absorption cooling capabilities into NEMS would require modifications to at least two of the demand modules and to incorporate DG applications in non-represented sectors would require modifications to each module individually. This work focuses on the commercial sector only, and therefore offers only an incomplete picture of DG potential. However, the commercial sector as defined by NEMS is broad and accounts for 35 percent of U.S. electricity and 20 percent of the U.S. natural gas consumption in year 2005 (Energy Information Administration 2005a). This sector is also increasingly the focus of DG R\&D.

EIA requires that any modified version of NEMS be named differently, to distinguish them from EIA's AEO Reference Case version. Throughout this paper, NEMS-DE is used to refer to the modified version used at the Berkeley Lab, while the AEO version of the model is referred to as simply NEMS. In this work, Berkeley Lab used the AEO2005 version as the starting point for out NEMS-DE version of the model.

\subsection{Overview of GPRA and DE}

The Government Performance and Results Act (GPRA) of 1993 was established to monitor the performance of Federal programs. Each Federal program is required to annually report multiyear strategic plans, annual performance plans, and annual performance reports associated with the request for the next upcoming budget under consideration (Government Accounting Office 2005). In this analysis, three different cases are discussed. The first is the AEO2005 Reference Case results, which represent EIA's official NEMS run used to produce the AEO2005. The second is the Baseline Case, which represents the AEO2005 Reference Case without the DE Program present. The third is referred to as the Program Case and represents the AEO2005 Reference Case with the DE office program goals in place. The GPRA benefits are then interpreted as the difference between the Program and Baseline cases.

For the past three years (since 2003), Berkeley Lab has been contracted by the DE R\&D Program to estimate the DE GPRA program benefits. The DE office of DOE was established in 2001 and represents a suite of advanced, on-site, small-scale, energy conversion and delivery systems for industrial, commercial, residential, and utility applications. The program is divided into two main research areas: distributed generation technology development and integrated energy systems (Distributed Energy Program 2005a).

On the technology side, the DE office focuses on:

- natural gas fired reciprocating engines with improved electrical efficiency, lowered $\mathrm{NO}_{\mathrm{x}}$ emissions, reduced overall costs, and improved fuel flexibility;

- industrial gas turbines with enhanced performance and lowered $\mathrm{NO}_{\mathrm{x}}$ and $\mathrm{CO}$ emissions;

- microturbines with high efficiency and low emissions; and

- thermally activated technologies such as absorption cooling/refrigeration and desiccant dehumidification systems 
The integrated systems branch of the DE office focuses on CHP applications by increasing awareness and improving the regulatory barriers associated with siting small-scale DG with CHP. The purpose of the integration program is to advance the packaging of DER technologies developed in the various technology programs with CHP capabilities.

To model these technology developments and integration goals, Berkeley Lab has traditionally used NEMS-DE. The next three sections explore the current structure of the NEMS commercial module, with a focus on how building types are defined, how the commercial DG submodule currently operates, and a discussion of the current limitations of NEMS.

\subsection{Commercial Building Representation in NEMS}

The commercial sector is divided into 11 building types: assembly, education, food sales, food services, healthcare (inpatient), lodging, large offices $\left(>4,645 \mathrm{~m}^{2}\right.$ including outpatient medical facilities of the same size), small offices $\left(\leq 4,645 \mathrm{~m}^{2}\right.$ including outpatient facilities), mercantile and service, warehouse, and other, i.e., laboratories, etc. These building types loosely correspond to the CBECS database developed by EIA (Energy Information Administration 2003a). Within the building types, NEMS considers 10 different energy consuming service classes: space heating, space cooling, ventilation, water heating, lighting, cooking, refrigeration, personal computers, other office equipment, and other. Additional input characteristics include building shell efficiency for new and existing buildings, age class of the building, floorspace sorted by each of the nine U.S. Census Divisions, energy use intensities, building type, and fuels. These parameters characterize an approximate distribution of buildings in the U.S. that are used to determine energy needs throughout the forecast and evaluate DG potential (Energy Information Administration 2005b). The next section explains how these commercial buildings are treated in NEMS for DG adoption.

\subsection{Overview of DG Treatment in the Commercial Demand Module}

The existing DG NEMS adoption modeling logic involves cost and performance characteristics of the defined DER technologies, an economic cash-flow analysis, a penetration function that implies a logistic curve for DG adoption over time, and consideration of waste heat for water heating or space heating. This section briefly summarizes the current NEMS logic in the DG adoption process. For a more detailed discussion please see Appendix A.

The commercial module has 10 different DER technologies, as shown in Table 18. The three DER technologies on which the DE Program conducts R\&D are shown in italics. These technology characteristics are provided as input to the model for determining the economic attractiveness of adopting DG. As shown in the DER-CAM results presented in Section 3, gas turbine adoption is not economic due to the small sizing of buildings considered in this study. The results in Section 5.8 show that gas turbines, shows the least adoption potential of the three technologies. Results therefore focus on gas engine and microturbine adoption. 
Table 18. Summary of AEO2005 NEMS Commercial DER Technology Types

\begin{tabular}{|c|c|c|c|c|c|c|c|}
\hline \multirow[t]{2}{*}{ Technology Name } & \multirow[t]{2}{*}{$\begin{array}{c}\text { Lifetime } \\
\text { (years) }\end{array}$} & \multirow[t]{2}{*}{$\begin{array}{c}\text { Capacity } \\
\text { Factor } \\
\text { (\%) }\end{array}$} & \multicolumn{2}{|c|}{$\begin{array}{c}\text { Conversion } \\
\text { Efficiency (\%) }\end{array}$} & \multicolumn{2}{|c|}{$\begin{array}{c}\text { Equipment Cost } \\
(2003-\$ / k W)\end{array}$} & \multirow[t]{2}{*}{ Size $(\mathbf{k W})$} \\
\hline & & & 2000 & 2025 & 2000 & 2025 & \\
\hline Solar Photovoltaic & 30 & 100 & 11 & 22 & 6500 & 2650 & 25 \\
\hline Fuel Cell & 20 & 86 & 36 & 52 & 5200 & 1450 & 200 \\
\hline Gas Reciprocating Engine & 20 & 86 & 31 & 34 & 1160 & 915 & 200 \\
\hline Gas Turbine & 20 & 86 & 22 & 28 & 1600 & 1340 & 1000 \\
\hline Microturbine & 20 & 86 & 25 & 39 & 1926 & 818 & 200 \\
\hline Conventional Coal & 20 & 86 & 30 & 30 & & & 200 \\
\hline Conventional MSW & 20 & 86 & 14 & 14 & & & 200 \\
\hline Conventional Oil & 20 & 86 & 31 & 31 & 1390 & 990 & 200 \\
\hline Biomass & 20 & 86 & 7 & 7 & & & 1500 \\
\hline Hydroelectric & 20 & 86 & 29 & 29 & & & 1000 \\
\hline
\end{tabular}

\subsubsection{Cash-Flow Approach}

Commercial sector DG adoption in NEMS is determined by a submodule that uses a cash-flow analysis to evaluate the economic attractiveness of a DG system in a given building, region, and year. The adoption rate of DG in new and existing construction is determined by how quickly an investment in DG takes to recover its costs. For each potential DG purchase in the commercial sector, a 30-year cash flow analysis is performed. The result is the number of years required to reach a positive cash flow. If the net return is positive, the cumulative net cash flow increases. In some cases, the cash flow is never positive and the number of years is set to 30 . Please see Appendix A for further explanation of this analysis.

\subsubsection{NEMS DG Adoption Logic}

For every year in the NEMS forecast analysis, a given technology payback based on the cash flow analysis is calculated for the 99 different combinations of 11 building types and nine Census Divisions. The payback value determines the total capacity installations for each year based on defined market penetration curves. The penetration values correspond to a share of the new building market, while the existing building market automatically adopts the lesser of 0.5 percent of the existing construction or 2 percent of what the new building market does.

Caps are set on DG penetration in both new and existing buildings, but the submodule imposes strict limits on DG installations in the existing stock by imposing a much stricter limit. Building starts and stock together with the results from the cash flow analysis are passed into the penetration function, which uses a logistic curve to determine adoption. The submodule then tallies up the amount of DG installed and assumes any excess waste heat available to supply water heating or space heating demand. As discussed above, there is no consideration of thermally activated cooling. The average electricity and hot water consumption is used to determine any need that DG cannot offset. Additionally, the submodule checks whether excess DG generation is available for sales back to the grid, and if so, passes them back to the Electricity Market Module, while natural gas requirements for DG fuel are added to commercial 
sector gas consumption (LaCommare et al. 2003). Capacity additions therefore depend on both the years to positive payback and the shape of the penetration curves. The following subsection summarizes some of the important limitations Berkeley Lab has found in the NEMS approach to modeling DG.

\subsection{Limitations to the NEMS DG Adoption Logic}

A number of limitations in the DG submodule of NEMS can be identified to help explain why the ComSeM approach is needed.

NEMS only focuses on DG penetration in new structures. The retrofit penetration is a fixed fraction of new. The limitation on the number of commercial DG retrofit installations into existing buildings was relaxed from 0.5 percent to 10 percent of the existing construction per year in the GPRA analysis. More specifically, the constraint is the lesser of 0.5 percent of all existing buildings in a given year or the DG penetration rate in new construction divided by 50 . According to the model documentation, this is only binding if the penetration in new construction is greater than 25 percent. Either assumption would be quite arbitrary, making the absence of direct treatment of existing buildings a major handicap.

Demand charges on commercial electricity bills are not explicitly included in the NEMS payback calculation. Average commercial electricity rates are generally in the range of 6-9 U.S. $\phi / \mathrm{kWh}$. This range corresponds to average commercial costs for electricity, but does not consider the effect of commercial demand charges, which tend to favor peak reductions. The undervaluation of on-peak electricity together with the absence of absorption cooling is a major impediment to DG.

Additionally, there is only a single rated capacity option for each DER technology, which does not allow technologies to be optimized for building sizes. This is a more serious disadvantage than it may seem because the capacity factor of the equipment is fixed and any excess electricity must be sold at the unattractive wholesale price, i.e., at a loss.

DER technologies do not have waste heat driven absorption cooling capabilities. With previous GPRA analyses, Berkeley Lab made crude assumptions including that the cooling option lowered paybacks by one year, or have tried to incorporate these benefits in a rudimentary way using an exogenous spreadsheet model that estimates any potential reductions in the years to positive payback calculation used in NEMS-DE. However, this consideration was added only for gas reciprocating engines and microturbines. This selective enhancement showed that healthcare, lodging and large offices are the buildings with the greatest absorption cooling potential and the northeast and southwest are the most favorable regions, but in general the penetration of cooling technologies is low. Also, as explained below, adoption is only sensitive to payback over a narrow range of paybacks. That is, the DG payback calculation is on a knife edge, being highly sensitive to small variations in input parameters, changing from a high to a low value over a narrow range of inputs. In addition, the number of years until a positive cumulative net cash flow is highly dependent on the assumptions of system down payment, which is fixed at 25 percent in NEMS-DE. 
With these aforementioned limitations, Berkeley Lab set out to improve the way DE is modeled for the GPRA analysis. Ideally, improvements would directly address the NEMS-DE coding and structure. However, the daunting nature of this task forced Berkeley Lab to explore exogenous options as discussed in Sections 3 and 4. Under the ComSeM approach, adoption is determined outside of NEMS-DE using DER-CAM, then scaled to all regions using DER-MaDiM. The next section discusses the cost and performance assumptions used in both the traditional and ComSeM approaches and Section 5.7 explains how the exogenously calculated DG benefits are fed back in NEMS-DE.

\subsection{Cost and Performance Assumptions}

In both the traditional and ComSeM approaches, cost and performance assumptions for the three commercial DER technologies are the same. In the traditional approach, NEMS determines the adoption using cost and performance assumptions as input, whereas in the ComSeM approach, these assumptions are inputs to DER-CAM that are used to make the adoption decision. These assumptions represent the program goals provided to Berkeley Lab by the DE office. Figure 36, Figure 37, and Figure 38 represent the installed cost (2003-\$/kW), electrical efficiency (\%), and combined efficiency (\%) trajectories assumed for each of the three DER technologies in the Baseline and Program cases, respectively. ${ }^{9}$ These figures represent assumed typical sizes for these technologies: $1 \mathrm{MW}$ gas reciprocating engine (GE), $5 \mathrm{MW}$ gas turbine (GT), and $200 \mathrm{~kW}$ microturbine (MT).

Figure 36 shows the accelerated decline of the gas engine and microturbine costs in the Program case relative to the Baseline. For the Baseline, the general assumption used is a 10-year lag, whereby the installed cost of these technologies in the Baseline is assumed to lag the Program case by 10 years. No changes to the gas turbine installed cost are attributed to the DE Program goals.

\footnotetext{
${ }^{9}$ Combined efficiency here is a simple higher heating value useful energy out of fuel in value.
} 


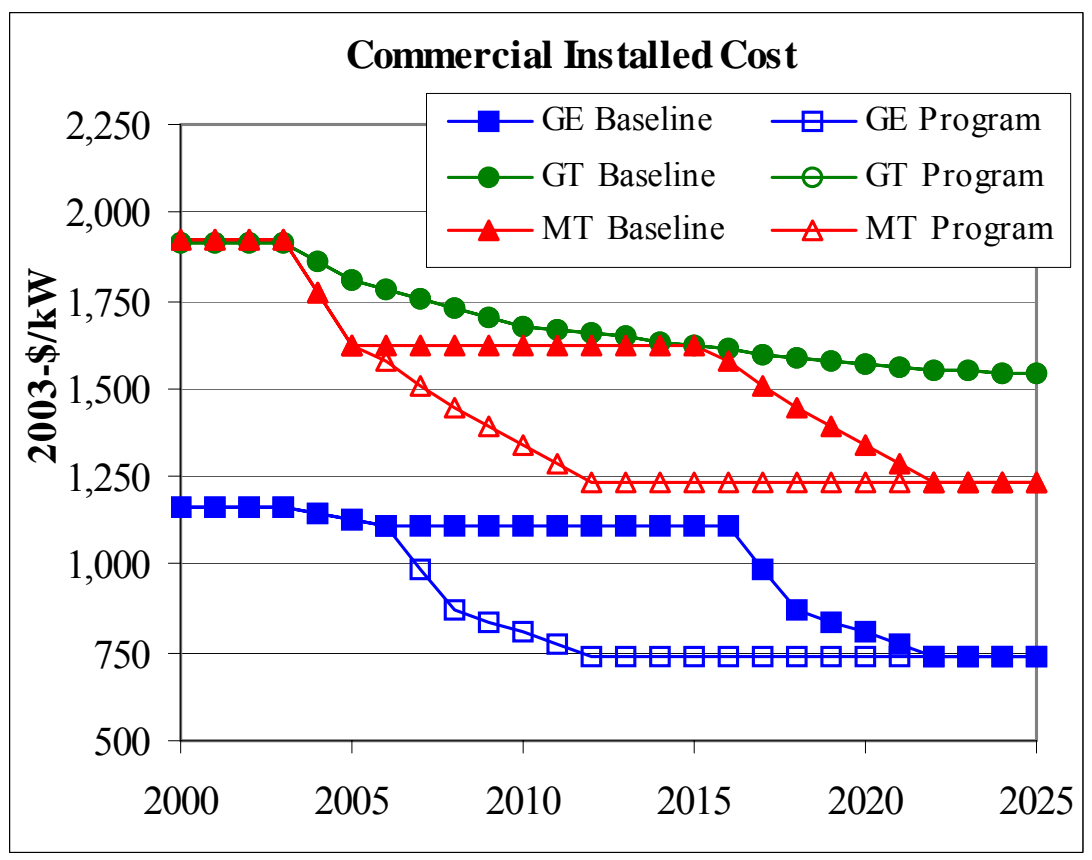

Figure 36. Installed Cost Assumptions for Three Commercial DER Technologies

Figure 37 shows the comparable illustration for the electric heat rate. Heat rate improvements are predicted for all three commercial DER technologies. Again, the ten-year lag is assumed to determine the Baseline projection from the Program case. The gas engine achieves the highest heat rate of 39.5 percent in the Program case.

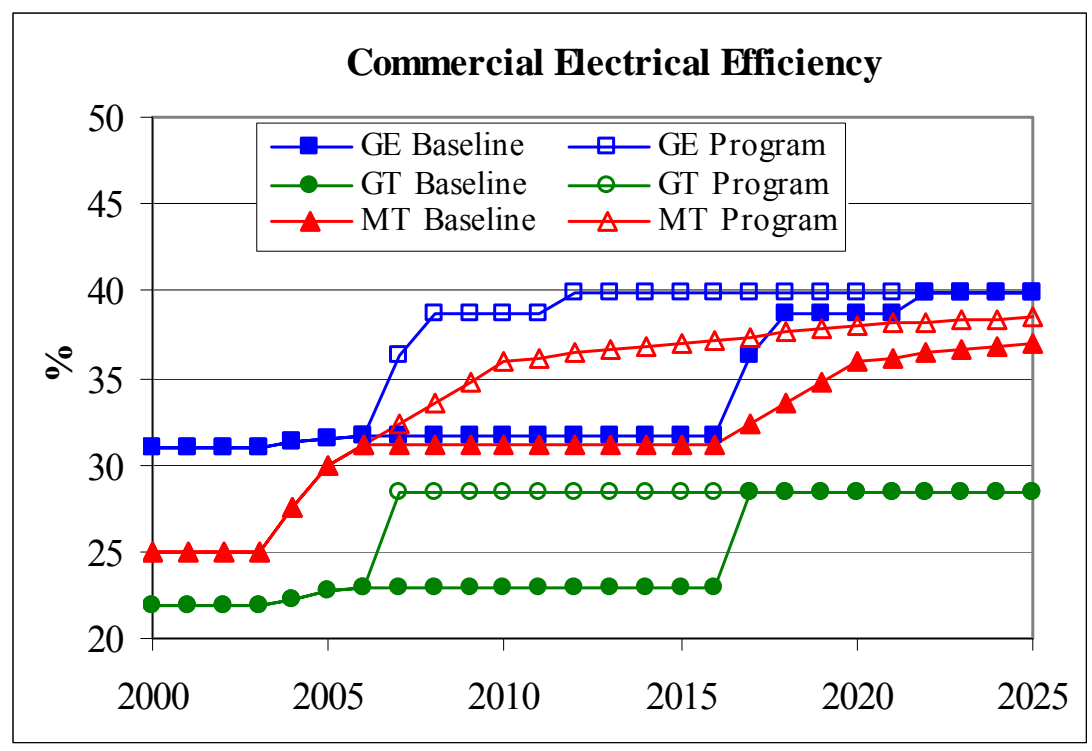

Figure 37. Electric Heat Rate Assumptions for Three Commercial DER Technologies

Figure 38 shows the combined efficiencies where again the Baseline case represents a ten-year lag of the Program case. The combined efficiency goals are achieved by 2012 in the Program case. Once more, the gas engines achieve the highest combined efficiency target of 82 percent by 2012 for a typical 1 MW size unit. 


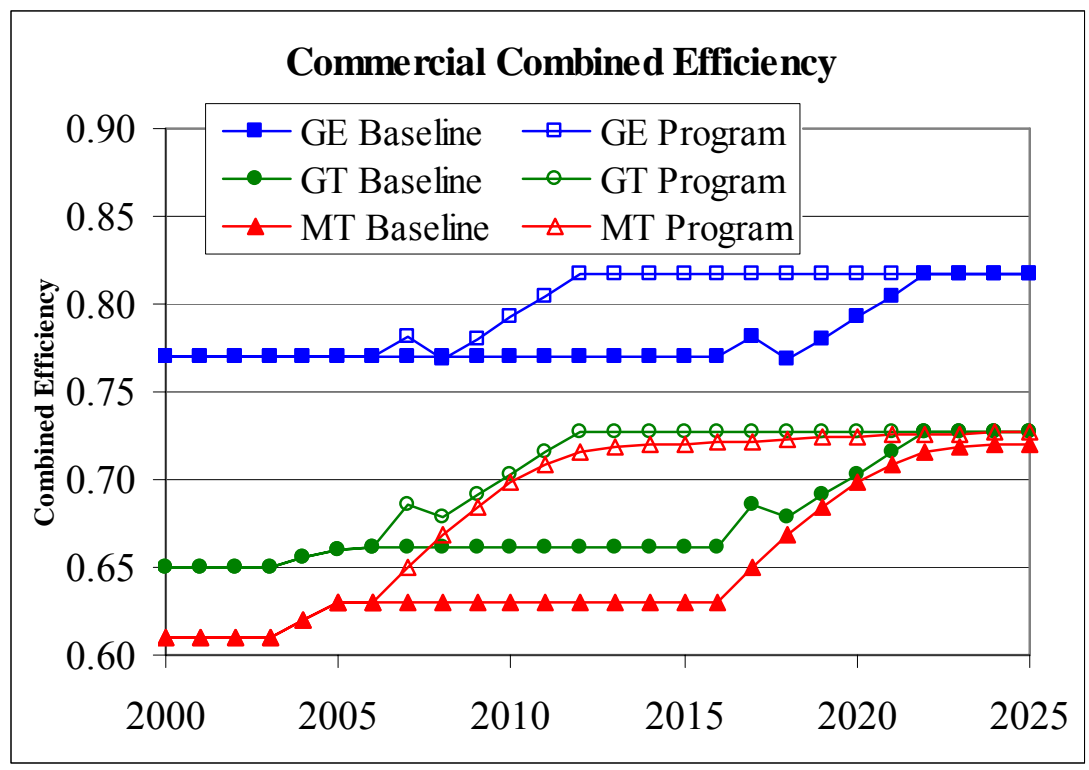

Figure 38. Combined Efficiency Assumptions for Three Commercial DER Technologies

The cost and performance assumptions for these three DER technologies are directly input to NEMS-DE in the traditional approach, and as input to the DER-CAM modeling in the ComSeM approach. The following section details the NEMS-DE modeling step of the ComSeM approach.

\subsection{Incorporating the ComSeM Approach for Modeling Commercial DG Adoption to NEMS-DE}

The final stage of the ComSeM approach involves incorporating the DER-MaDiM model results presented in Section 4 back into NEMS-DE.

In order to allow ComSeM results to be read back into NEMS-DE, the adoption logic in NEMSDE needed to be turned off. However, because only three of the 10 commercial DER technologies were modeled exogenously for the DE GPRA analysis, the entire submodule could not be turned off without inadvertently hindering the advancement of other commercial DER technologies, i.e. solar PV and fuel cells. To address this concern, NEMS adoption from commercial gas engines, gas turbines, and microturbines was turned off by inflating the capital cost of these select technologies to over $100,0002003-\$ / \mathrm{kW}$ for all forecast years. This modification prevents any economically-driven DG adoption in these technologies. Forced or planned adoption of these DER technologies reflected in the AEO2005 version of NEMS, which are likely the result of legislation mandating specified levels of certain DER technologies, was left intact.

The DER-MaDiM results are fed back into NEMS-DE for the Baseline and Program cases. Each case is run separately and the GPRA DE benefits are determined as the difference between these two cases. Three DER-MaDiM result variables are input to NEMS-DE: site electricity decrement, site natural gas consumption increment, and forced DG capacity additions. Energy expenditures were also output from this diffusion model, however problems with incorporating these changes into NEMS-DE have not yet been resolved; therefore, energy expenditures are 
calculated solely within NEMS-DE. For reasons still unknown, the NEMS energy expenditures actually increase in the Program relative to the Baseline case, whereas the DER-CAM and DERMaDiM results show savings of energy expenses as expected.

The electricity decrement and natural gas increment are read in for each forecast year from 2007 to 2025 , by Census Division, by building type in trillion Btu and applied to the commercial electricity and natural gas end-use consumption parameter. The electricity savings reduce the electric space cooling end use, while the natural gas increment raises the natural gas space heating end use. The space cooling and space heating end uses were chosen to match the likely affected load associated with electricity or natural gas changes. The forecasted DG adoption from DER-MaDiM is incorporated as a forced build in a commercial input file by Census Division by DER technology type and by year. Unfortunately, these forced builds are not partitioned by building type so one of the last steps of the DER-MaDiM model was to aggregate the adoption across building types to accommodate the NEMS-DE format.

Although this paper focuses on DG in the commercial sector, there are some technologies defined in the industrial and electric utility sectors that are also covered under the DE program goals. This includes industrial natural gas reciprocating engines up to $7 \mathrm{MW}$ and turbines up to $20 \mathrm{MW}$ and utility-owned DG units defined in the Electricity Market Module of NEMS-DE (Distributed Energy Program 2005b; Distributed Energy Program 2005c). To ensure the DEGPRA analysis is complete and incorporates all technologies, both the industrial and EMM DG are modeled using the same assumptions used in the traditional approach. That is, changes to capital cost, electrical heat rate, and combined heat rate are applied to the appropriate input files and NEMS-DE is responsible for determining the level of economic attractiveness of these noncommercial DER technologies.

With the input modifications to NEMS-DE in place, the following subsection presents results from the ComSeM Baseline and Program cases with some comparison to the traditional approach results.

\subsection{Results}

Figure 39 shows a series of pie charts for each building type, representing the AEO2005 share of DG adoption relative to the total floorspace forecast in year 2025. The size of each pie represents the share of each building's total commercial floorspace relative to the total floorspace across all commercial buildings. Each of the three commercial DER technologies in focus are shown, where the "other" category represents other non-DER technologies, e.g., central station natural gas combined cycle plant, as well as other DER technologies, e.g., solar PV, used to serve the commercial sector demand. This figure shows that in the Reference Case, even by 2025, DG in the commercial sector still does not serve a significant share of this sector's total floorspace. Only the healthcare sector provides even a noticeable share of the total at slightly over 5 percent. While it is not feasible to expect DG adoption to account for more than half the total floorspace, it is clear that DG has a lot of potential for increased penetration in the commercial sector. 

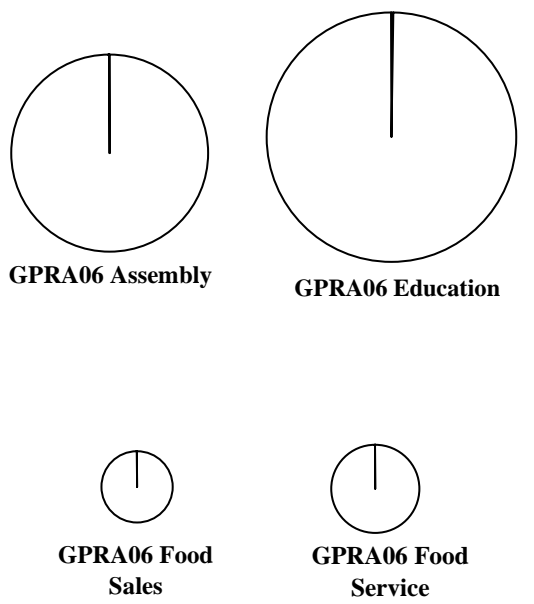
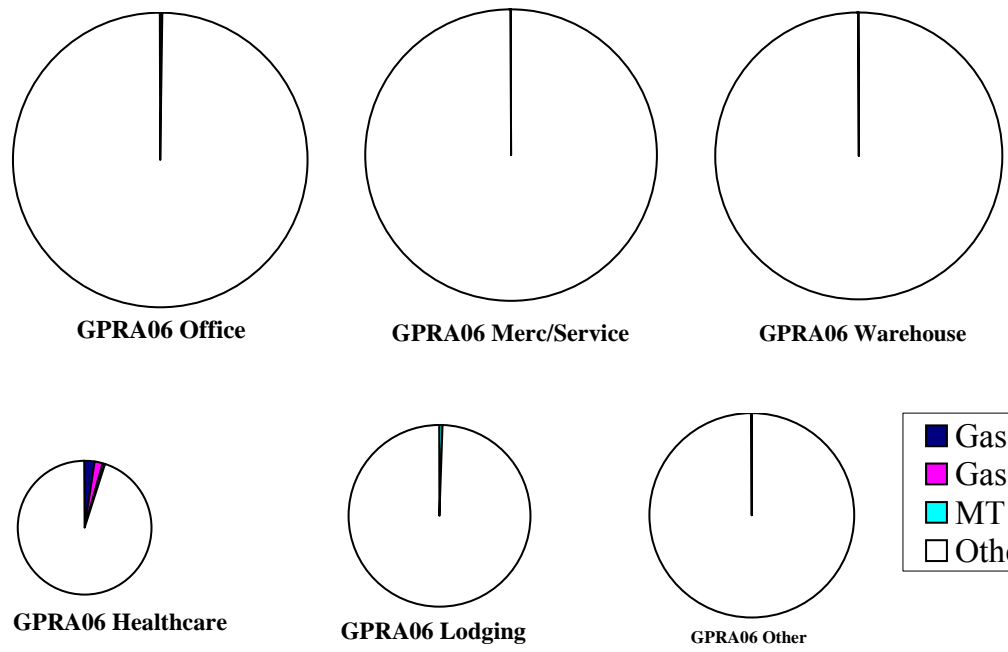

Gas Eng $\square$ Gas Turb $\square \mathrm{MT}$ $\square$ Other

Figure 39. AEO2005 Commercial DG 2025 Adoption as Share of Total Floorspace

Figure 40 and Figure 41 show a similar illustration for the Baseline and Program cases, respectively using the ComSeM approach. In both cases, the buildings showing the greatest potential for DG are offices and healthcare, and to a lesser extent education and lodging buildings. In large offices, the adoption is split evenly between gas engine and microturbine adoption, while in healthcare more than half of the DG adoption is from gas engines and the remainder from microturbines.

In general, gas turbine adoption is minimal. Again, the adoption level of gas engines, gas turbines, and microturbines are pre-determined by DER-CAM and DER-MaDiM, but are shown here to provide perspective on how these adoption levels compare to the forecasted demand of the commercial sector using floorspace. Although the "other" category in these pie charts include both other commercial DG as well as non-DER technologies like solar PV or fuel cells. A brief analysis revealed that virtually all of it is DG. For example, 96 percent of the Baseline adoption of commercial DG is from gas engines, gas turbines, or microturbines, leaving only 4 percent from other commercial DER technologies. In the Program case, this ratio is 97 percent and 3 percent, respectively. 

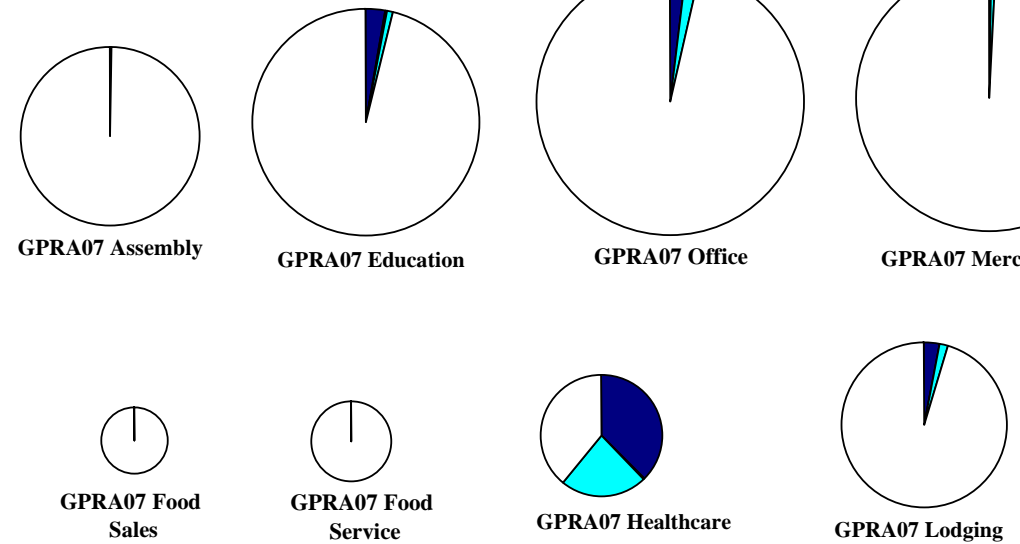
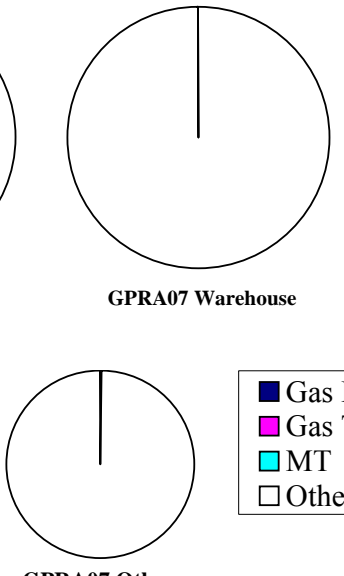

Figure 40. ComSeM Baseline Commercial DG 2025 Adoption as Share of Total Floorspace
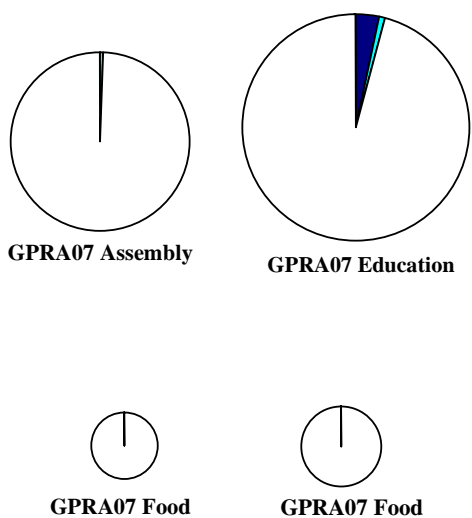

Sales

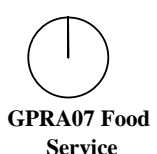

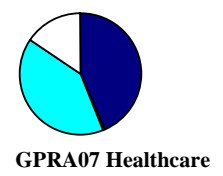
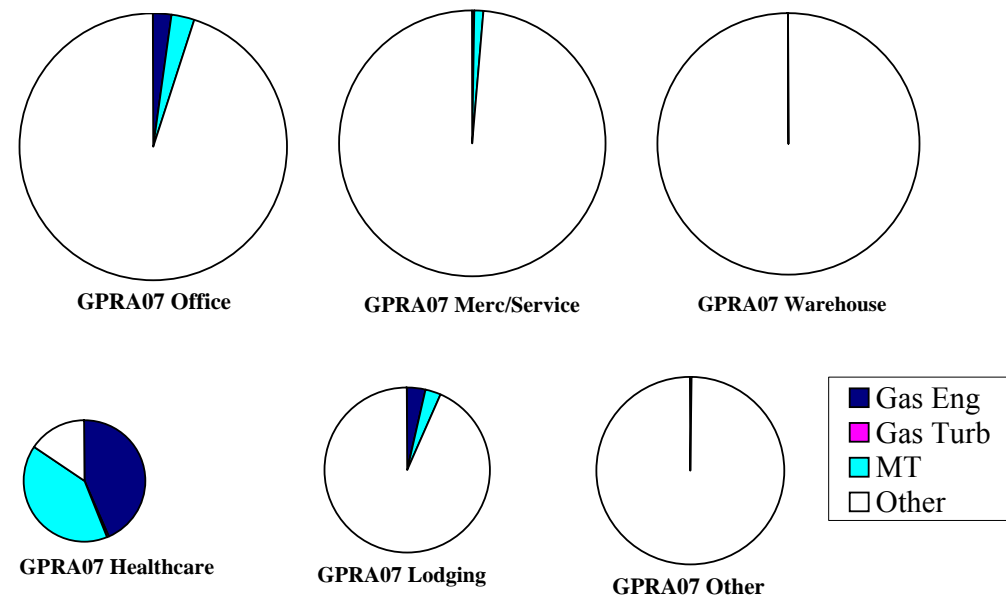

Figure 41. ComSeM Program Commercial DG 2025 Adoption as Share of Total Floorspace

Figure 42 and Figure 43 show the comparable figures using the traditional approach. Overall, net DG adoption between Baseline and Program is moderately higher using the traditional approach over the ComSeM approach, 8.2 GW versus 6.6 GW more in 2025. In general, the traditional approach shows more adoption in the lodging sector and less in large offices and healthcare. The lower DG adoption using the ComSeM approach over the traditional approach is likely due to the high natural gas price forecast taken from the AEO2005 Reference Case that hinders any further adoption in the Program case over the Baseline case. 

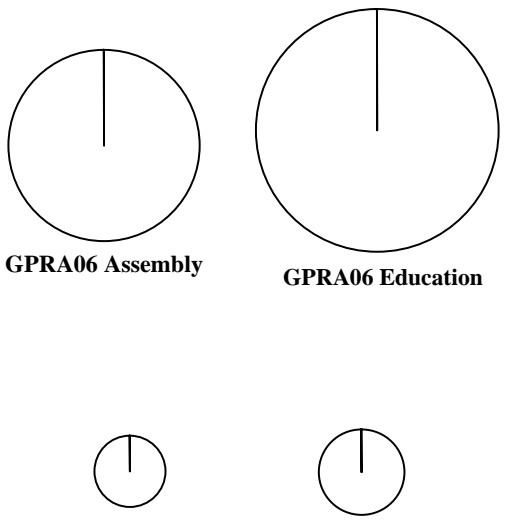

GPRA06 Food Sales

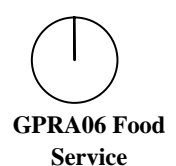

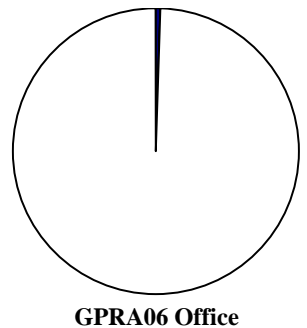
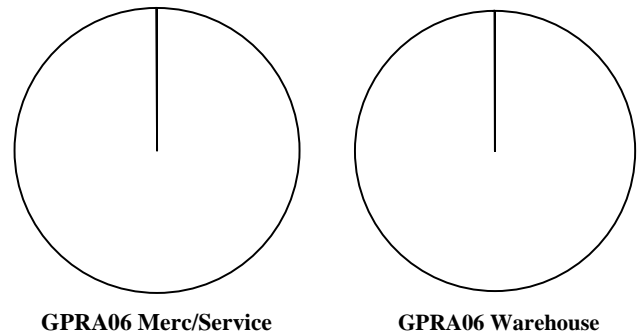

GPRA06 Warehouse

Figure 42. Traditional Approach Baseline Commercial DG 2025 Adoption as Share of Total Floorspace
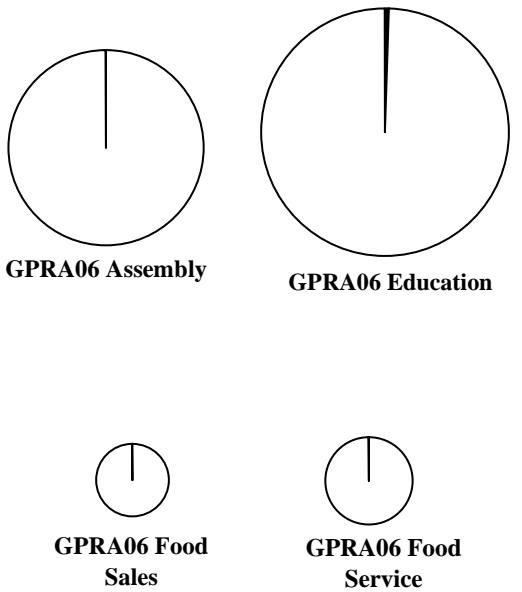
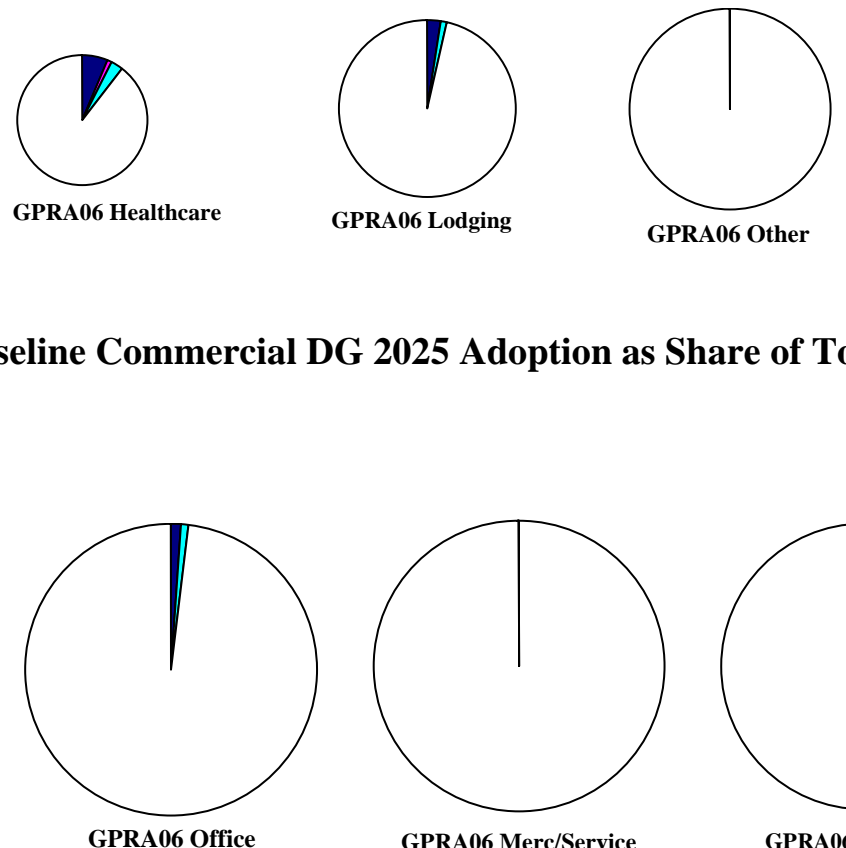

Gas Eng $\square$ Gas Turb $\square \mathrm{MT}$

$\square$ Other

Figure 43. Traditional Approach Program Commercial DG 2025 Adoption as Share of Total Floorspace

Table 19 and Table 20 show a summary of the 2025 results in tabular form based on the ComSeM approach and the traditional approach, respectively. What is interesting to note in these tables is that although the incremental 2025 commercial DG adoption is lower using the ComSeM approach, the total commercial DG adoption is significantly higher using ComSeM. For example, the AEO2005 forecasts only $1.8 \mathrm{GW}$ of commercial DG capacity in 2025, while the Baseline using the ComSeM approach forecasts $17.0 \mathrm{GW}$, and the Baseline using the traditional approach is only $4.5 \mathrm{GW}$. This is a significant difference of $12.5 \mathrm{GW}$ that is easily overlooked when measuring the DE GPRA benefits as the difference between the Baseline and Program cases. Although no one obvious reason can explain why the ComSeM Baseline results 
in 12.5 GW more DG over the traditional approach Baseline because the structural differences in the DG modeling from each approach are so major. As mentioned earlier, one limitation with the NEMS-DE approach is that the commercial module only allows one $\mathrm{kW}$ size per technology, a key disadvantage that DER-CAM is able to overcome by properly sizing DG units to customer loads. Note that "Total DG" in this section of results includes CHP adopted in both the commercial and industrial sectors because the DE Program is able to take credit for these largerscale benefits.

Table 19. Summary of 2025 Results Using ComSeM Approach

\begin{tabular}{|c|cccccc|}
\hline & $\begin{array}{c}\mathbf{C O}_{2} \\
\text { Emissions } \\
\text { (Mt/a) }\end{array}$ & $\begin{array}{c}\text { Primary } \\
\text { Energy } \\
\text { Consumption } \\
\text { (EJ) }\end{array}$ & $\begin{array}{c}\text { Energy } \\
\text { Expenditures } \\
\text { (billion 2003-\$) }\end{array}$ & $\begin{array}{c}\text { Commercial } \\
\text { DG } \\
\text { Capacity } \\
\text { (GW) }\end{array}$ & $\begin{array}{c}\text { Other } \\
\text { Small- } \\
\text { Scale DG } \\
\text { Capacity } \\
\text { (GW) }\end{array}$ & $\begin{array}{c}\text { Total } \\
\text { DG }\end{array}$ \\
\hline $\begin{array}{c}\text { AEO2005 } \\
\text { Reference }\end{array}$ & 8,060 & 133.2 & 1,059 & 1.8 & 92 & 94 \\
Baseline & 8,004 & 132.7 & 1,061 & 17.0 & 107 & 124 \\
Program & 7,903 & 131.6 & 1,065 & 23.6 & 157 & 181 \\
Difference P-B & -101 & -1.1 & 4.0 & 6.6 & 51 & 57 \\
$\begin{array}{c}\text { Difference as } \\
\text { \% of Baseline }\end{array}$ & $-1.3 \%$ & $-0.8 \%$ & $0.4 \%$ & $38.8 \%$ & $47 \%$ & $46.1 \%$ \\
\hline
\end{tabular}

Table 20. Summary of 2025 Results Using Traditional Approach

\begin{tabular}{|c|cccccc|}
\hline & $\begin{array}{c}\mathbf{C O}_{2} \\
\text { Emissions } \\
\text { (Mt/a) }\end{array}$ & $\begin{array}{c}\text { Primary } \\
\text { Energy } \\
\text { Consumption } \\
\text { (EJ) }\end{array}$ & $\begin{array}{c}\text { Energy } \\
\text { Expenditures } \\
\text { (billion 2003-\$) }\end{array}$ & $\begin{array}{c}\text { Commercial } \\
\text { DG } \\
\text { Capacity } \\
\text { (GW) }\end{array}$ & $\begin{array}{c}\text { Other } \\
\text { Small- } \\
\text { Scale DG } \\
\text { Capacity } \\
\text { (GW) }\end{array}$ & $\begin{array}{c}\text { Total } \\
\text { (GW) }\end{array}$ \\
\hline $\begin{array}{c}\text { AEO2005 } \\
\text { Reference }\end{array}$ & 8,060 & 133.2 & 1,059 & 1.8 & 92 & 94 \\
Baseline & 8039 & 132.9 & 1057 & 4.5 & 111 & 115 \\
Program & 7940 & 131.9 & 1057 & 12.7 & 164 & 177 \\
Difference P-B & -99 & -1.0 & 0.0 & 8.2 & 53 & 61 \\
$\begin{array}{c}\text { Difference as } \\
\text { \% of Baseline }\end{array}$ & $1.2 \%$ & $0.8 \%$ & $0 \%$ & $182 \%$ & $48 \%$ & $53 \%$ \\
\hline
\end{tabular}


Reference Case total installed DG is dominated by CHP. In the AEO2005 Reference Case, the $94 \mathrm{GW}$ of total forecasted DG in 2025 is made up of $87 \mathrm{GW}$ (or 93 percent) CHP and $7 \mathrm{GW}$ (or 7 percent) of non-CHP utility sector DG. In the ComSeM Baseline, this breakdown is 85 percent and 15 percent, respectively and in the Program case is 73 percent and 27 percent, respectively. This means that a large share of the increasing total DG is due to DG adoption in the utility sector. Of the $57 \mathrm{GW}$ of incremental DG forecasted under the ComSeM Program case shown in Table 19, roughly half $(28 \mathrm{GW})$ is from CHP with the other half $(29 \mathrm{GW})$ is made up of nonCHP DG from the utility sector. Figure 44 illustrates the significant share of non-CHP DG in the utility sector to total DG from NEMS-DE using the ComSeM approach.

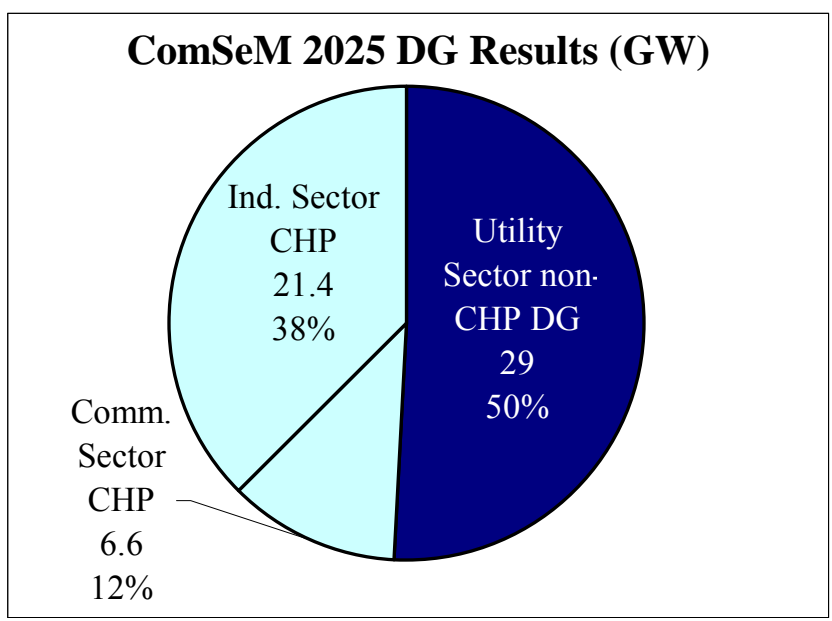

Figure 44. ComSeM Total DG Adoption for Program Case by 2025

Of the $28 \mathrm{GW}$ CHP increase, only $6.6 \mathrm{GW}$ is from commercial sector DG with the remainder from large scale industrial sector gas turbines. The incremental results highlight the sensitivity of the utility sector DG adoption decision, something that still requires further analysis and understanding.

\subsection{A Comparison to External Literature}

To put the ComSeM NEMS-DE results into perspective, Berkeley Lab provided a comparison with other external studies that have recently estimated the future potential of CHP in the U.S.

Looking at a recent study by Paul LeMar of Resource Dynamics Corporation, the 2020 market potential of CHP in the commercial and institutional sectors is $35.5 \mathrm{GW}$. Comparing this to the $52 \mathrm{GW}$ incremental DG in 2025 and noting that only $28 \mathrm{GW}$ is CHP and of that only $6.6 \mathrm{GW}$ is from the commercial sector, our ComSeM analysis is less than 20 percent of LeMar's estimate five years earlier than the Berkeley Lab's 2025 result. The LeMar study focuses on the End-Use Integration branch of the DE Program so is directly addressing the CHP potential considered by the DE Program. It is important to note that his study presents the CHP potential and therefore should be greater than the predicted real world forecasted U.S. CHP level. That said, this study 
indicates the importance of advancing the CHP program to maximize the forecasted CHP potential (Resource Dynamics Corporation 2002).

In a second study by OnSite Consulting, the total commercial sector CHP potential is estimated at $77 \mathrm{GW}$ in year 2005 , of which only $5 \mathrm{GW}$ is currently installed, leaving $72 \mathrm{GW}$ of remaining CHP potential. Figure 45 shows the breakdown of the $77 \mathrm{GW}$ of total CHP potential by building type. Almost three-quarters of the total are from offices, education, and healthcare buildings, each showing 16-18 GW of potential CHP.

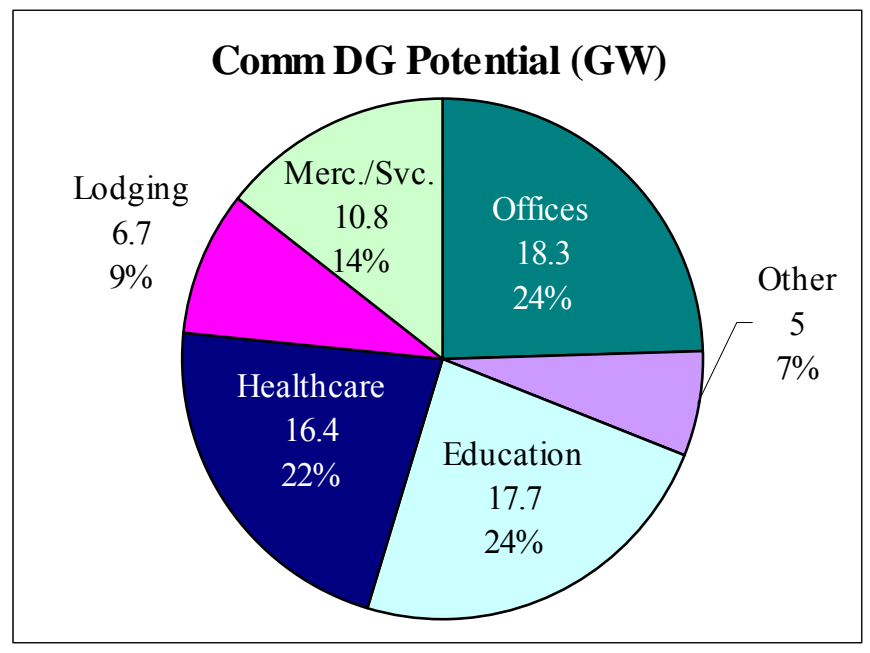

Figure 45. OnSite Sycom Commercial CHP Potential by Building Type

For comparison, Figure 46 shows how this CHP potential compares to what the ComSeM approach predicts will be adopted by 2025 . This figure breaks down by building type the $6.6 \mathrm{GW}$ of total commercial DG capacity predicted by 2025 . Not surprisingly, office buildings also make up a large share of the pie with $1.9 \mathrm{GW}$ of adoption. The mercantile, education, lodging and healthcare buildings also show notable levels of adoption not too different from the OnSite study. The mercantile/service sector surprisingly makes up a similar share of each respective pie.

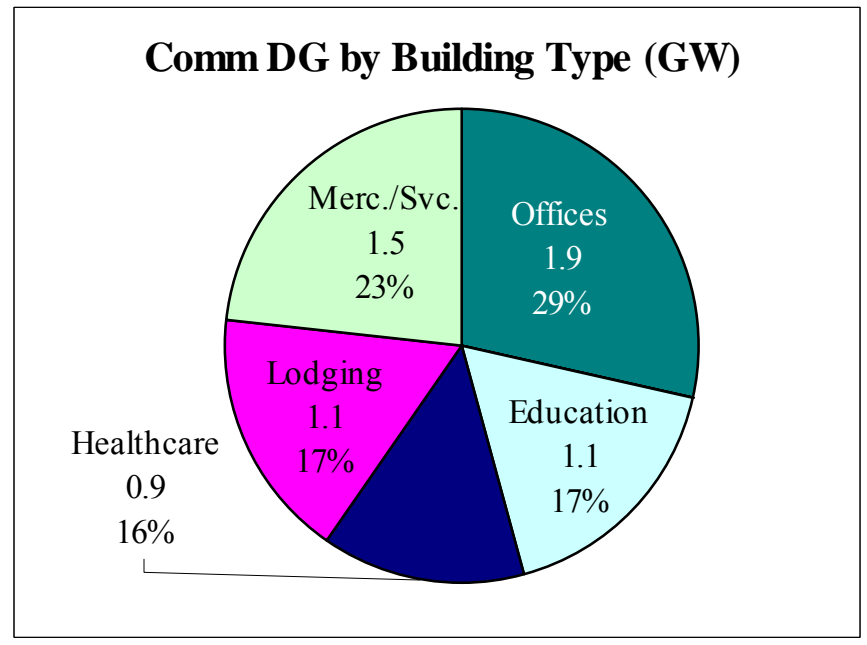

Figure 46. Incremental ComSeM Commercial DG Adoption by Building Type by 2025 
The On-Site study shows that the greatest potential exists in California, Texas, and Florida and many northeast states. Of the $77 \mathrm{GW}$ total CHP potential, $26 \mathrm{GW}$ is predicted to come from 100 $\mathrm{kW}-500 \mathrm{~kW}$ sized applications. This study suggests a huge potential for CHP in the commercial sector (Onsite Sycom Energy 2000).

Thus, both external studies offer hope that CHP benefits could significantly increase with more DE R\&D, while serving as confirmation that ComSeM results fall well short of the independent estimates of potential.

\subsection{Summary of NEMS-DE Analysis}

In the NEMS-DE stage of the ComSeM process, the existing DG adoption logic is turned off and the independently estimated DG adoption directly injected. Although incremental DG benefits show a decline from the traditional approach, overall, the total DG adopted in the ComSeM Program case is almost $11 \mathrm{GW}$ higher in 2025 at $23.6 \mathrm{GW}$ compared to $12.7 \mathrm{GW}$ using the traditional approach. In general, the building types indicating DG adoption are roughly the same in both approaches, with the most likely adoption in healthcare, large offices, and education. The traditional approach shows somewhat more adoption in the lodging sector. As well, both approaches indicate minimal adoption of commercial gas turbines. A comparison to external studies indicates that the ComSeM results are well within reason of the stated potential for CHP in the U.S. More work is needed to improve the energy expenditures parameter, making sure it reflects the ComSeM analysis instead of allowing NEMS to calculate it. In addition, the NEMSDE analysis reveals the sensitivity of the utility sector DG adoption, indicating that the incremental DG increase comprises roughly half of the DE Program benefits. 


\section{Conclusions}

Berkeley Lab performed an extensive analysis to develop an alternative approach to modeling the benefits of DG in the commercial sector. The new approach, called ComSeM, was developed as a four-step process designed to improve the modeling capability of DG benefits for the DE Program as part of the annual GPRA exercise.

To summarize, in the first step DOE-2 was used to develop 40 sets load profiles to represent the broad spectrum of buildings across the U.S. These cover four target cities, and five building types, each with a small and large size. The second step then uses these load profiles together with the DER technology cost and performance assumptions to determine the DG potential for the 40 representative buildings. The DER-MaDiM diffusion model is then used as the third step to scale the DER-CAM results to sensible adoption levels for all buildings and regions of the U.S and all forecast years from 2007-2025. The final step is then to feed the DER-MaDiM results back into NEMS-DE for final reporting of all other key results.

Our key findings from this study are:

- The DOE-2 generated load profiles reveal the diversity of load profiles in U.S. commercial buildings. Building-specific findings include that space heating in healthcare peaks at night because of the high occupancy. High space cooling during the day is required to maintain a high level of air circulation. Water heating load is also high in healthcare buildings. The office and mercantile buildings have significantly higher heating load in winter than in summer. On a regional level, San Francisco space cooling and heating loads are lower than in Boston, Chicago or Atlanta. San Francisco also has surprisingly little seasonal variation.

- The DER-CAM analysis shows a strong correlation between high DG potential and high electricity rates with the greatest adoption in San Francisco and Boston and none in Atlanta. A noticeable technology shift from gas reciprocating engines to microturbines is evident over the forecast period and, in general, DG adoption increases over time. Gas turbines are not favorable in any of the small-sized buildings with high thermal loads considered in this study.

- The DER-MaDiM diffusion modeling represents a mix of different diffusion modeling approaches that extend the DER-CAM results to all buildings in the U.S. and show that the market for DG in the U.S. is large. DG adoption over time is represented by an S-curve. Both Baseline and Program cases exhibit this temporal adoption shape, although the Baseline progresses at a slower pace. The diffusion modeling assumptions reveal that improving DER technology characteristics, word of mouth, and enhanced outreach programs can significantly affect DG growth. And as expected, the West region, which is dominated by California with its high electricity prices and moderate cooling demand and the Northeast, are well suited for DG adoption.

- The NEMS-DE analysis presents the DG adoption results in the context of a large energy sector model. A comparison of the alternative ComSeM results with the traditional approach results indicate an overall net reduction in DG adoption using the ComSeM approach from 
$8.8 \mathrm{GW}$ down to $6.6 \mathrm{GW}$ in 2025 . However, this reduction overshadows the significant increase in total DG adoption in the Baseline case, forecasting an additional $11 \mathrm{GW}$ of commercial DG in the ComSeM Baseline over the traditional approach Baseline by 2025 . This difference reflects the wildly different modeling structures assumed in each approach. 


\section{References}

Bailey, O. C., and C. Marnay. 2005. Distributed Energy Resources at Naval Base Ventura County Building 1512: A Sensitivity Analysis. Lawrence Berkeley National Laboratory. LBNL55340 Pt. 2. June. Berkeley CA.

Boedecker, E., J. Cymbalsky, and S. Wade. 2000. Modeling Distributed Electricity Generation in the NEMS Buildings Models. EIA. Washington, DC.

Distributed Energy Program. 2005a. "About the Distributed Energy Program." DOE/EERE. http://www.eere.energy.gov/de/about.html. July.

Distributed Energy Program. 2005b. "Advanced Generation: Advanced Industrial Gas Turbines." DOE/EERE. http://www.eere.energy.gov/de/pdfs/advanced_industrial gas turbines.pdf. July.

Distributed Energy Program. 2005c. "Advanced Reciprocating Engines Systems (ARES) Program: Technology Overview." DOE/EERE. http://www.eere.energy.gov/de/pdfs/ares program.pdf. July.

Energy Efficiency Standards Group. 2005. "Tariff Analysis Project." Lawrence Berkeley National Laboratory. http://tariffs.lbl.gov/. July.

Energy Information Administration. 2003a. 2003 Commercial Buildings Energy Consumption Survey (CBECS). EIA/DOE. Washington D.C.

Energy Information Administration. 2003b. The National Energy Modeling System: An Overview 2003. EIA/DOE. March 2003. Washington D.C. 72.

Energy Information Administration. 2005a. Annual Energy Outlook 2005. EIA/DOE. DOE/EIA0383(2005). February. Washington D.C. 233 pages.

Energy Information Administration. 2005b. Commercial Sector Demand Module of the National Energy Modeling System, Model Documentation 2005. EIA/DOE. DOE/EIA-M066. May 2005. Washington D.C. 203 pages. 
Firestone, R. 2004. "Distributed Energy Resources Customer Adoption ModelTechnology Data." Lawrence Berkeley National Laboratory. http://der.lbl.gov/data/DERCAMTechDataOnline.pdf. July.

Geroski, P. A. 2000. "Models of Technology Diffusion." Research Policy, 29, 603-625.

Goldstein, L., B. Hedman, D. Knowles, S. I. Freedman, R. Woods, and T. Schweizer. 2003. GasFired Distributed Energy Resource Characterizations. National Renewable Energy Laboratory for the U.S. Department of Energy. NREL/TP-620-34783. November 2003. Golden, CO.

Government Accounting Office. 2005. "Reports on the Government Performance and Results Act." GAO,. http://www.gao.gov/new.items/gpra/gpra.htm. July.

Huang, C.-Y., H. Akbari, L. Rainer, and R. Ritschard. 1991. 481 Prototypical Commercial Buildings for 20 Urban Market Areas. Lawrence Berkeley National Laboratory. LBL-29798. April 1. Berkeley CA. 208 pages.

LaCommare, K. H., J. L. Edwards, and C. Marnay. 2003. Distributed Generation Capabilities of the National Energy Modeling System. Lawrence Berkeley National Laboratory. LBNL-52432. January. Berkeley. 47 pages.

Onsite Sycom Energy. 2000. The Market and Technical Potential for Combined Heat and Power in the Commercial/Institutional Sector. January 2000.

Peperman, G., J. Driesen, D. Haeseldonckx, R. Belmans, and W. D'haeseleer. 2005. "Distributed Generation: Definition, Benefits, and Issues." Energy Policy, 33 (6), 787-798.

Resource Dynamics Corporation. 2002. Integrated Energy Systems (IES) for Buildings: A Market Assessment. DOE. August. Vienna VA. 76 pages.

Siddiqui, A. S., C. Marnay, O. Bailey, and K. Hamachi LaCommare. 2005. "Optimal selection of on-site power generation with combined heat and power applications." international journal of distributed energy resources, 1 (1), pp. 33-62. 


\section{Appendix A. Detailed Treatment of DG in the NEMS Commercial Demand Module}

This appendix details how NEMS is structured to treat DG and represents and serves as a more in-depth discussion of Section 5.4.

Figure A- 1 shows a flowchart that summarizes how the DG submodule is structured and shows what information is passing in and out of the submodule.

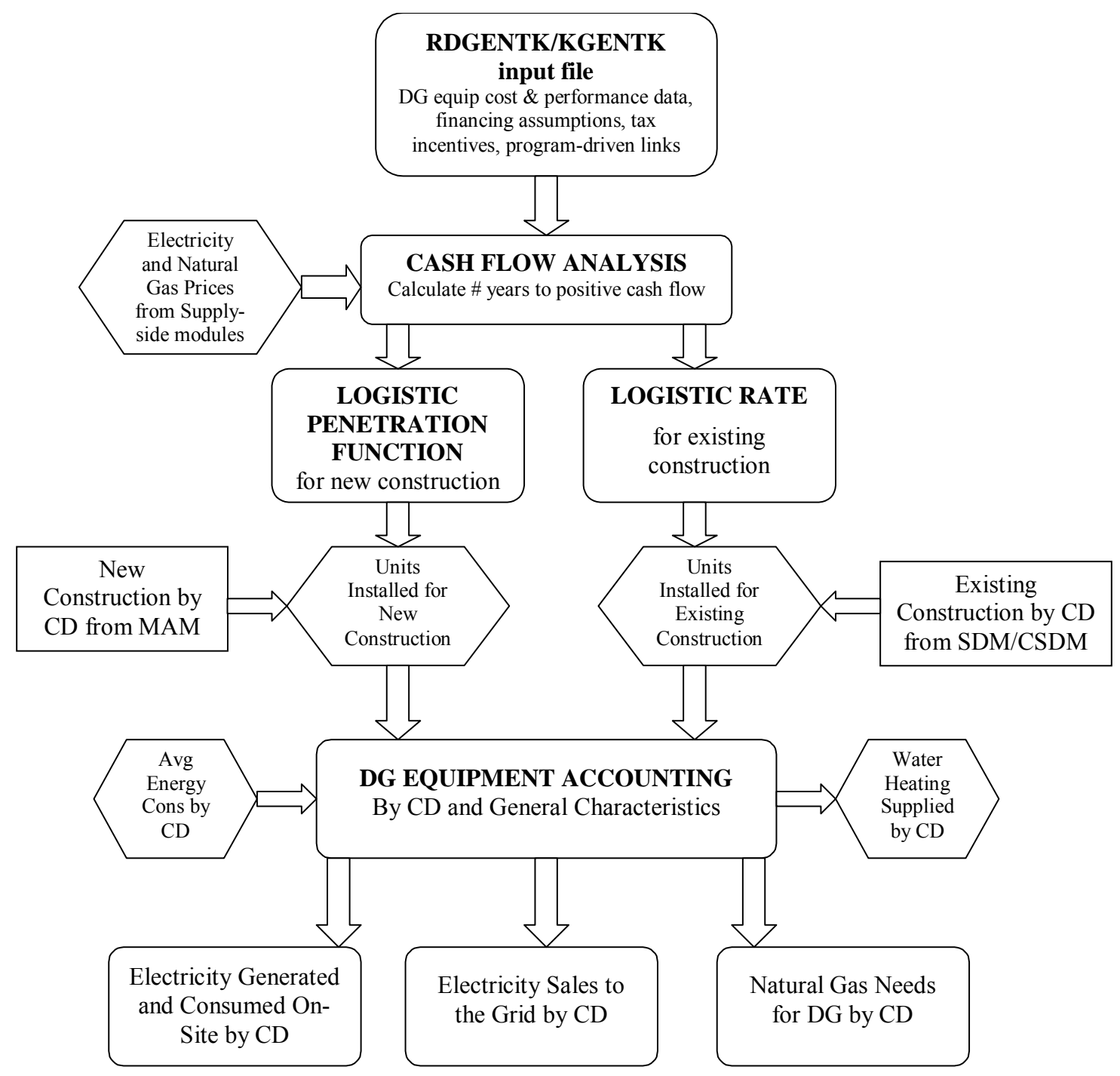

Figure A- 1. Flow Chart of DG in NEMS Commercial Building Sector

This flowchart was adapted from a figure in the NEMS commercial module documentation (Energy Information Administration 2005b). At the top of the flowchart, two DER technology input files, one for the residential sector and the other for the commercial sector, provide the cost and performance data for each DER technology, financing assumptions, any applicable tax incentives, and any non-economic, program-driven exogenous penetrations of DG. This 
technology information is used in the cash flow analysis. The submodule reads in the electricity and natural gas prices from the NEMS supply-side modules at the Census Division level. Commercial building starts and stocks at the Census Division level are also passed into the model to determine the amount of new and existing construction available for potential DG penetration. Although NEMS accounts for both DG purchases to new construction as well as retrofits to existing construction, the submodule focuses mainly on additions to new construction. According to the documentation, estimating the costs associated with retrofitting an existing building carries costs too complex to be generalized in NEMS (Boedecker et al. 2000). Upper limits are set on DG penetration in both new and existing buildings, but the submodule ensures minimal DG installations in the existing stock by imposing a much stricter limit on the amount of DG deployment. The available building starts and stock are used along with the results from the cash flow analysis and passed into the penetration function, which uses a logistic curve to determine the share of buildings that will adopt DG. The submodule then tallies up the amount of DG installed to determine whether there is any excess waste heat that can be used to supply water heating or space heating demand. There is no consideration of thermally activated cooling. The average electricity and hot water consumption is used to determine building fuel demand that DG can offset. Additionally, the submodule checks if excess DG generation is available for sales back to the grid. The DG submodule passes back electricity sales to the grid to the Electricity Market Module (EMM) and the natural gas requirements for DG back to the appropriate building sector.

\section{Cash-Flow Approach}

For each potential DG purchase in the commercial sector, a 30-year cash flow analysis is performed. This calculation includes both costs and returns and consists of a down payment amount, which is assumed to be 25 percent of the capital cost, loan payments, maintenance costs, and fuel costs. The returns include energy cost savings, tax deductions, and any applicable tax credits. According to EIA, the main advantage of a cash-flow analysis approach versus a simple payback approach, i.e. the investment cost divided by the estimated savings, is the inclusion of financing assumptions (Boedecker et al. 2000; Energy Information Administration 2005b). The added consideration of financing has the advantage of potentially yielding a faster positive payback. The reason for using a cash-flow approach is assuming that the investment in DG is rolled into the mortgage of the commercial building. The result is the number of years required to reach a positive cash flow. If the net return is positive, the cumulative net cash flow increases. In some cases, the cash flow is never positive and the number of years is set to 30 .

The DG module also incorporates the benefits of tax credits when DG is purchased. If tax credits apply, they are applied as a one-time payment in the second year of the investment as part of the 30 -year cash flow calculation. This assumes an average one-year waiting period is required in order to receive the credit. Sensitivity exercises of the tax credit indicate that a tax incentive can provide a significant boost to the potential of various DER technologies in the buildings sectors by quickly reducing the number of years required to obtain a positive cash flow.

Traditional DG Payback Approach 
DER technologies in NEMS are adopted annually by each of the 11 commercial building types based on the number of years required to achieve a positive cumulative net cash flow. The payback calculation differs from the traditional definition of simple payback to account for financing options. In the traditional simple payback, all system capital costs are paid for in full in the first year of the investment and there is no discounting of future cash flows. Net annual savings from the investment are accumulated until the initial investment cost is recovered. In the NEMS payback approach, the system investment costs are financed over 20 or 30 years at an 8.5 percent interest rate with a 25 percent down payment in the first year. The net cash flow in subsequent years includes interest and principal payments for financing and the annual net cash flows are added to the initial down payment until a positive cumulative net cash flow occurs. In general, the NEMS payback period will be shorter than the traditional payback. 



\section{Appendix B. Recent Modifications to DER-CAM}

DER-CAM, described in detail in Siddiqui (2003), was used for a case study to compare the decision-making process and results of actual DG adopters and DER modeling and optimization (Bailey, 2003). Based on findings from several case studies, the following modifications were made to DER-CAM for use in the ComSeM.

- Minimum load constraints: all electricity generation equipment except PV was constrained to operate between minimum and full load, or not at all, during any hourly timestep.

- Effect of DG reliability on demand charges: demand charges were based on the statistically expected charge for each month or day (monthly or daily demand), rather than on the assumption of 100 percent reliability. The expected maximum demand depends on the number, capacity, and reliability of generators installed.

- Payback period: a maximum payback period constraint was included on all investments. In practice, most economically motivated adopters would not consider solutions with long payback periods, even if savings were maximized.

- Monthly pricing: electricity pricing was changed from seasonal to monthly.

- Multiple natural gas rates: natural gas rates were changed from a single monthly rate (fixed and volumetric components) to three separate rates for typical, air-conditioning, and DG. Natural gas costs for DG are often lower than for typical use because of the lower load factor of DG natural gas consumption. 



\section{Appendix C. Detailed DER-CAM Results}

This appendix displays results of the DER-CAM runs described in Section 3. Each figure consists of DER-CAM results for 2004, 2012, and 2022. For each year, results are shown for both the baseline (top row) and program (bottom row) cases. Each column of charts is for a different building type, and within each chart, results for the four cities are shown. The following abbreviations are used for the four cities:

- Chic: Chicago

- Bost: Boston

- Atla: Atlanta

- S.F.: San Francisco

For all of the bar charts, the legend shown in Figure 22 applies. 

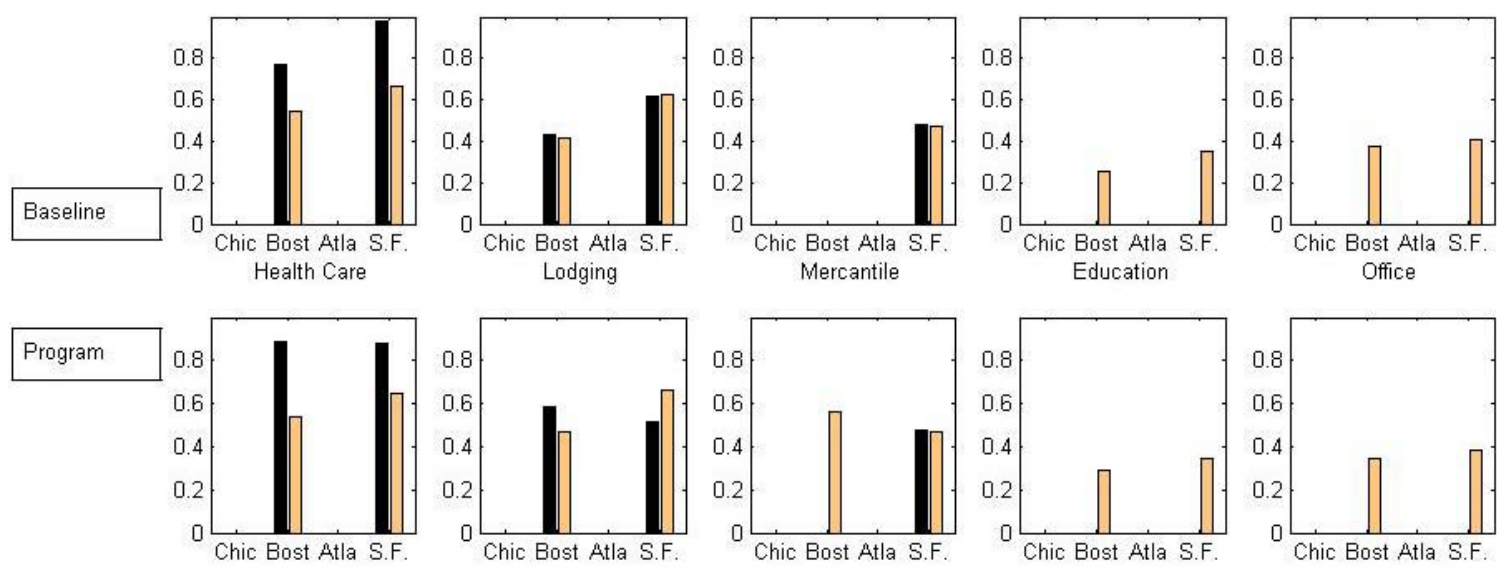

2012
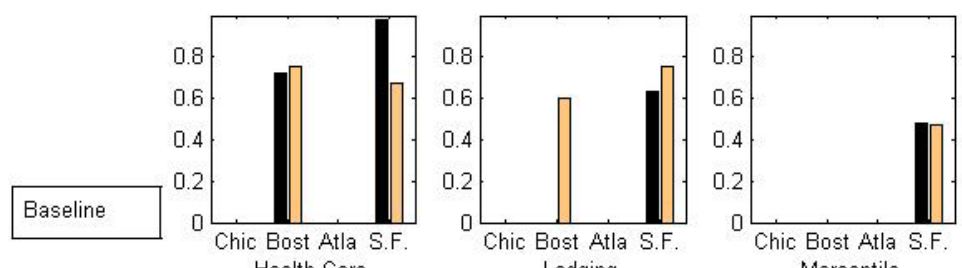

Health Care
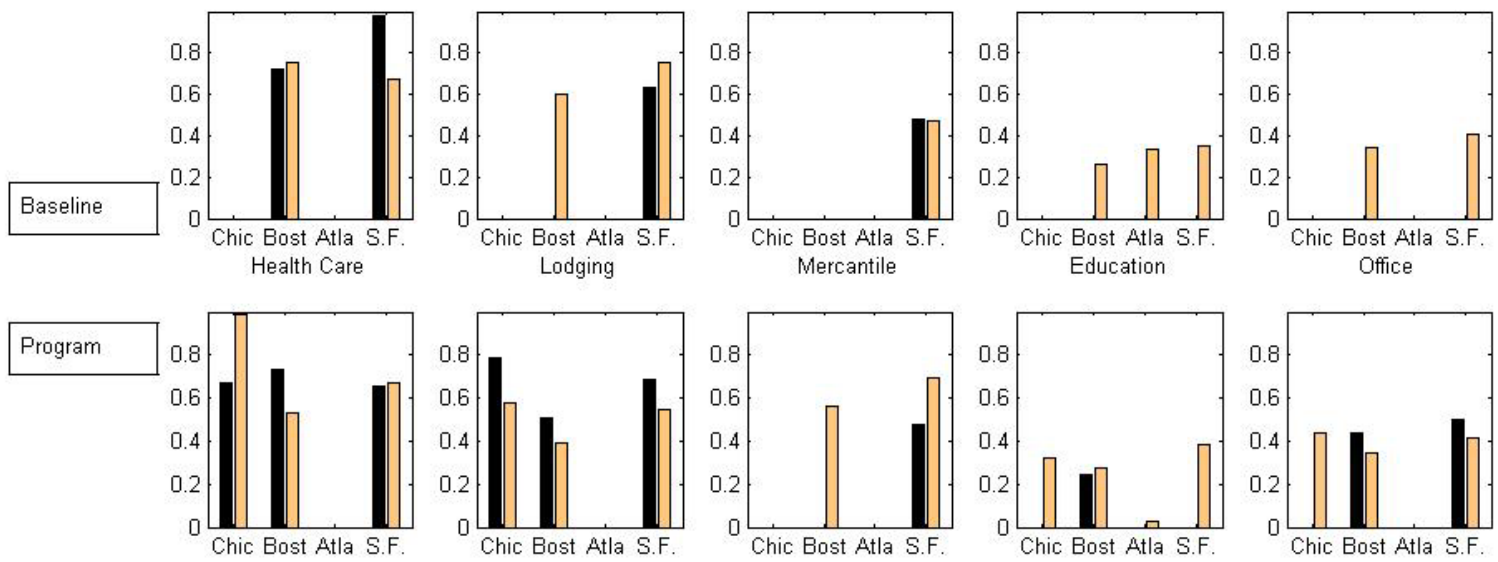

Education
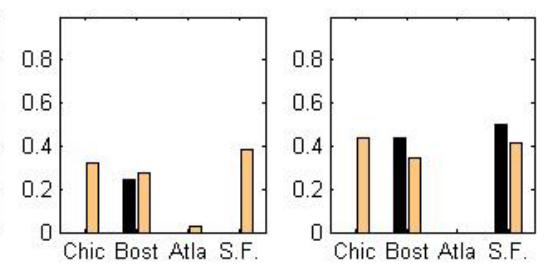

2022
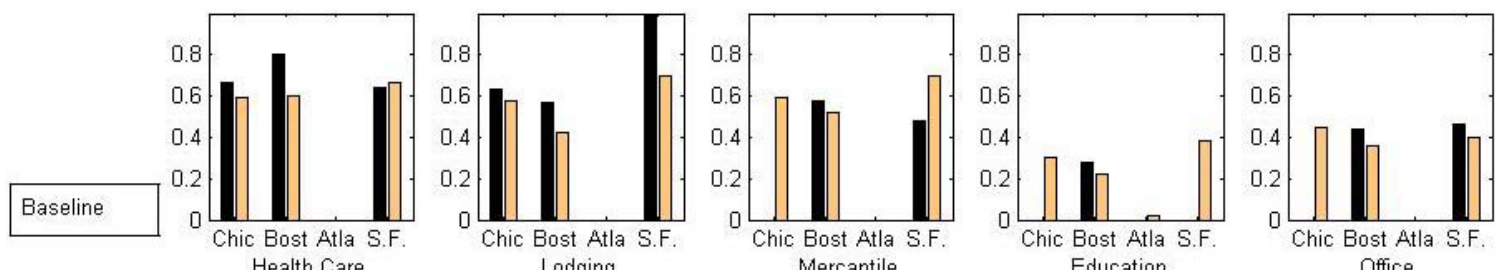

Program
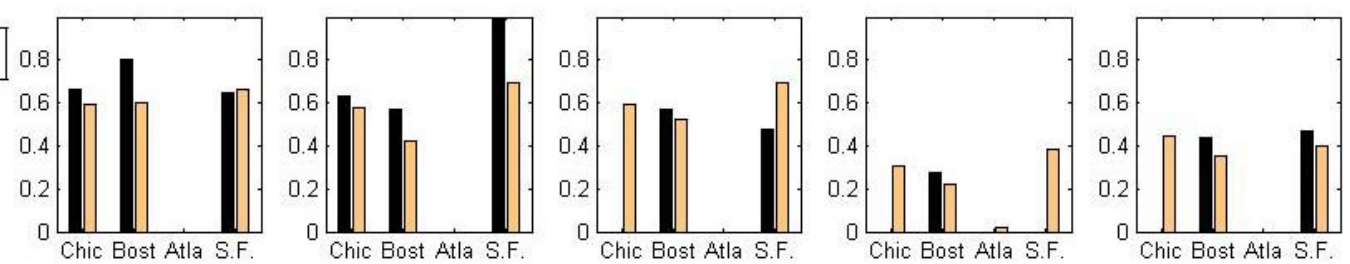

Figure C- 1. DG Load Factor 

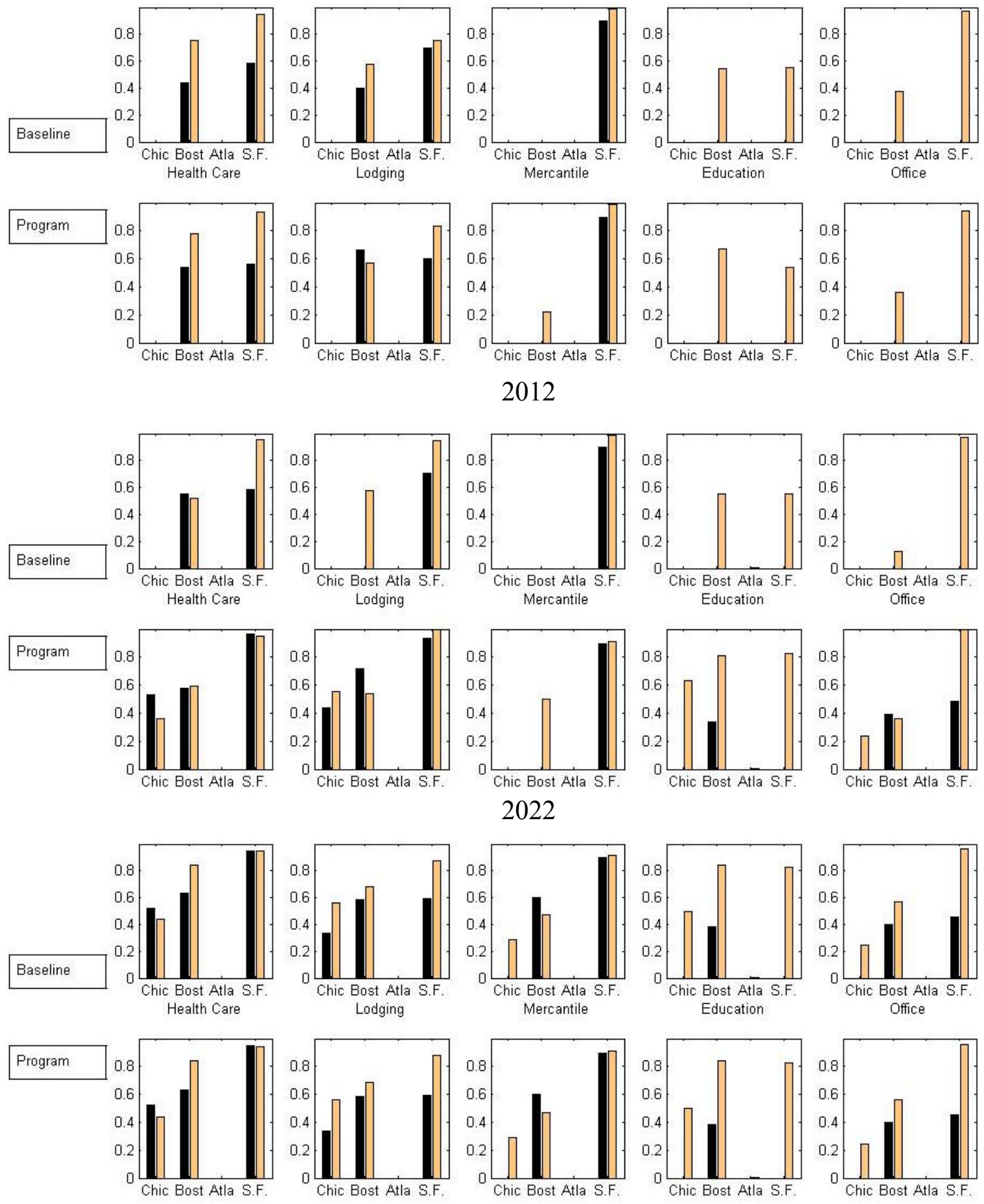

Figure C- 2. Fraction of Electricity Load Met by DG 

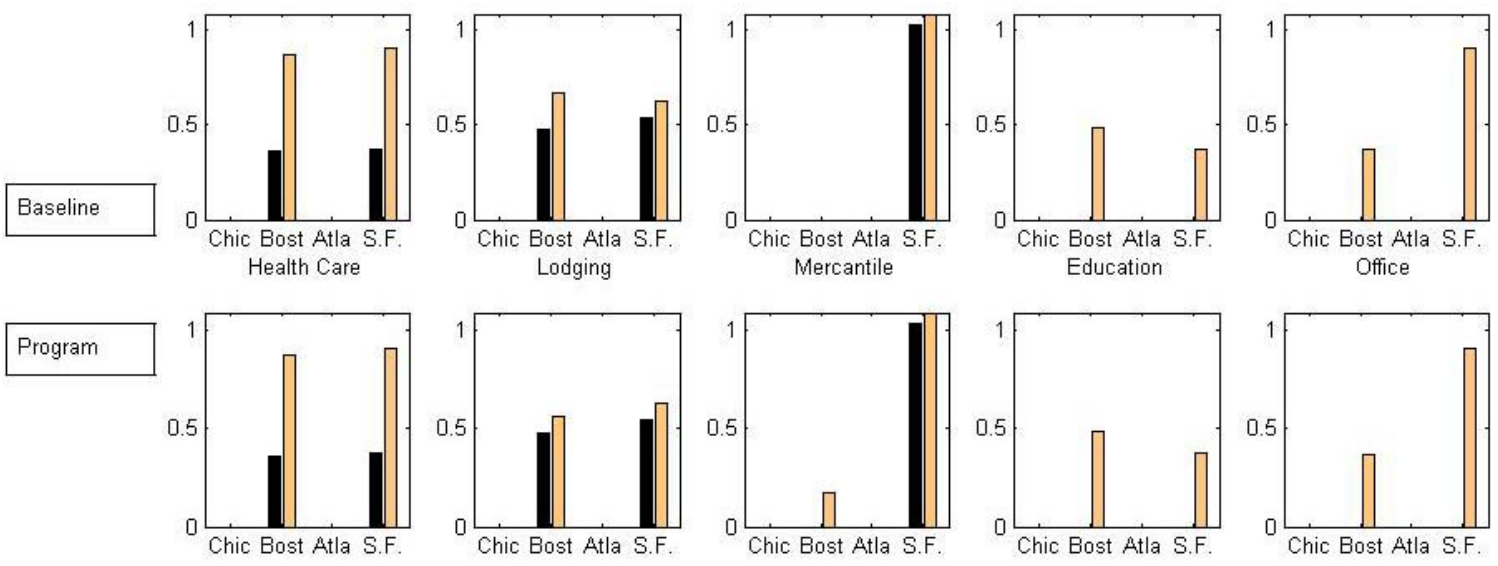

2012
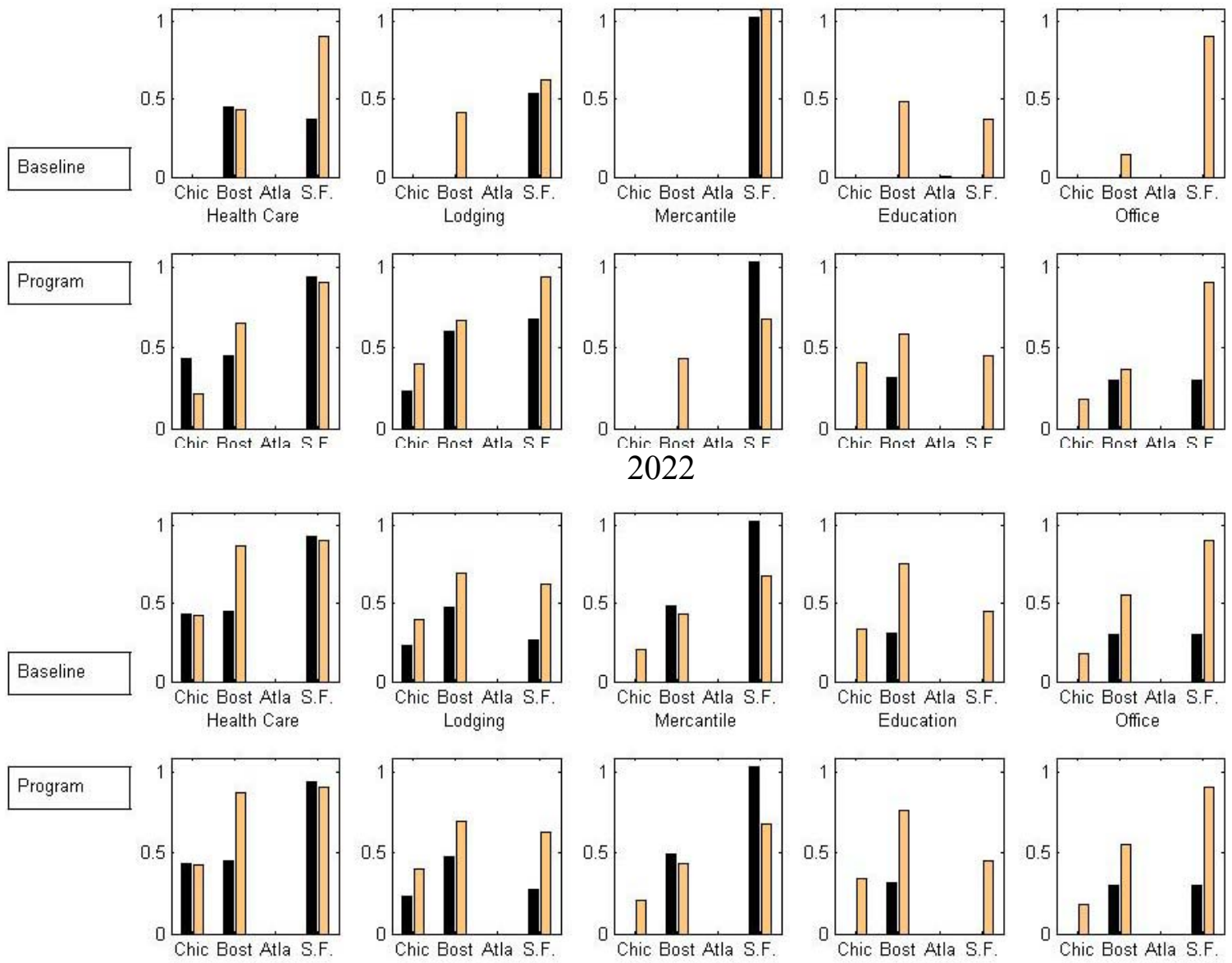

Figure C- 3. Fraction of Peak Load Met by DG 

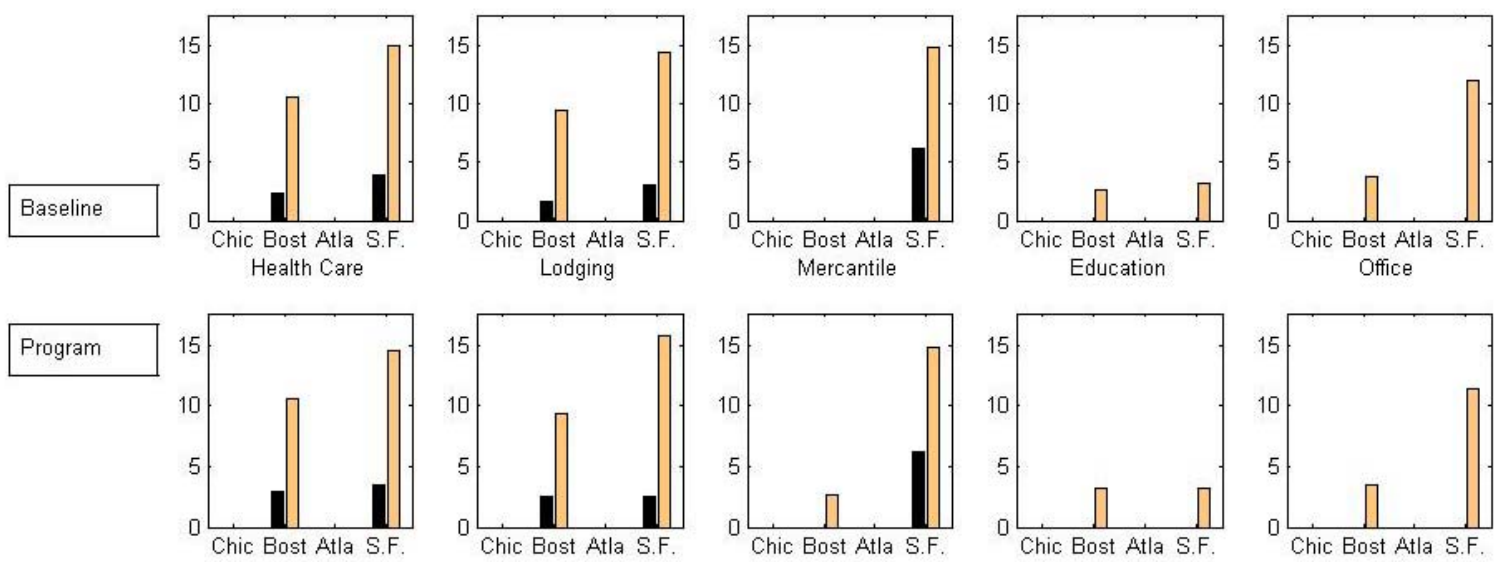

2012
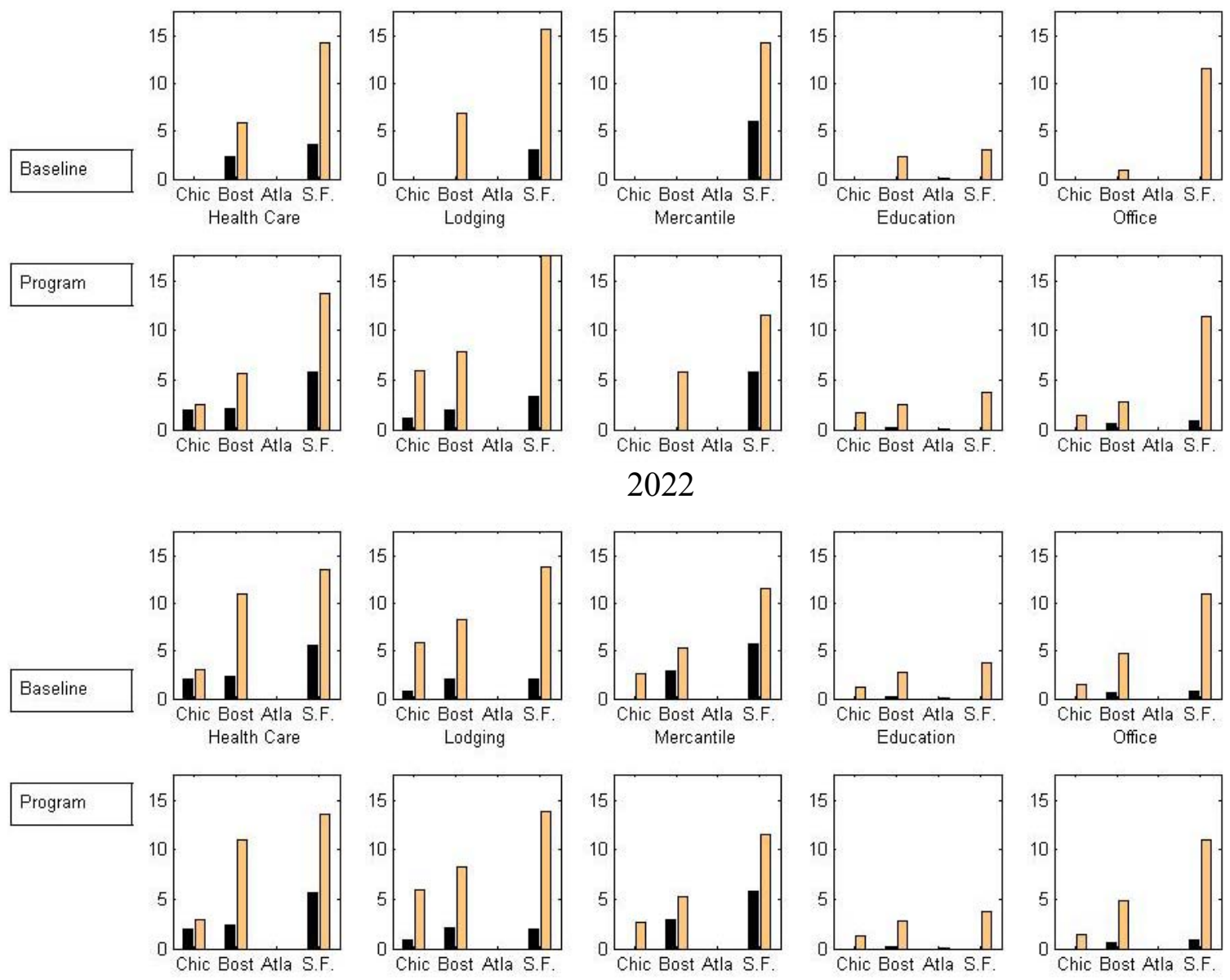

Figure C- 4. Increase in Utility NG Consumption (GWh) 

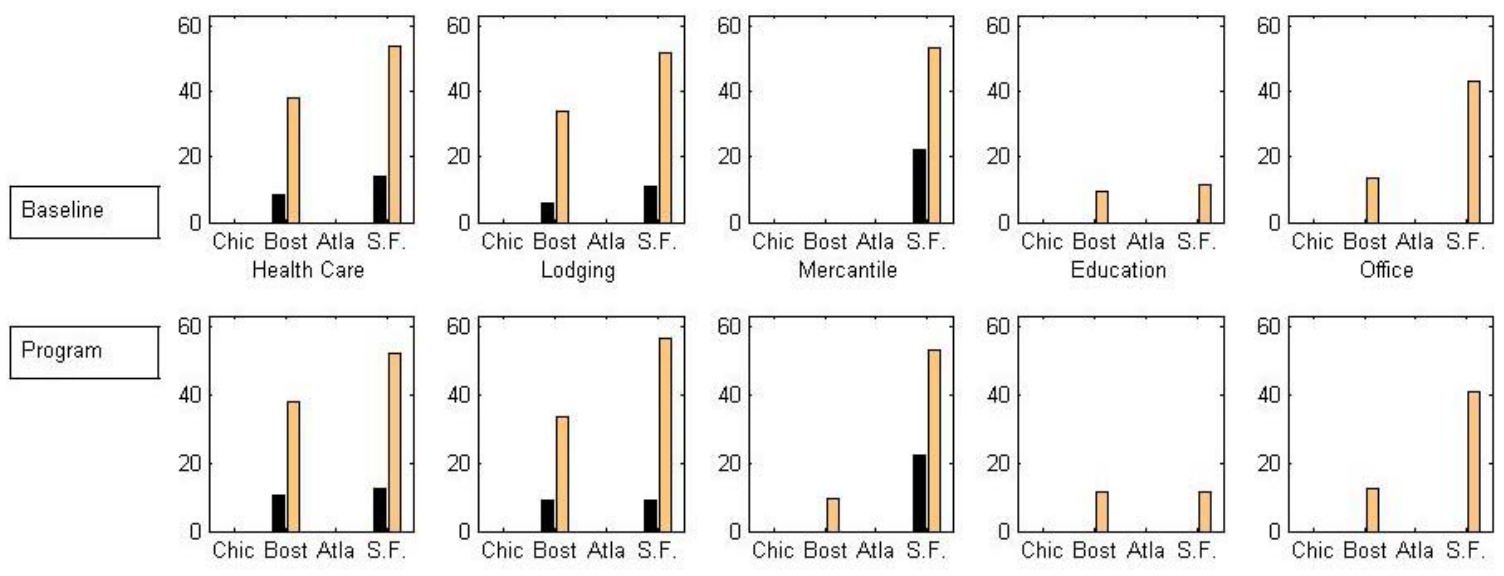

2012
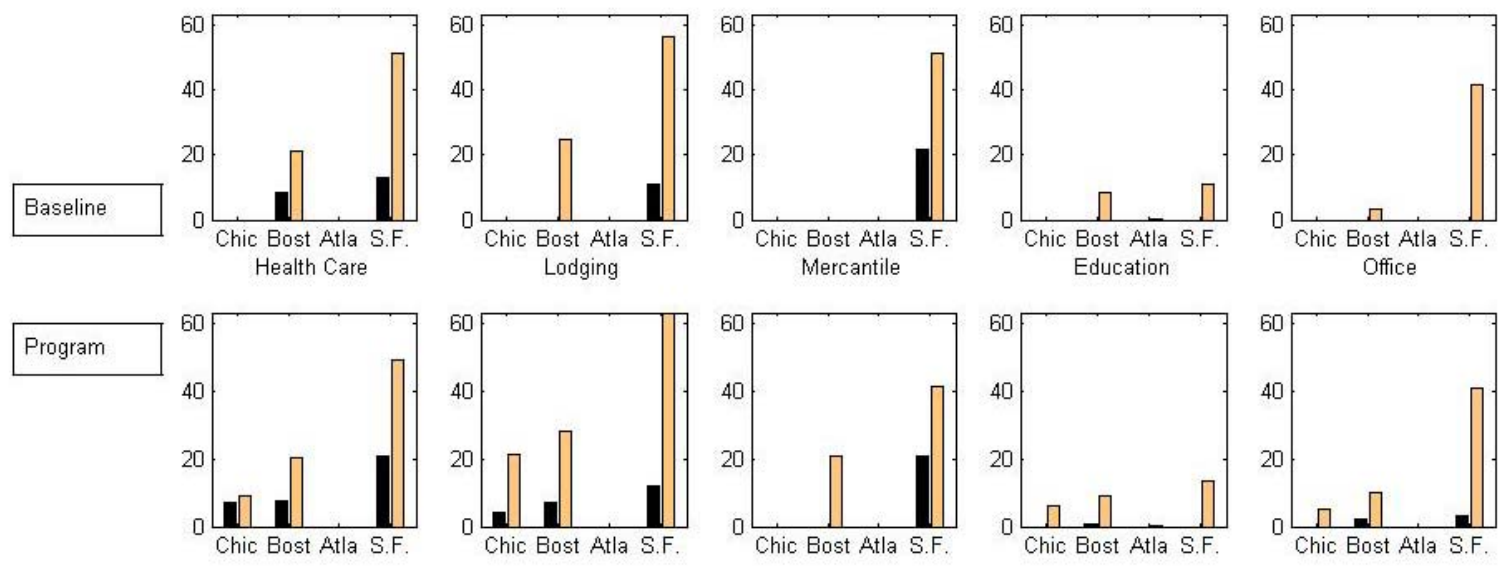

2022
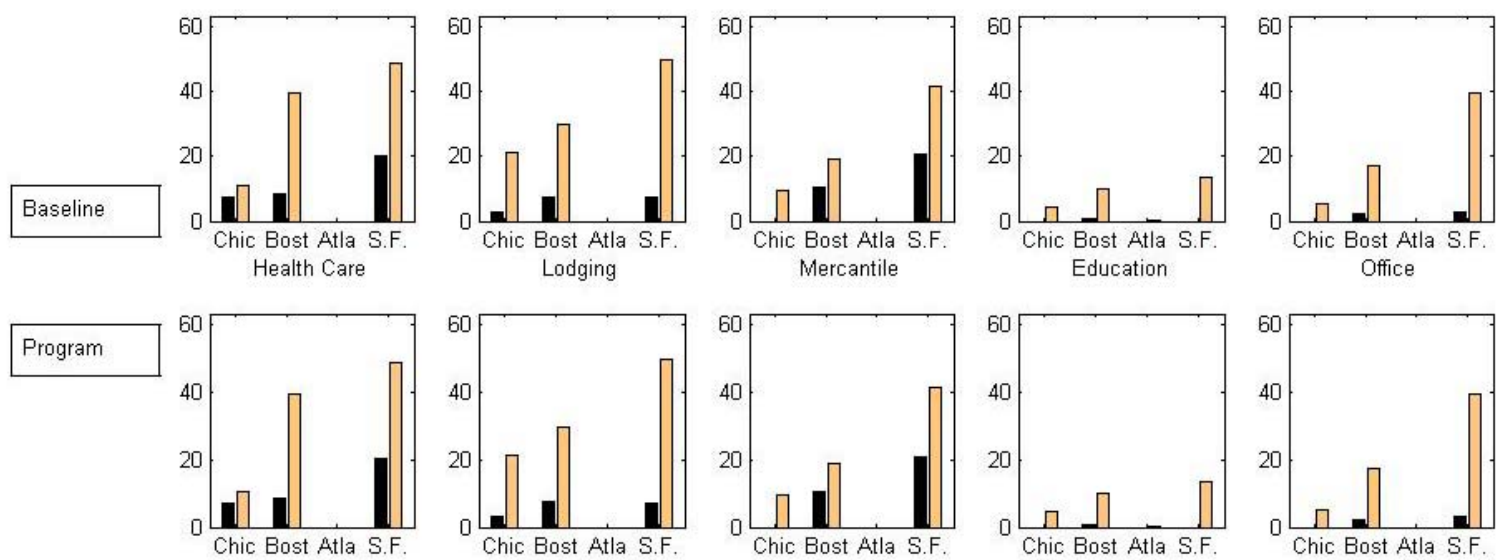

Office

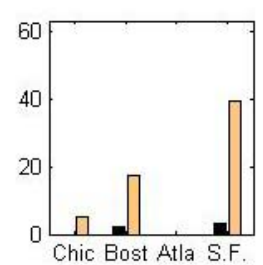

Figure C- 5. Increase in Utility NG Consumption (GJX10 ${ }^{3}$ ) 

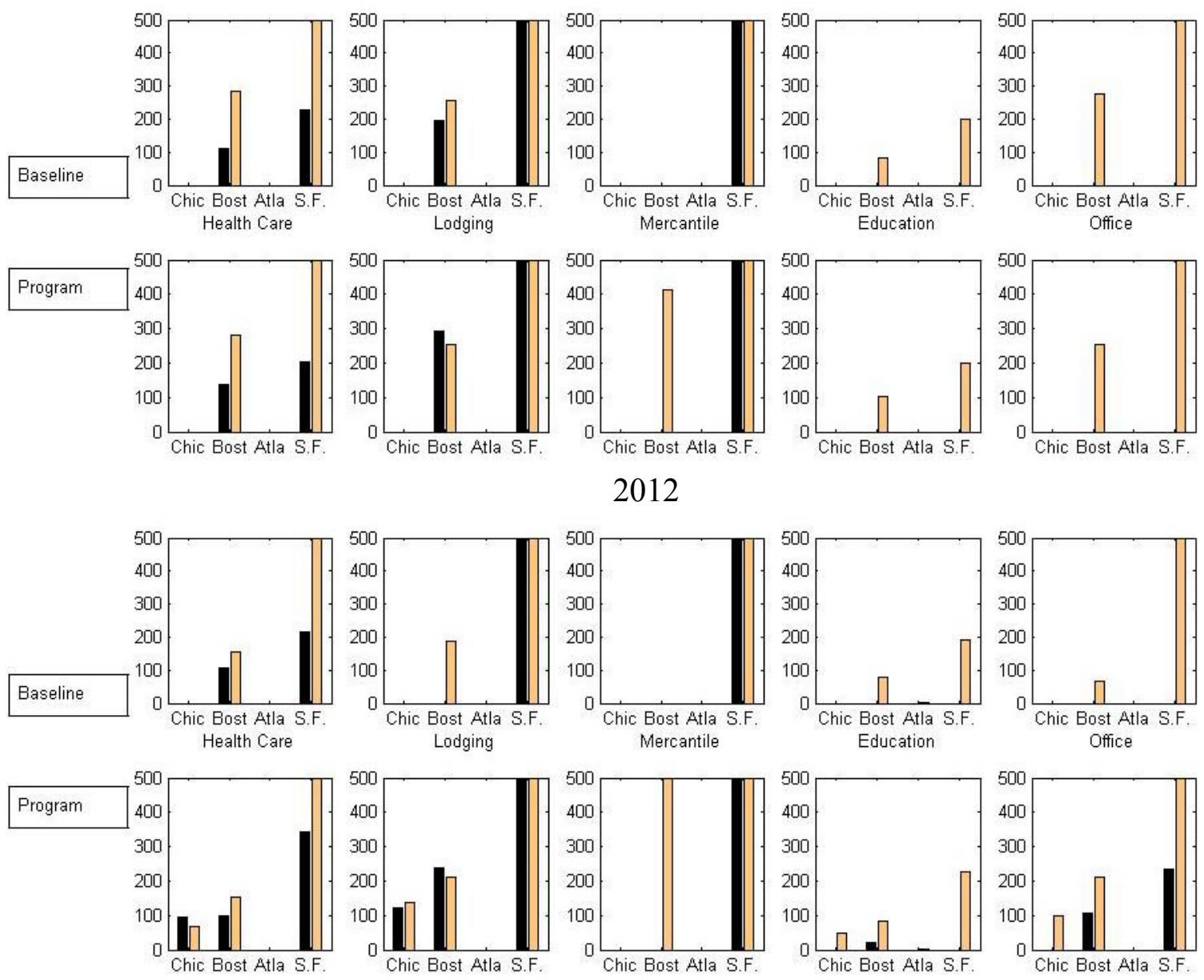

Office

2022
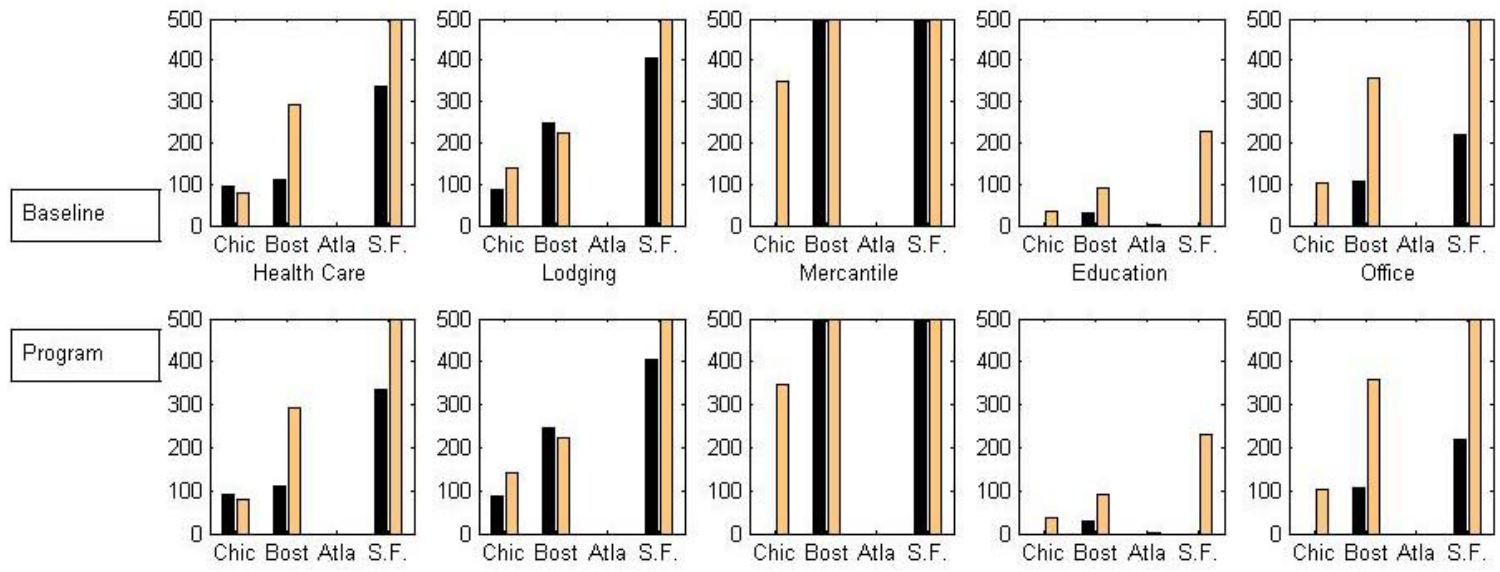

*note that certain values for Boston and San Francisco mercantile, and San Francisco office are well in excess of the $500 \%$ limit on these charts.

Figure C- 6. Increase in Utility NG Consumption (\% of No-invest) 

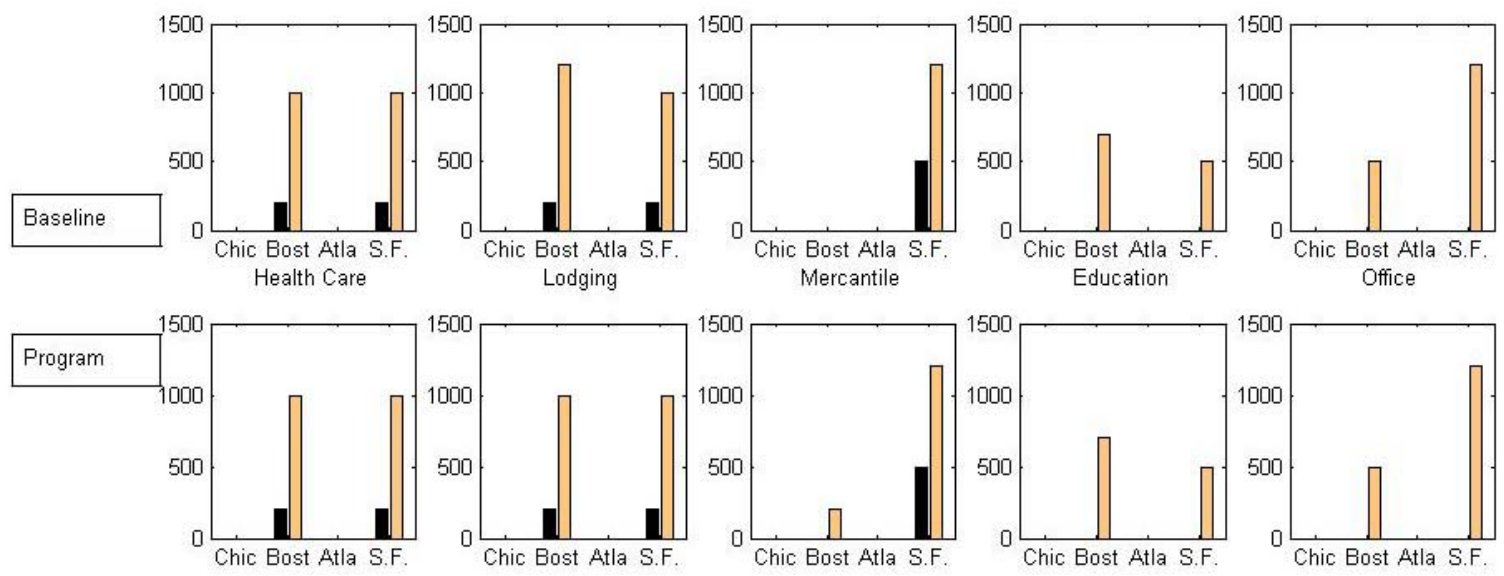

2012
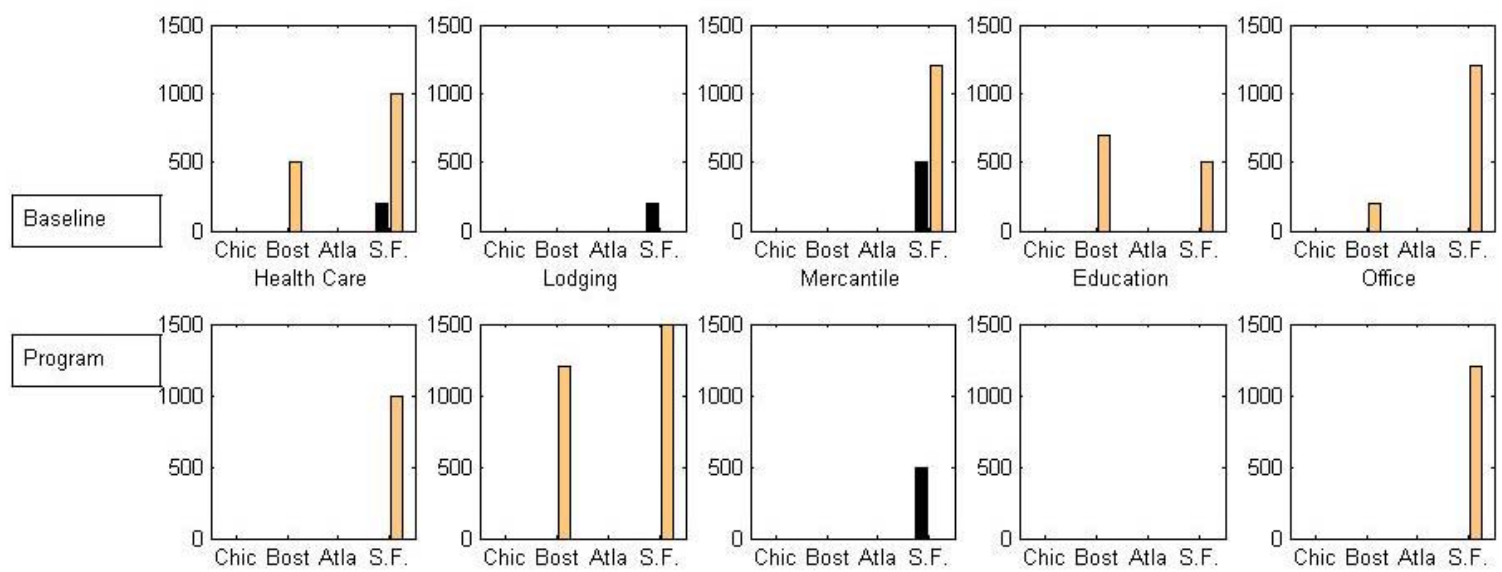

2022
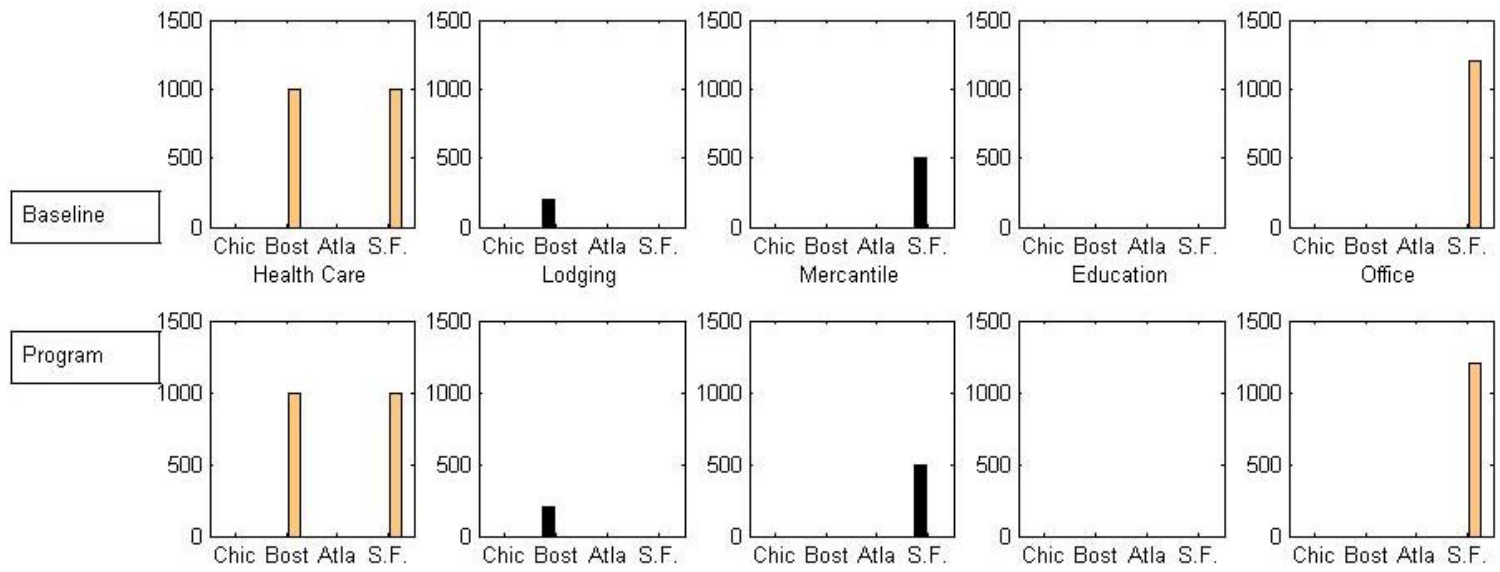

Figure C- 7. Installed Capacity - Reciprocating Engines (kW) 

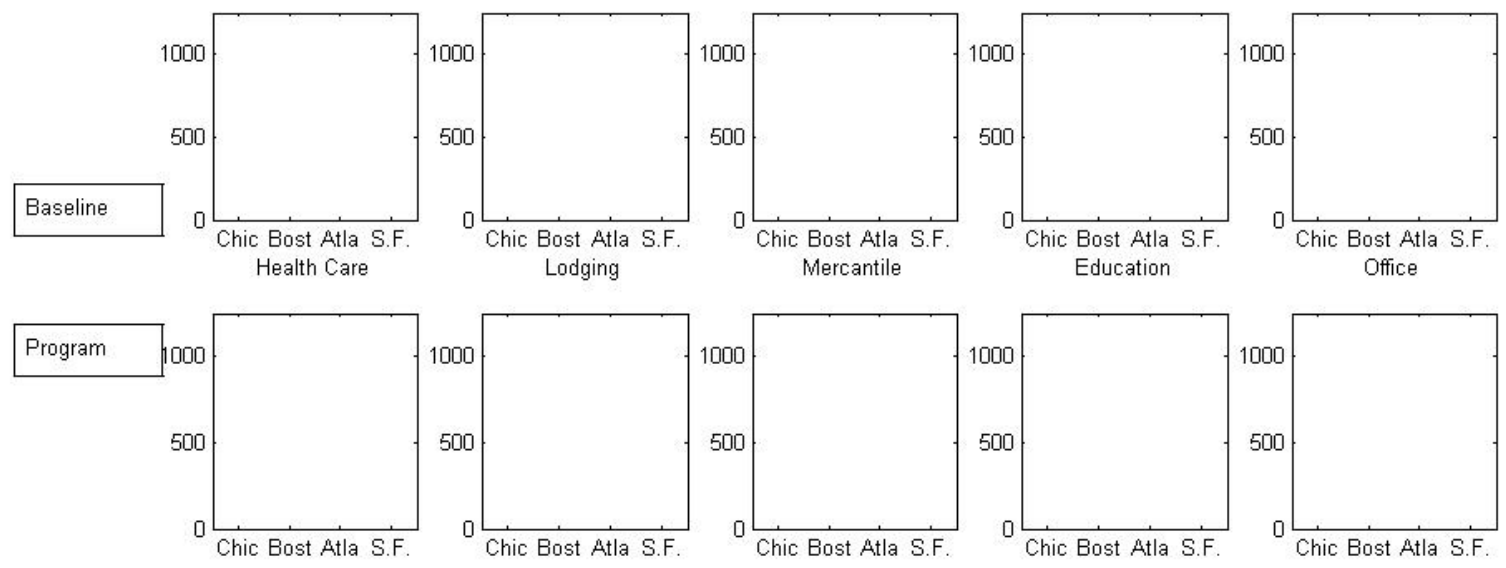

2012
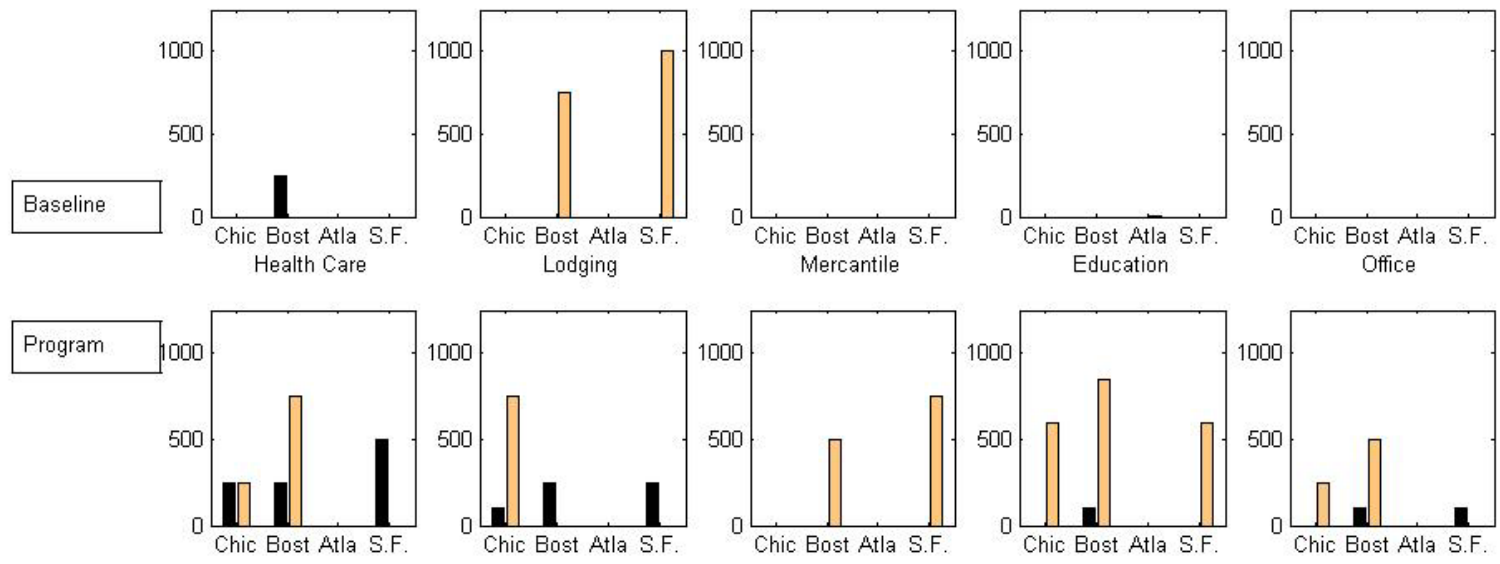

Office

2022
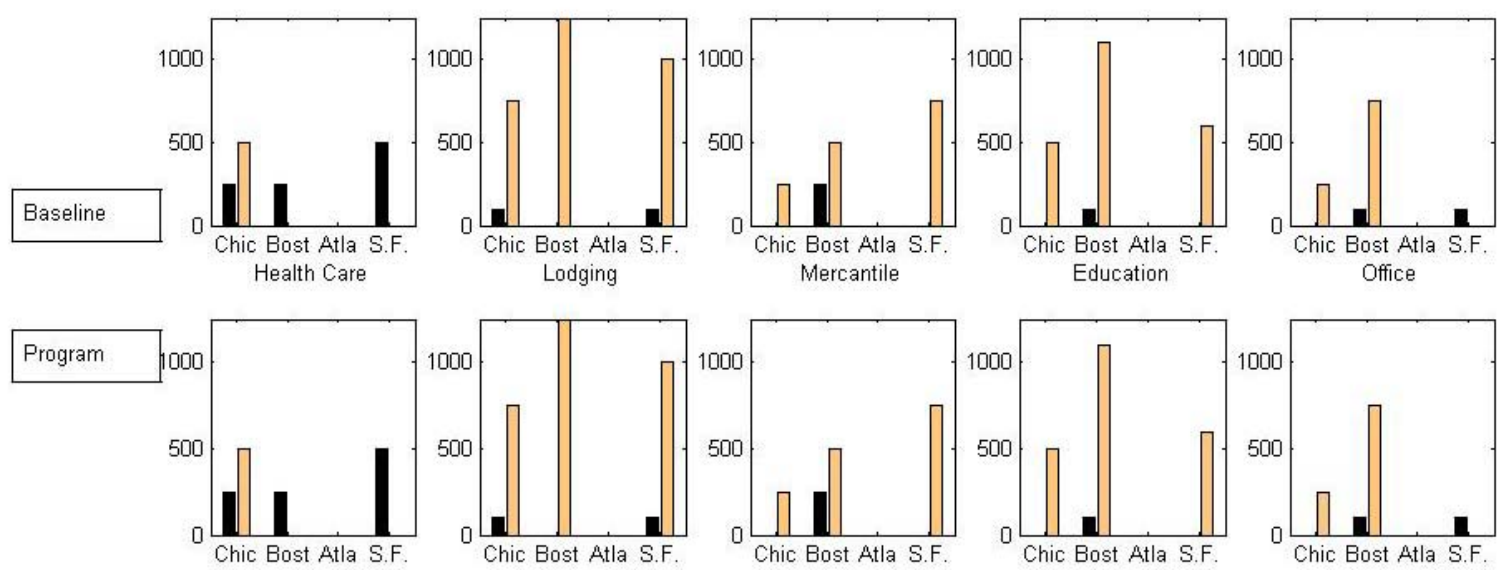

Figure C- 8. Installed Capacity - Microturbines (kW) 

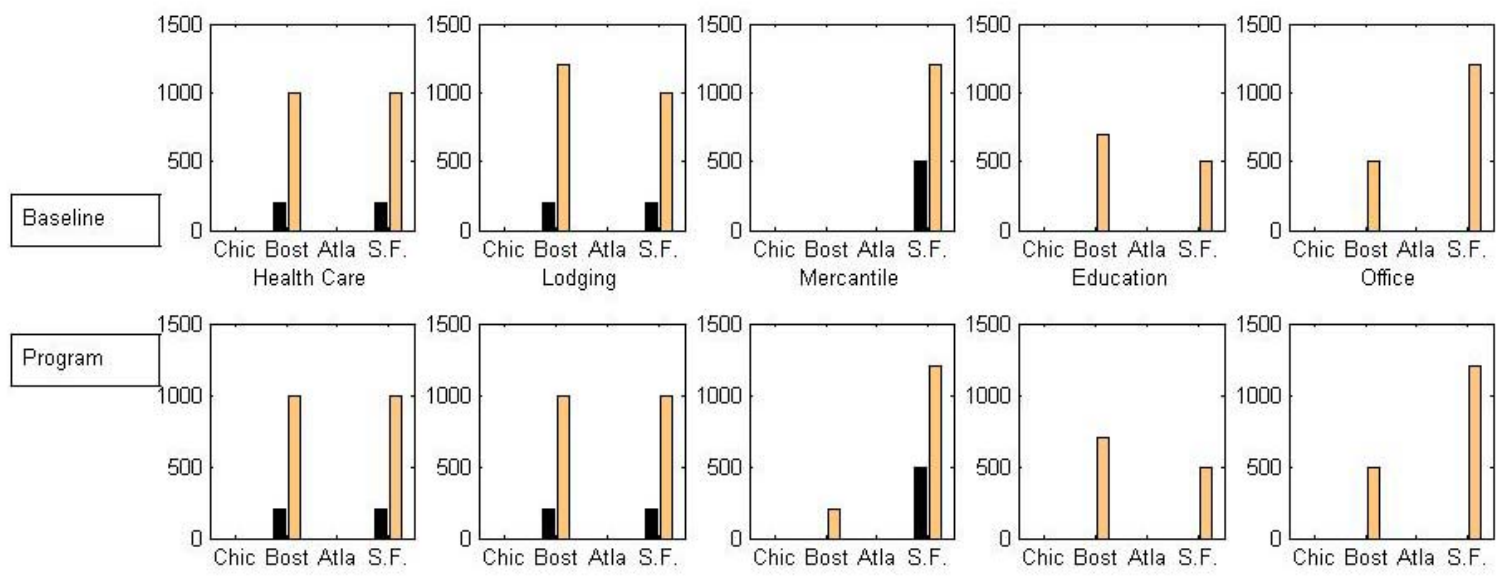

2012
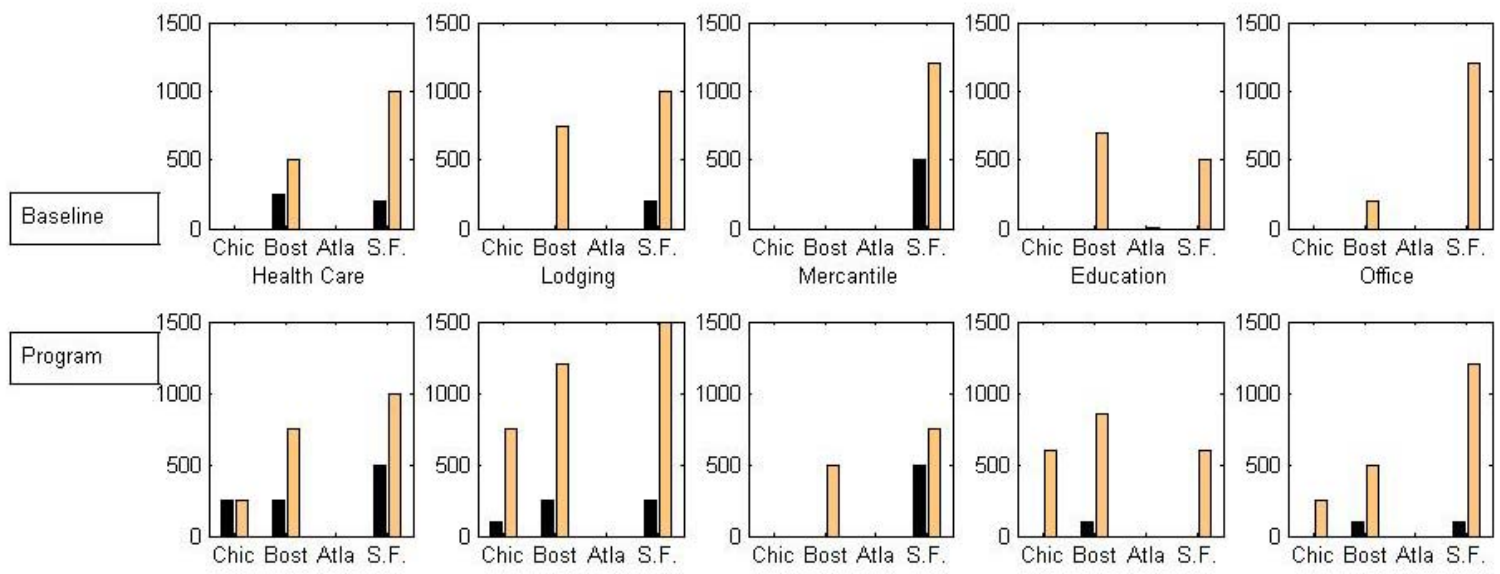

2022
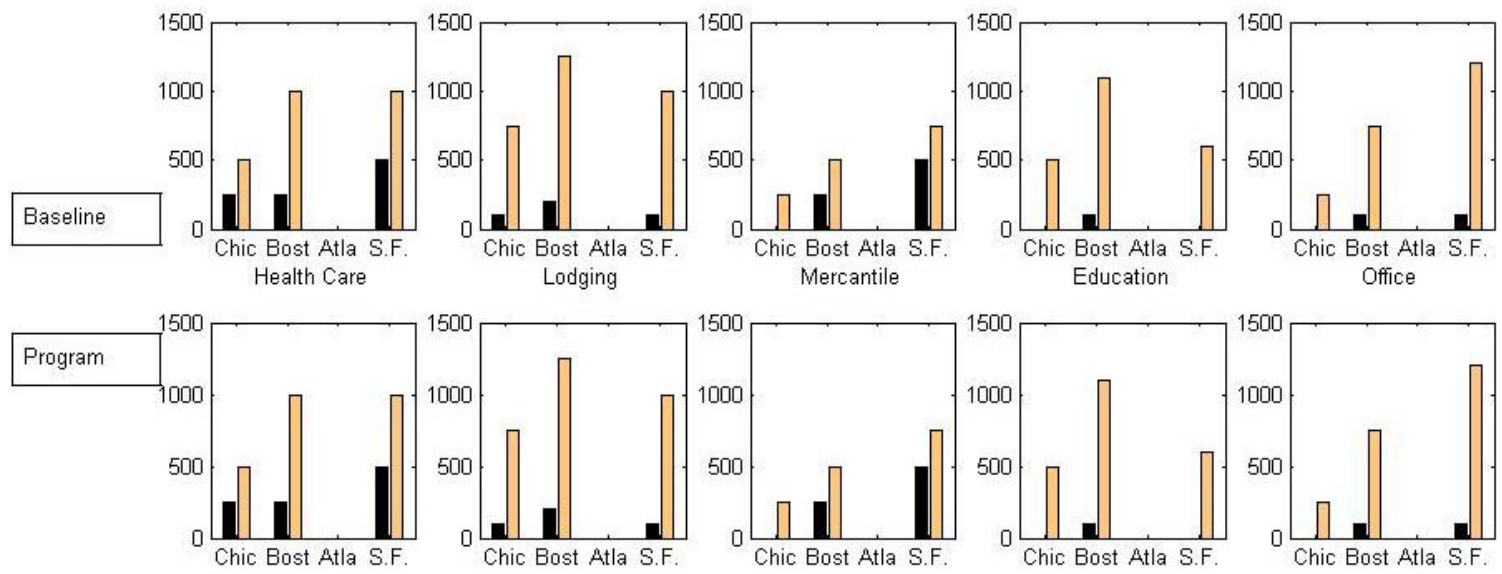

Figure C- 9. Installed Capacity - Total (kW) 

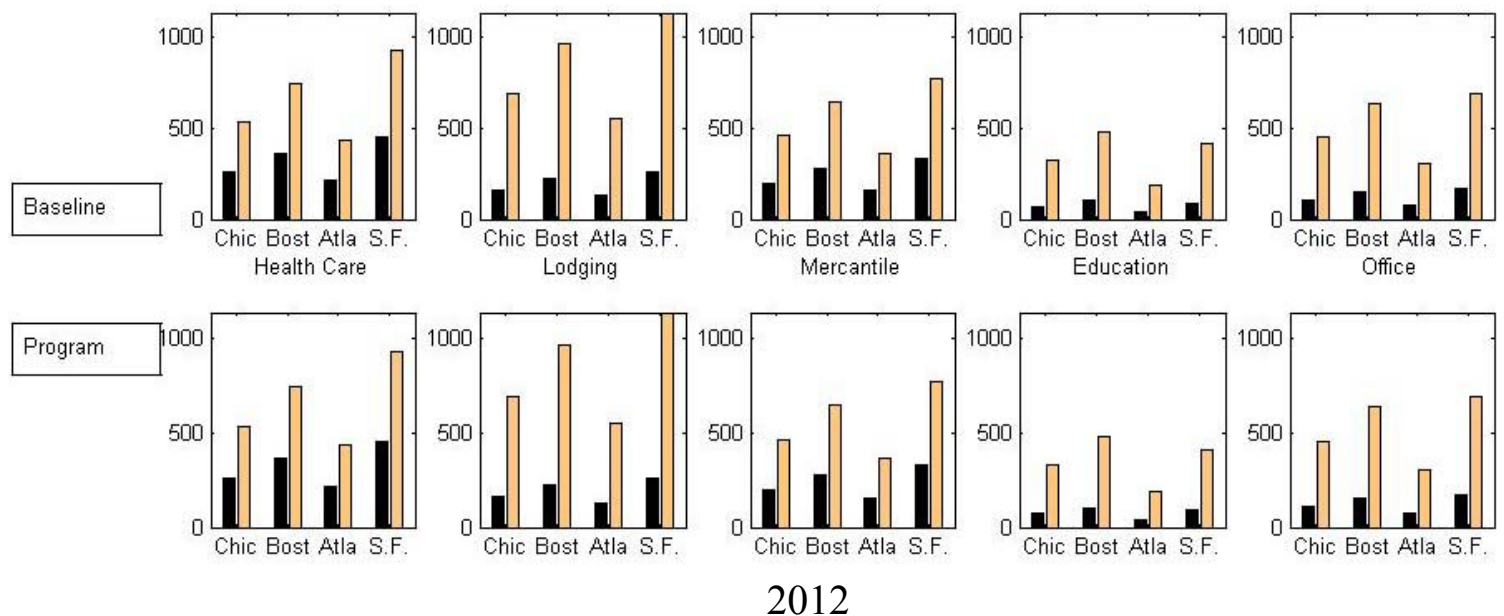

2012
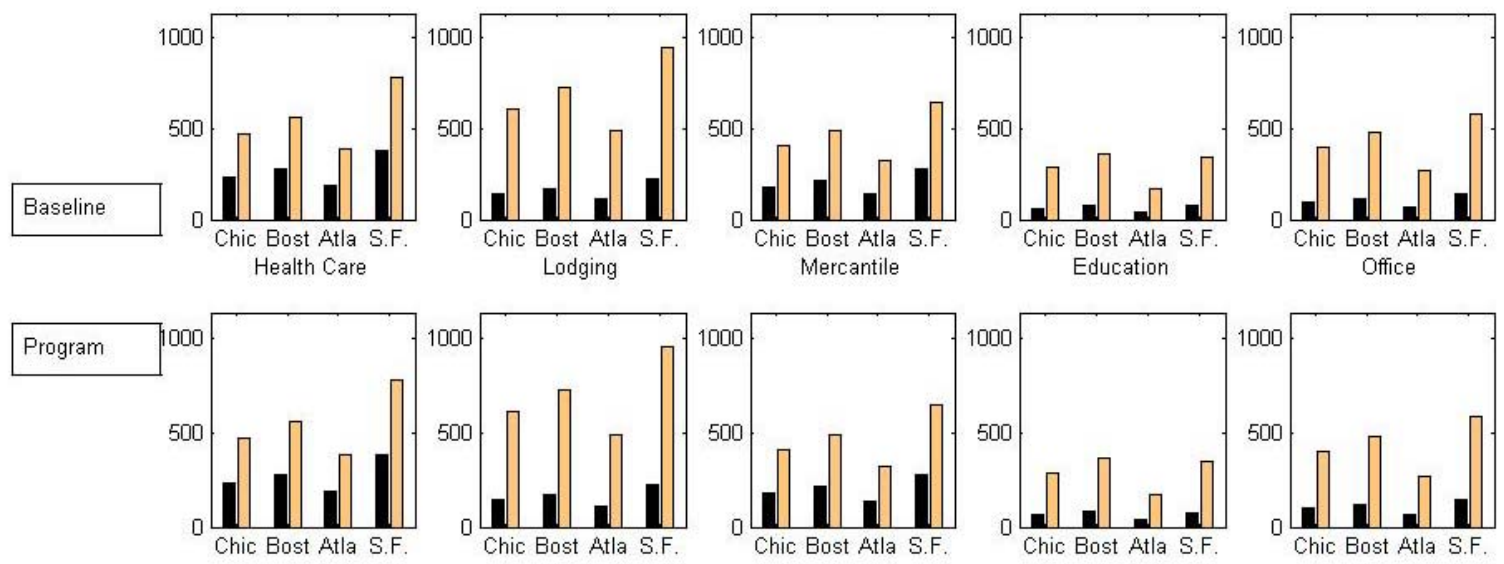

2022
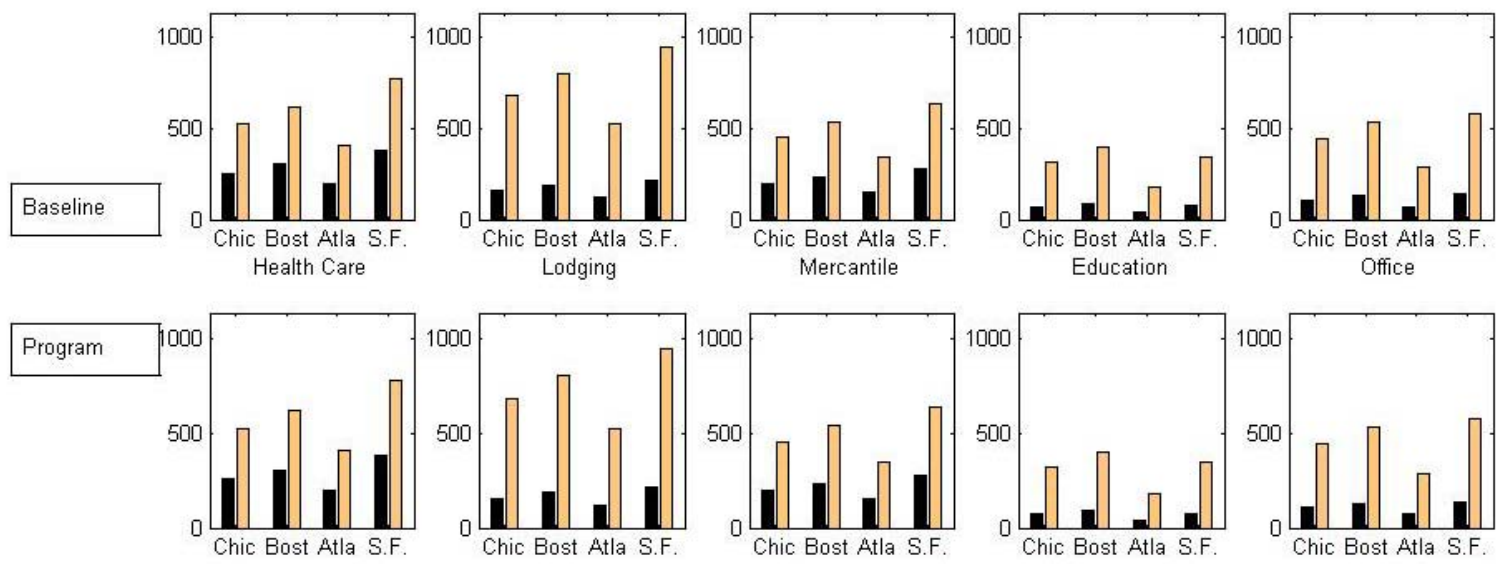

Figure C- 10. Pre-invest Annual Utility Electricity Costs (k\$) 

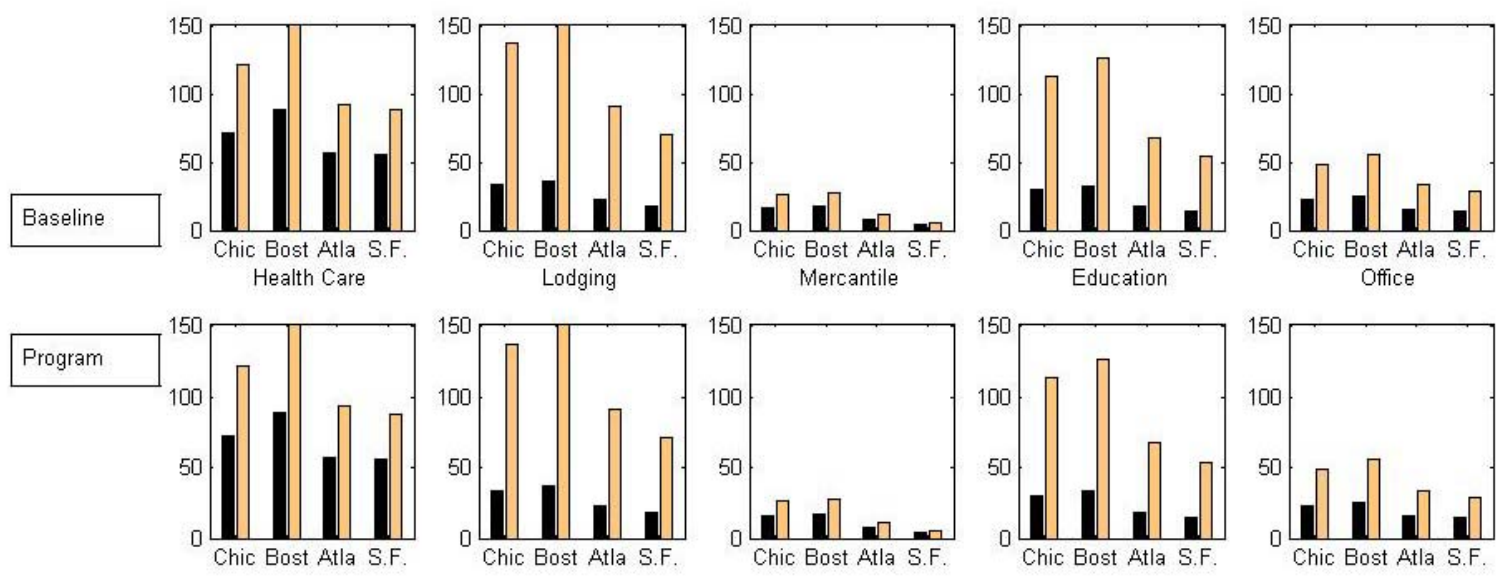

2012
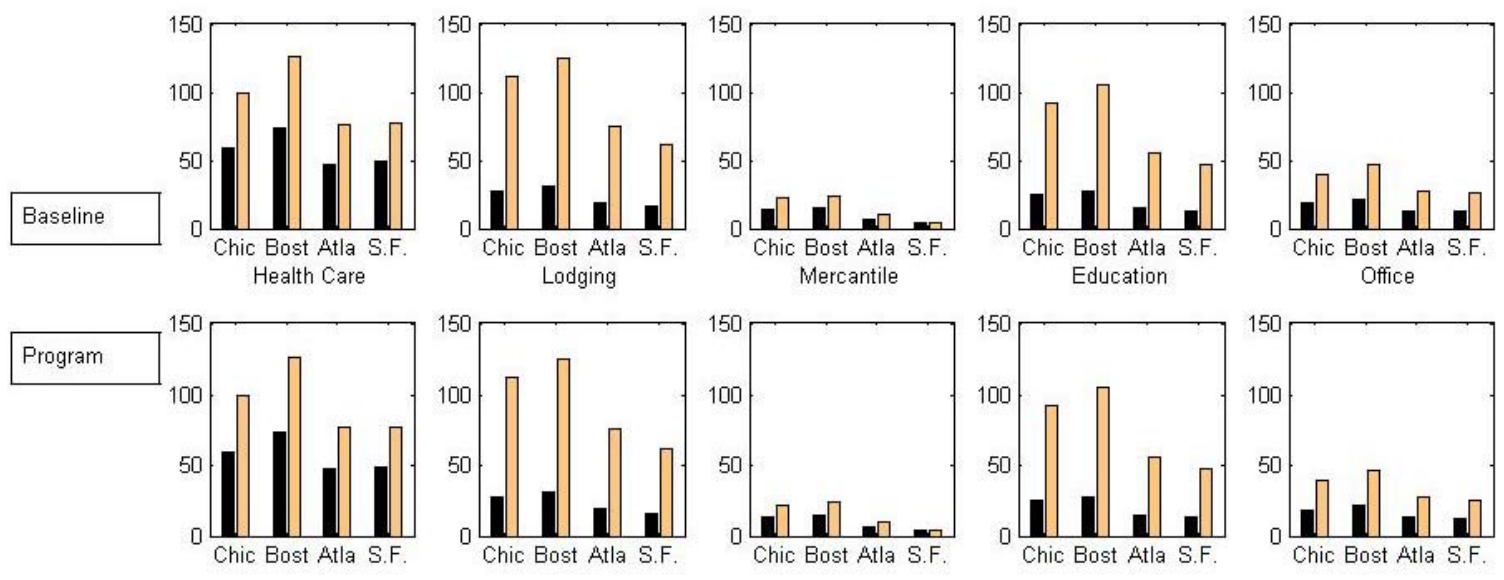

2022
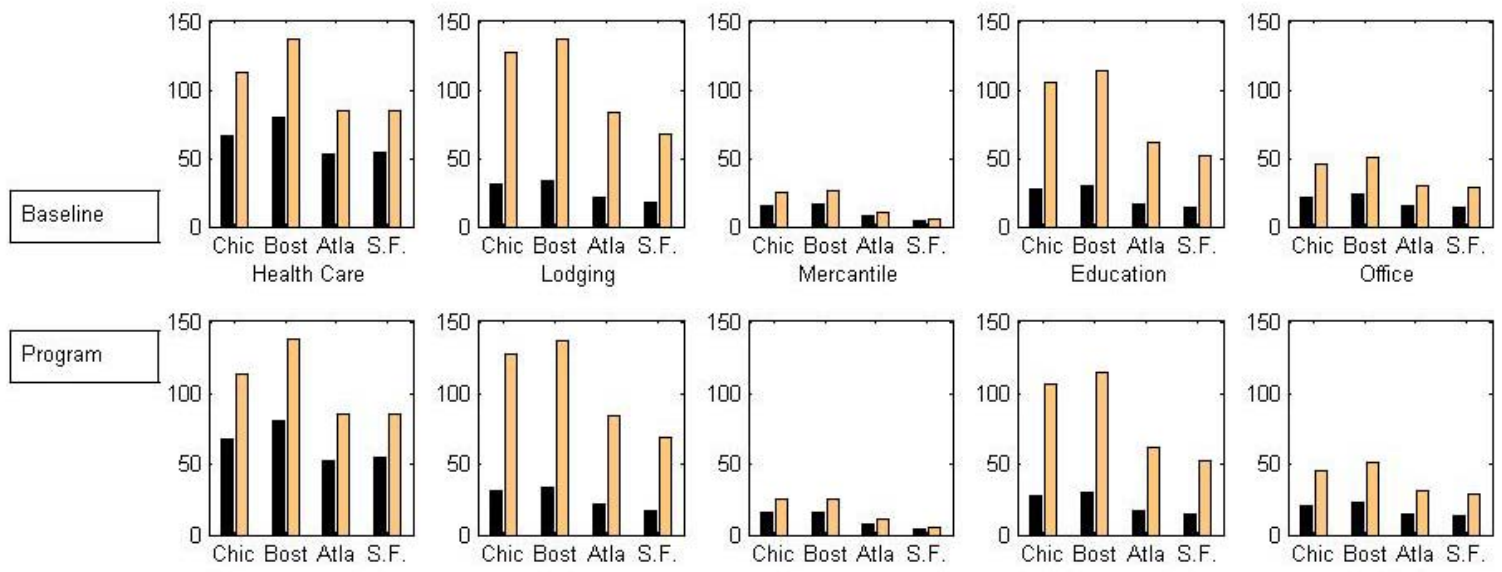

Figure C- 11. Pre-invest Annual Utility NG Costs (k\$) 

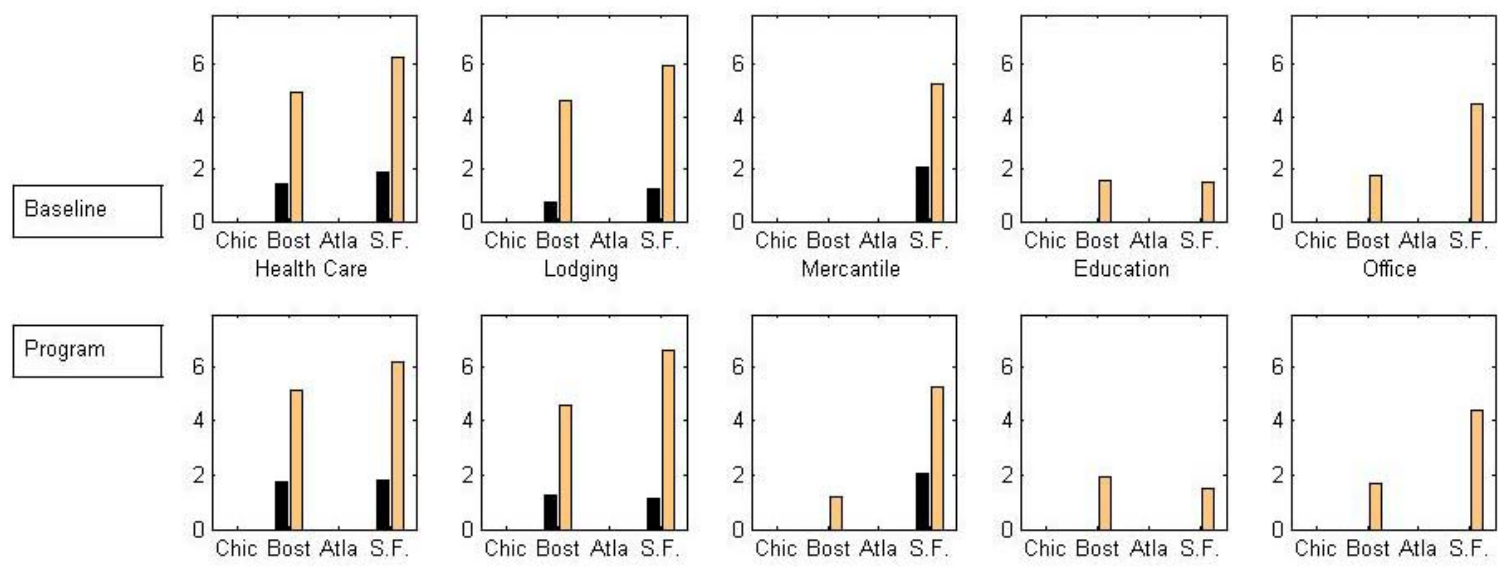

2012
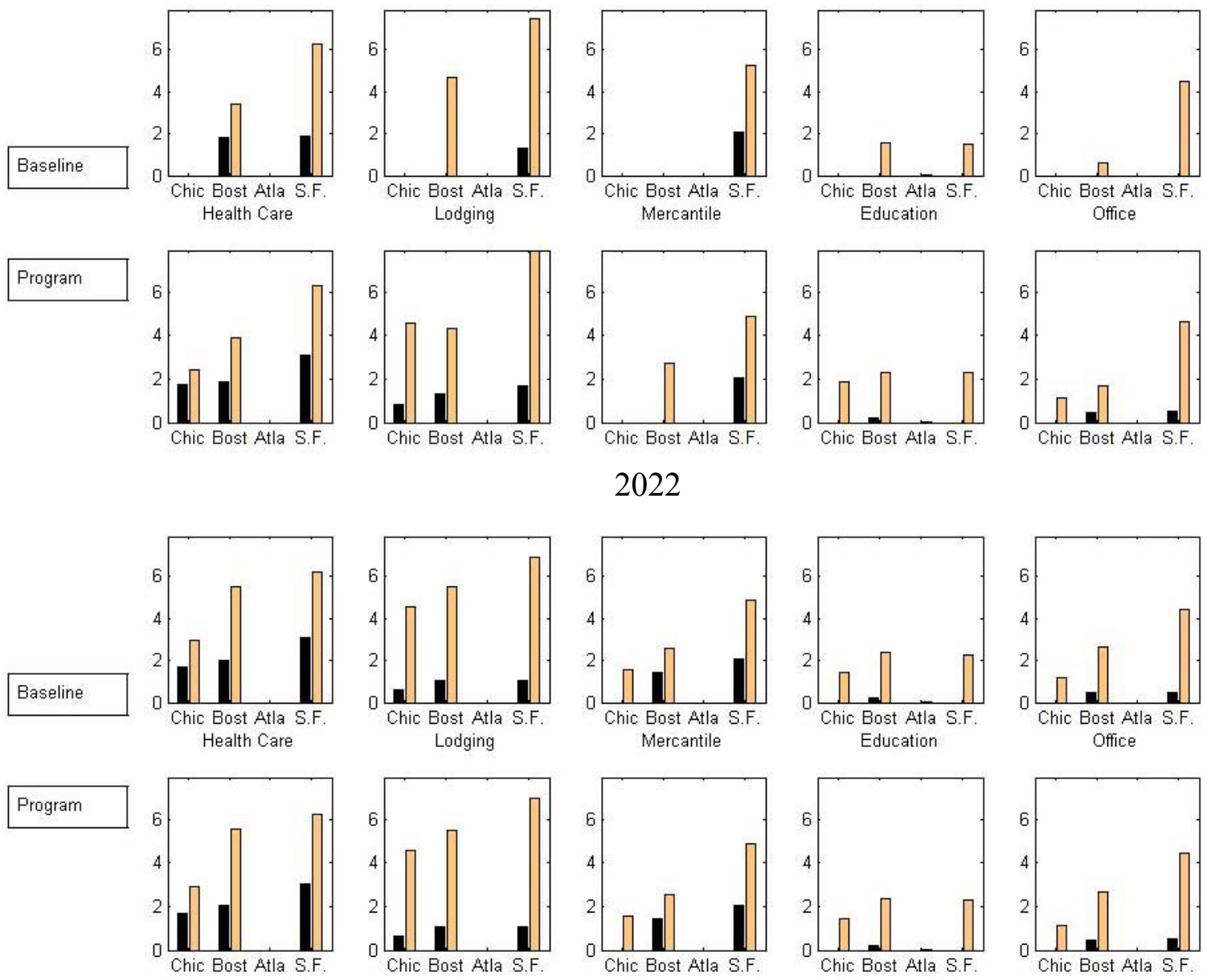

Figure C- 12. Reduction in Annual Utility Electricity Consumption (GWh) 



\section{Appendix D. Mathematical Formulation}

This appendix describes the core mathematical optimization problem solved by DER-CAM, including a listing of the various input parameters, decision variables, and model constraints.

\section{Input Parameters}

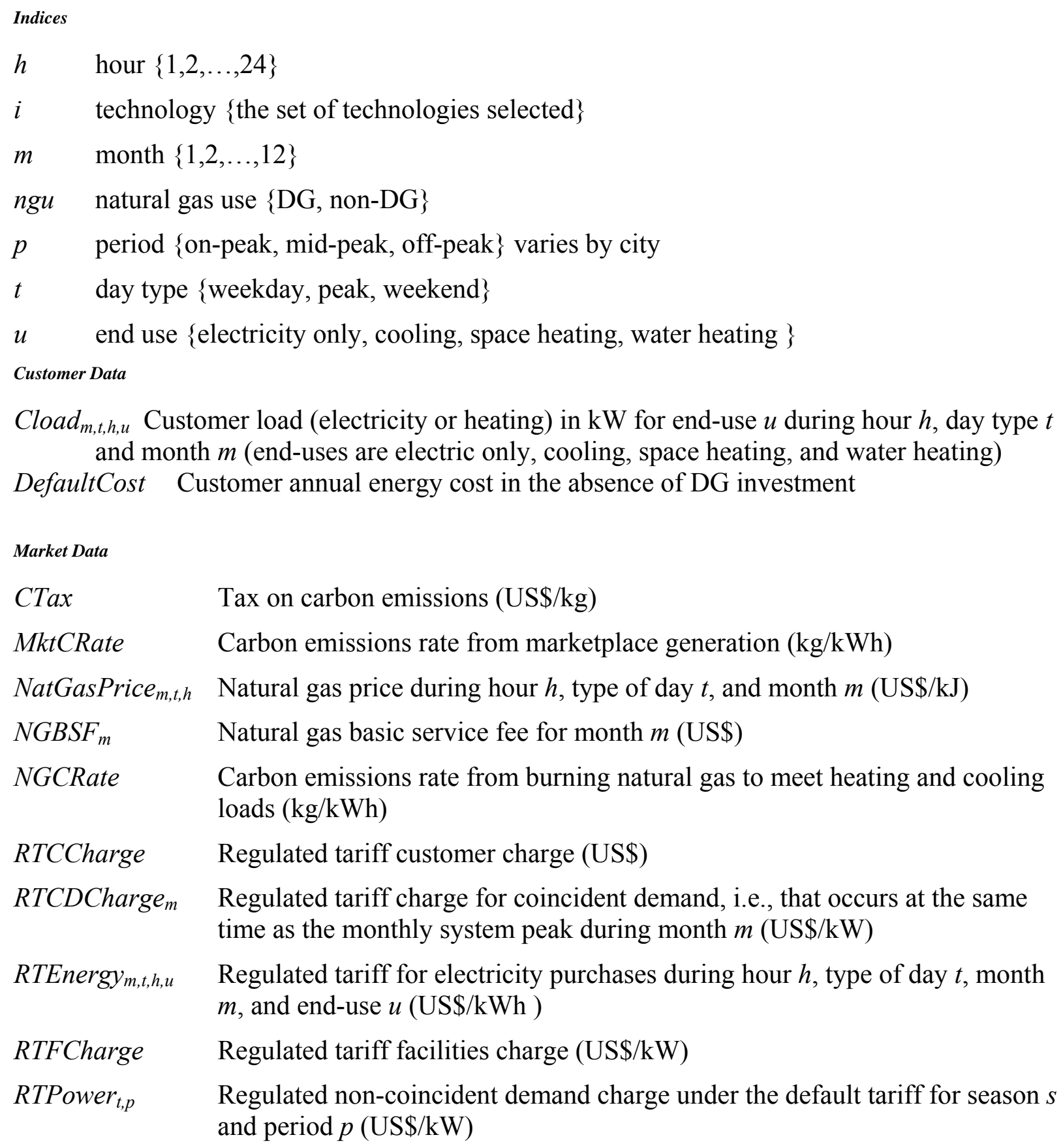


Annuity $_{i} \quad$ Annuity factor for DER technology $i^{10}$

CRate $_{i} \quad$ Carbon emissions rate from technology $i(\mathrm{~kg} / \mathrm{kWh})$

DERcapcost $t_{i} \quad$ Turnkey capital cost of technology $i(\mathrm{US} \$ / \mathrm{kW})$

DERCostkWh $h_{i, m} \quad$ Production cost of technology $i$ during month $m(\mathrm{US} \$ / \mathrm{kWh})$

DERhours $_{i} \quad$ Maximum number of hours technology $i$ is permitted to operate during the year (h)

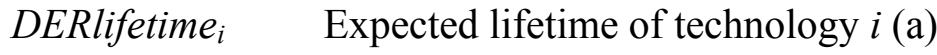

DERmaxp $_{i} \quad$ Nameplate power rating of technology $i(\mathrm{~kW})$

DERminp $_{i} \quad$ Minimum load rating of technology $i(\mathrm{~kW})$

DEROMfix $x_{i} \quad$ Fixed annual operation and maintenance costs of technology $i(\mathrm{US} \$ / \mathrm{kW})$

DEROMvar $_{i} \quad$ Variable operation and maintenance costs of technology $i$ (US\$ $\left./ \mathrm{kWh}\right)$

MaxExpOffsetNonTOU(InvGen $\left.{ }_{i}\right)$ The maximum expected value of all-hours demand offset for a given set of investments, $\operatorname{InvGen}_{i}$. This value depends on the load profile of the site, the number of units purchased, their respective capacities, and reliabilities.

$\operatorname{MaxExpOffsetTOU}_{p}\left(\operatorname{InvGen}_{i}\right)$ The maximum expected value of time-of-use demand offset for time period, $p$, for a given set of investments, $\operatorname{InvGen}_{i}$. This value depends on the load profile of the site, the number of units purchased, their respective capacities, and reliabilities.

MaxExpOffsetCoinc(InvGen ${ }_{i}$ ) The maximum expected value of coincident demand offset for a

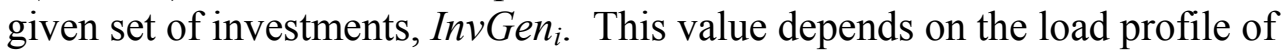
the site, the number of units purchased, their respective capacities, and reliabilities.

MaxPaybackPeriod Maximum acceptable simple payback period (years) of DG investment

$S(i) \quad$ Set of end-uses that can be met by technology $i$

Other Parameter

DaysOfType $_{m, t}$ Number of days in each month, $\mathrm{m}$, of daytype, $\mathrm{t}$

Efficiency $_{i} \quad$ Electrical efficiency (higher heating value) of technology $i$

$h(m) \quad$ Hour in month $m$ when system demand peaks

IntRate Interest rate on DER investments (\%)

NGHR Natural gas heat rate $(\mathrm{kJ} / \mathrm{kWh})$

${ }^{10}$ For a given technology, $\mathrm{i}$, the annuity factor is

Annuity $F_{i}=\frac{\text { IntRate }}{\left(1-\frac{1}{(1+\text { IntRate })^{\text {DERlifetime }_{i}}}\right)} \forall i$ 
Solar $_{m, h} \quad$ Average fraction of maximum solar insolation received (\%) during hour $h$ and month $m$ used to power photovoltaic (PV) cells ${ }^{11}$

$t(m) \quad$ Day type in month $m$ when system demand peaks

$\alpha_{i} \quad$ The amount of heat (in $\mathrm{kW}$ ) that can be recovered from unit $\mathrm{kW}$ of electricity that is generated using DER technology $i$ (this is equal to 0 for all technologies that are not equipped with either a heat exchanger (HX) or an $\mathrm{AC}$ )

$\beta_{u} \quad$ The amount of heat (in $\mathrm{kW}$ ) generated from unit $\mathrm{kW}$ of natural gas purchased for end-use $u$ (since the electricity-only load never uses natural gas, the corresponding $\beta_{\mathrm{u}}$ value equals 0 )

$\gamma_{i, u} \quad$ The amount of useful heat (in $\mathrm{kW}$ ) that can be allocated to end-use $u$ from unit $\mathrm{kW}$ of recovered heat from technology $i$ (note: since the electricity-only load never uses recovered heat, the corresponding $\gamma_{\mathrm{i}, \mathrm{u}}$ values equal 0 )

Variables

\section{Decision Variables}

Deploy $_{i, m, t, h} \quad$ Number of units of technology $i$, set to run at hour $h$, in month $m$. This is an integer variable limited to be greater than or equal to zero and less than or equal to the number of units purchase.

Gas $\mathrm{P}_{\mathrm{m}, \mathrm{th}, \mathrm{u}} \quad$ Purchased natural gas during hour $h$, type of day $t$, and month $m$ for end-use $u$ $(\mathrm{kW})$

GenL $L_{i, m, t, h, u} \quad$ Generated power by technology $i$ during hour $h$, type of day $t$, month $m$ and for end-use $u$ to supply the customer's load (kW)

InHeat $_{i, m, t, h} \quad$ Amount of heat from technology $i$ that is diverted towards the heat storage unit during hour $h$, type of day $t$, and month $m(\mathrm{~kW})$

InvGen $_{i} \quad$ Number of units of technology $i$ installed by the customer

RecHeat $_{i, m, t, h, u}$ Amount of heat recovered from technology $i$ that is used to meet end-use $u$ during hour $h$, type of day $t$, and month $m(\mathrm{~kW})$

\section{Dependent Variables}

AnnualDGCost Annual site DG cost (\$), excluding fuel consumption

AnnualElectric Cost Annual site electric utility cost (\$)

AnnualEnergyCost Annual site energy cost (\$)

AnnualEnergyCostNoDG Annual site energy cost (\$) prior to DG investment

AnnualNGCost Annual site natural gas utility cost (\$)

DemandCoinc $_{m} \quad$ Coincident demand for month, $m$

DemandNonTOU ${ }_{m} \quad$ All hours peak demand $(\mathrm{kW})$ for month, $\mathrm{m}$

DemandTOU $U_{m, p} \quad$ Time-of-use peak demand $(\mathrm{kW})$ for month, $\mathrm{m}$, and time period, $\mathrm{p}$

DGCapitalCost Upfront capital cost (\$) of DG investment

${ }^{11}$ We do not consider PV cells in this paper. 
DRLoadm,t,h,u

GasPurchase $_{m, t, h, n g u}$ ngu.
Purchased electricity from the distribution company by the customer during hour $\mathrm{h}$, type of day $\mathrm{t}$, and month $\mathrm{m}$ for end-use $\mathrm{u}(\mathrm{kW})$ (this variable is derived from other variables, but listed here for clarity) Natural gas purchase at month $m$, daytype $t$, hour $h$, for natural gas use

\section{Problem Formulation}

It is assumed that the site acquires the residual electricity that it needs beyond its self-generation from the utility at the regulated tariff. The mathematical formulation of the problem follows:

$$
[\text { InvGen,GenL,GasP,RecHeat }]^{*}=\operatorname{argmin}(\text { AnnualEnergyCost })
$$

where

$$
\text { AnnualEnergyCost }=\text { AnnualElectricCost }+ \text { AnnualNGCost }+ \text { AnnualDGCost }
$$

in which the annual electric cost is

$$
\begin{aligned}
& \text { AnnualElectricCost }=\sum_{m} \text { RTCCharge }+ \\
& \sum_{m}{\text { RTFCharge } \cdot \text { DemandNonTOU }_{m}} \\
& +\sum_{m} \sum_{p} \text { RTPower }_{m, p} \cdot \text { DemandTOU }_{m, p} \\
& +\sum_{m} \sum_{u \in\{\text { electric-only,cooling }\}} \text { RTCDChre }_{m} \cdot \text { DemandCoinc }_{m} \\
& +\sum_{m} \sum_{t} \sum_{h} \sum_{u} \text { DRLoad }_{m, t, h, u} \cdot\left(\text { RTEnergy }_{m, t, h}+\text { CTax } \cdot \text { MktCRate }\right) \cdot \text { DaysOfType }_{m, t}
\end{aligned}
$$

the annual natural gas cost, including consumption for DG, is

$$
\begin{aligned}
& \text { AnnuaNaturalGasCost }=\sum_{m} N G B S F_{m} \\
& +\sum_{m} \sum_{t} \sum_{h} \sum_{n g u} \text { Gas }_{m, t, h, n g u} \cdot(\text { NatGasPrice } \\
& m, n g u \\
& + \text { CTax } \cdot N G C R a t e) \cdot \text { DaysOfType }_{m, t}
\end{aligned}
$$

and the annual DG cost, excluding natural gas, is 


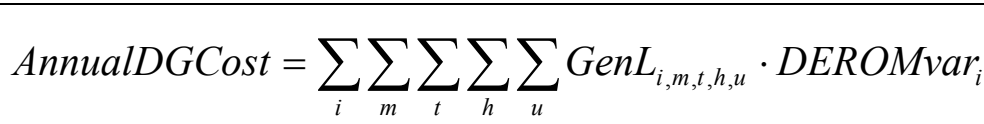

$$
\begin{aligned}
& +\sum_{i} \operatorname{InvGen}_{i} \cdot \text { DERmaxp }_{i} \cdot \text { DEROMfix }_{i} \\
& +\sum_{i} \operatorname{InvGen}_{i} \cdot \text { DERmaxp }_{i} \cdot \text { DERcapcost }_{i} \cdot \text { Annuity }_{i}
\end{aligned}
$$

Other derived parameters include:

- the upfront capital costs of DG investment:

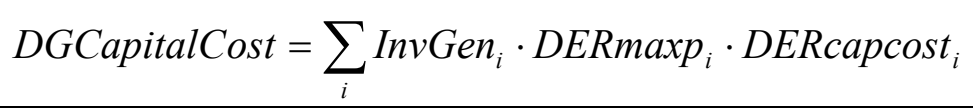

- Natural gas purchases for all uses except DG:

$$
\text { GasPurchase }_{m, t, h, n g u}=\sum_{u \in\{\text { space-heating, water-heat }, \text { natural }- \text { gas }- \text { only }\}} \forall_{\mathrm{m}, \mathrm{t}, \mathrm{h}, \mathrm{ngu} \in\{\text { non } D G\}}
$$

- Natural gas purchases for DG:

$$
\text { GasPurchase }_{m, t, h, n g u}=\frac{\sum_{i} \text { GenL }_{i, m, t, h, u}}{\text { Efficiency }_{i}} \quad \forall_{\mathrm{m}, \mathrm{t}, \mathrm{h}, \mathrm{ngu} \in\{D G\}}
$$

\section{Constraints}

A maximum payback period constraint is imposed on investments:

$$
\frac{\text { DGCapitalCost }}{\text { AnnualEnergyCostNoDG - AnnualEnergyCost }} \leq \text { MaxPaybackPeriod }
$$

At any given time, an integer number of generators of type i purchased can be dispatched:

$$
\text { Deploy }_{i, m, t, h} \in\left\{0,1,2, \ldots, \text { InvGen }_{i}\right\} \quad \forall i, m, t, h
$$

The dispatched generators are constrained to run above the minimum operating capacity of the units:

$$
\sum_{u} \operatorname{GenL}_{i, m, t, h, u} \geq \text { Deploy }_{i, m, t, h} \cdot \text { DERminp }_{i} \quad \forall i, m, t, h
$$

The dispatched generators are also constrained to run below the maximum operating capacity of the units:

$$
\sum_{u} \operatorname{GenL}_{i, m, t, h, u} \leq \text { Deploy }_{i, m, t, h} \cdot \operatorname{DERmaxp}_{i} \quad \forall i, m, t, h
$$

All-hours peak demand is at least as large as the peak electricity purchase during the month: 


$$
\text { DemandNonTOU }_{m} \geq \max _{t, h}\left(\sum_{u \in\{\text { electric-only,cooling }\}} \text { DRLoad }_{m, t, h, u}\right) \forall m
$$

The maximum all-hours demand offset over the no-invest case is the maximum expected offset that the installed DG system is capable of. This value depends on the reliability, size, and number of generators.

$$
\text { DemandNonTOU } \left._{m} \geq \sum_{u \in\{\text { electric-only,cooling }\}} \text { Cload }_{m, t, u}-{\text { MaxExpOffsetNonTOU }\left(\text { InvGen }_{i}\right)}\right) \quad \forall m
$$

Time-of-use peak demand is at least as large as the peak electricity purchase during the specific time-of-use:

$$
\text { DemandTOU }_{m, p} \geq \max _{(t, h) \in p}\left(\sum_{u \in\{\text { electric-only,cooling }\}} \text { DRLoad }_{m, t, h, u}\right) \forall m, p
$$

The maximum time-of-use demand offset over the no-invest case is the maximum expected offset that the installed DG system is capable of:

$$
\text { DemandTOU }_{m, p} \geq \sum_{u \in\{\text { electric-only,cooling }\}} \text { Cload }_{m, h, u}-\operatorname{MaxExpOffsetTOU}_{p}\left(\operatorname{InvGen}_{i}\right) \quad \forall m, p,(t, h) \in p
$$

Coincident peak demand is at least as large as the peak electricity purchase during coincident hour.

$$
\text { DemandCoinc }_{m} \geq \sum_{u \in\{\text { electric-only, cooling }\}} \text { DRLoad }_{m, t(m), h(m)} \quad \forall m
$$

The coincident demand offset over the no-invest case is the maximum expected offset that the installed DG system is capable of:

$$
\text { DemandCoinc }_{m} \geq \sum_{u \in\{\text { electric-only,cooling }\}} \text { CLoad }_{m, t(m), h(m)}-\text { MaxExpOffsetCoinc } \quad \forall m
$$

Customer loads are met by on-site generation, utility electricity purchase, combustion of utility purchased gas, and recovery of waste heat from on-site generation:

$$
\text { Cload }_{m, t, h, u}=\sum_{i} \text { GenL }_{i, m, t, h, u}+\text { DRLoad }_{m, t, h, u}+\beta_{u} \cdot \operatorname{Gas}_{m, t, h, u}+\sum_{i}\left(\gamma_{i, u} \cdot \text { RecHeat }_{i, m, t, h, u}\right) \forall m, t, h, u
$$

Photovoltaics can produce electricity in proportion to the capacity of the installed system and the amount insolation.

$$
\sum_{u} \operatorname{GenL}_{i, m, t, h, u} \leq \operatorname{InvGen}_{i} \cdot \text { DER } \max p_{i} \cdot \text { Solar }_{m, h} \quad \forall i \in \text { solar }, m, t, h
$$

Units can only be dispatched up the a maximum number of hours per year:

$$
\sum_{m} \sum_{t} \sum_{h} \text { Deploy }_{i, m, t, h} \cdot \text { DaysOfType }_{m, t} \leq \text { InvGen }_{i} \cdot \text { DERhours }_{i} \forall i
$$

Recovered heat from generators is limited to the amount of heat produced by the generators: 
$\sum_{u}$ RecHeat $_{i, m, t, h, u} \leq \alpha_{i} \cdot \sum_{u} \operatorname{GenL}_{i, m, t, h, u} \forall i, m, t, h$

Recovered heat can only be used for end-uses for which heat is used:

$$
\text { RecHeat }_{i, m, t, h, u}=0 \quad \forall i, m, t, h \quad \text { if } \quad u \notin S(i)
$$

On-site generation of electricity can only be used for electricity-only and cooling end-uses:

$$
G e n L_{i, m, t, h, u}=0 \quad \forall i, m, t, h \quad \text { if } \quad u \notin\{\text { electricity-only,cooling }\}
$$

Utility electricity can only be used for electricity-only and cooling end-uses:

$$
\text { DRLoad }_{m, t, h, u}=0 \quad \forall m, t, h \quad \text { if } \quad u \notin\{\text { electricity-only,cooling }\}
$$

